Received by CSTI

MAY 071990
NUREG/CR-1667

SAND80-1429

\title{
Risk Methodology for Geologic Disposal of Radioactive Waste
}

Scenario Selection Procedure

Prepared by R. M. Cranwell, R. W. Guzowski,

J. E. Campbell, N. R. Ortiz

Sandia National Laboratories

Operated by

Sandia Corporation

Prepared for

U.S. Nuclear Regulatory Commission 


\section{AVAILABIUTY NOTICE}

\section{Avallablity of Reference Materials Cited in NRC Publications}

Most documents clted in NRC publications will be avallable from one of the following sources:

1. The NRC Publle Document Room, 2120 L Street, NW, Lower Level, Washington, DC 20555

2. The Superintendent of Documents, U.S. Government Printing Otflce, P.O. Box 37082, Washington. DC 20013-7082

3. The National Technical information Service, Springfield, VA 22161

Athough the isting that follows represents the majority of documents clted in NRC publicatlons, it is not intended to be exhaustive.

Referenced documents avallable for inspection and copylng for a fee from the NRC Publlo Document Room include NRC correspondence and Intermal NRC memoranda; NRC Office of Inspection and Enforcement bulletlns, clrculars, Information notlces, inspectlon and livestlgation notices; Licensee Event Peports; vendor reports and correspondence; Commission papers; and applicant and licensee documents and correspondence.

The following documents in the NUREQ cerles are avallable for purchase from the GPO Sales Program: formal NRC staff and contractor reports, NRC-sponsored conference proceedings, and NRC booklets and brochures. Also avallable are Regulatory Guldes, NRC regulations in the Code of Federal Regulations, and Nuclear Regulatory Commission Issuances.

Documents avallable from the National Technical Information Service include NUREQ sertes reports and technical reports prepared by other federal agencles and reports prepared by the Atomic Energy Commisslon, forerunner agency to the Nuclear Regulatory Commission.

Documents avallable from public and special technical librarles inchude. all open literature ltems, such as books, Journal and perlodical articles, and transactions. Federal Reglster notices, federal and state leglslation, and congressional reports can usually be obtalned from these lbrarles.

Documents such as theses, dissertatlons, forelgn reports and translations, and non-NRC conference proceedings are avallable for purchase from the organlzatlon sponsoring the publication clted.

Single coples of NRC draft reports are avaliable free, to the extent of supply, upon written request to the Otilce of information Resources Management, Distribution Sectlon. U.S. Nuclear Regulatory Commlssion, Washington, DC 20555.

Coples of hndustry codes and standards used $\mathrm{h}$ a substantlve manner in the NRC regulatory process are malntained at the NRC Lbrary, 7920 Norfok Avenue, Bethesda, Maryland, and are avallable there for reference use by the public. Codes and standards are usually copyrighted and may be purchased from the originating organization or, If they are Amerkan National Standards, from the American National Standards Institute. 1430 Broadway, New York, NY 10018.

\section{DISCLAIMER NOTICE}

This report was prepared as an account of work sponsored by an agency of the United States Govemment. Neither the United States Govemment nor any agency thereof, or any of their employoes, makes any warranty, expresed or implied, or assumes any legal liablity of responsibility for any third party's use, or the results of such use, of any information, apparatus, product or process disciosed in this report, or represents that its use by such third party would not infringe privately owned rights. 


\section{Risk Methodology for Geologic Disposal of Radioactive Waste}

Scenario Selection Procedure

Manuscript Completed: March 1990

Date Published: April 1990

Prepared by

R. M. Cranwell, R. V. Guzowski, *

J. E. Campbell, N. R. Ortiz

Sandia National Laboratories

Albuquerque, NM 87185

*Science Applications International Corporation

Albuquerque, NM 87106

Prepared for

Division of High Level Waste Management

Office of Nuclear Material Safety and Safeguards

U.S. Nuclear Regulatory Commission

Washington, DC 20555

NRC FIN A1165

This document is PUBLICLY RELEASABTE

Authorizing Official

Date: $3 / 22 / 06$ 


\section{DISCLAIMER}

This report was prepared as an account of work sponsored by an agency of the United States Government. Neither the United States Government nor any agency Thereof, nor any of their employees, makes any warranty, express or implied, or assumes any legal liability or responsibility for the accuracy, completeness, or usefulness of any information, apparatus, product, or process disclosed, or represents that its use would not infringe privately owned rights. Reference herein to any specific commercial product, process, or service by trade name, trademark, manufacturer, or otherwise does not necessarily constitute or imply its endorsement, recommendation, or favoring by the United States Government or any agency thereof. The views and opinions of authors expressed herein do not necessarily state or reflect those of the United States Government or any agency thereof. 


\section{DISCLAIMER}

Portions of this document may be illegible in electronic image products. Images are produced from the best available original document. 
This report contains the description of a procedure for selecting scenarios that are potentially important to the isolation of high-level radioactive wastes in deep geologic formations. In this report, the term scenario is used to Iepresent a set of naturally occurring and/or humaninduced conditions that represent realistic future states of the repository, geologic systems, and ground-water flow systems that might affect the release and transport of radionuclides from the repository to humans. The scenario selection procedure discussed in this report is demonstrated by applying it to the analysis of a hypothetical waste disposal site containing a bedded-salt formation as the host medium for the repository. A final set of 12 scenarios is selected for this site. 

1.0 INTRODUCTION $\ldots \ldots \ldots \ldots \ldots \ldots \ldots \ldots \ldots \ldots \ldots \ldots \ldots \ldots \ldots \ldots \ldots \ldots$

1.1 Purpose of Report ........................ 1

1.2 Summaxy of Report Contents $\ldots \ldots \ldots \ldots \ldots \ldots \ldots \ldots \ldots \ldots \ldots \ldots$

2.0 PROCEDURE FOR SCENARIO SELECTION $\ldots \ldots \ldots \ldots \ldots \ldots \ldots \ldots \ldots \ldots \ldots$

2.1 Identification of Events and Processes $\ldots \ldots \ldots \ldots \ldots \ldots \ldots 5$

2.2 Classification of Events and Processes ............... 5

2.3 Screening of Events and Processes $\ldots \ldots \ldots \ldots \ldots \ldots \ldots \ldots \ldots$

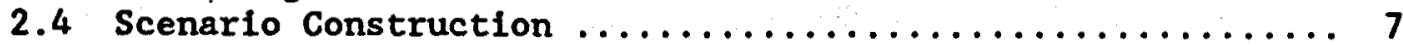

2.5 Screening of Scenarios ........................ 10

2.6 Use of Expert Judgment in Scenario Selection Procedure .... 11

2.7 Use of Scenarios in Evaluating Compliance with the

EPA's Containment Requirements ................. 11

2.8 Variants to Scenario Selection Procedure ............. 14

3.0 APPLICATION OF THE SCENARIO SELECTION PROCEDURE $\ldots \ldots \ldots \ldots \ldots$

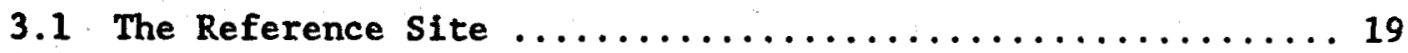

3.2 Hydraulic Characteristics of the Reference site ......... 19

3.3 Identification and Classification of Events and Processes for Reference Site .................. 25

3.4 Initial Screening Based on Physical Reasonableness and Probability Arguments...................... 27

3.5 Additional Screening Using Consequence Arguments ........ 34

3.6 Final Set of Release and Transport Phenomena .......... 72

3.7 Construction and Initial Screening of Scenarios ........ 72

3.8 Final Screening of Scenarios .................. 75

4.0 SUMMARY AND CONCLUSIONS $\ldots \ldots \ldots \ldots \ldots \ldots \ldots \ldots \ldots \ldots \ldots \ldots$

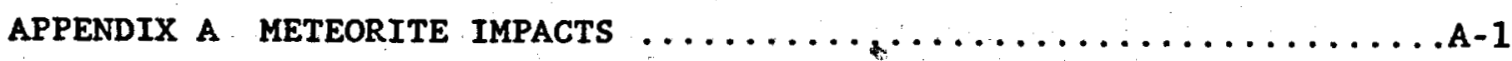

APPENDIX B VOLCANIC ACTIVITY.......................

APPENDIX $\mathrm{C}$ INADVERTENT INTRUSIONS $\ldots \ldots \ldots \ldots \ldots \ldots \ldots \ldots \ldots \ldots \ldots \ldots$

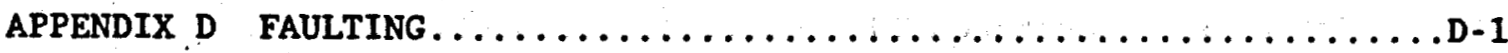

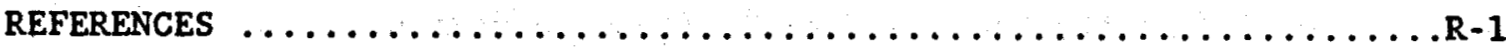


Figure $\quad$ Page

1 Graphical Illustration of Scenario Selection Procedure ..... 4

2. Potential Combinations of Two Release and Three Transport Phenomena ............................ 9

Schematic Diagram of the Reference site .............. 20

Physiographic Setting of the Reference Site ........... 22

Two-Dimensional SWIFT Setup for Reference Site ........... 22

Hydraulic Head Distribution of the Reference Site ......... 23

Hydraulic Head Distribution Near River L .............. 24

Fluid Velocity Vectors of the Reference Site ............ 24

Fluid Velocity Vectors Near River L ................. 25

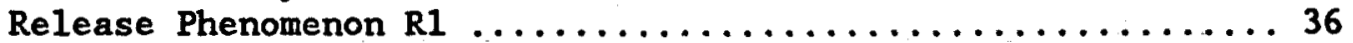

Fluid Velocity vectors for $R 1 \ldots \ldots \ldots \ldots \ldots \ldots \ldots \ldots \ldots \ldots \ldots$

Release Phenomenon R2 ....................... 38

Fluid Velocity Vectors for $R 2 \ldots \ldots \ldots \ldots \ldots \ldots \ldots \ldots \ldots$

Release Phenomenon R3 ......................... 40

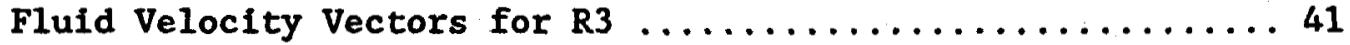

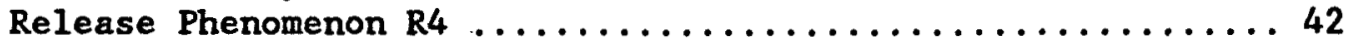

Dissolution Cavity at Salt/Shale Interface ............ 43

Release Phenomenon R5 ........................ 45

Formation of a Dissolution Cavity Below the Repository ..... 46

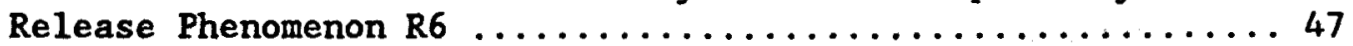

Hydraulic head Distribution for R6 ............... 48

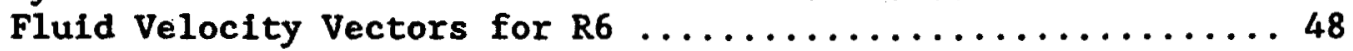

Hydraulic Head Distribution for $R 7 \ldots \ldots \ldots \ldots \ldots \ldots \ldots \ldots \ldots \ldots \ldots \ldots$

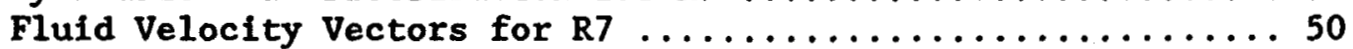

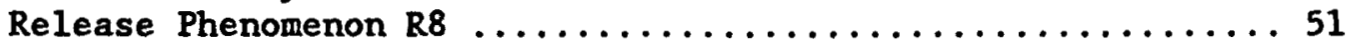

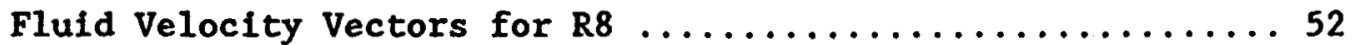

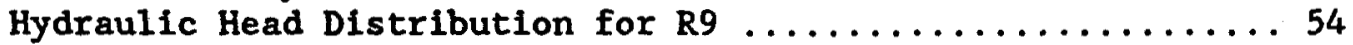

Fluid Velocity Vectors for $R 9 \ldots \ldots \ldots \ldots \ldots \ldots \ldots \ldots \ldots$

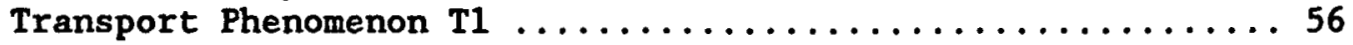

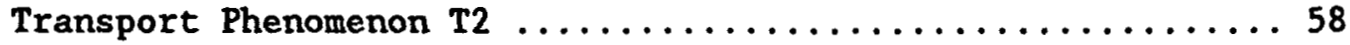

Transport Phenomenon T3 ........................... 59

Transport Phenomenon T4 ..................... 60

Hydraulic Head Distribution for $\mathrm{T} 5 \ldots \ldots \ldots \ldots \ldots \ldots \ldots \ldots \ldots \ldots$

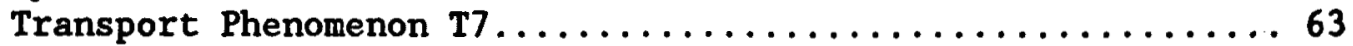

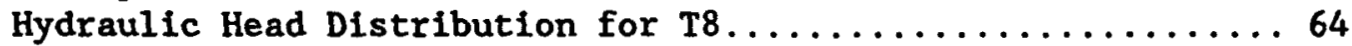

Fluid Velocity Vectors for T8.................... 64

Fluid Velocity Vectors for R2, T8 Combination...........65

Transport Phenomenon T9......................... 66

Hydraulic Head Distribution for $T 10 \ldots \ldots \ldots \ldots \ldots \ldots \ldots 6$

Fluid Velocity Vectors for R2, T10 Combination..........68 68

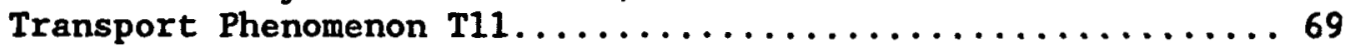

Hydraulic Head Distribution for T12............... 70

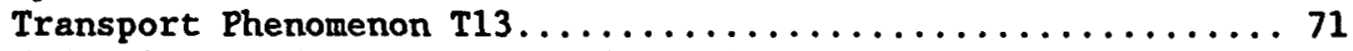

Hydraulic Head Distribution for T14............... 72 


\section{LIST OF FIGURES}

(Concluded)

\section{Eigure}

Page
A. 1
Schematic Representation of Meteorite Crater.
A-2
A. 2
Critical Region for Impact Craters
A-3
C. 1

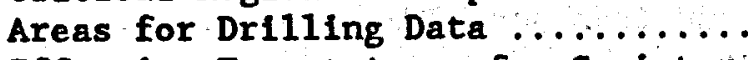
C-2
C. 2
Effective Target Area of a Canister
C-3 


\section{LIST: OF TABLES}

Table

1 Hydraulic Properties for Geologic Units Comprising the

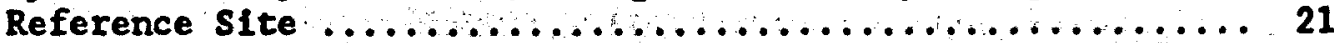

2 Potentially Disruptive Events and Processes $\ldots \ldots \ldots \ldots \ldots \ldots \ldots 26$

3. Final Set of Release and Transport Phenomena $\ldots \ldots \ldots \ldots \ldots \ldots 73$

$4 \quad$ Final Set of Scenarios ......................... 76

C.1 Drilling Rates for Areas Underlain by Bedded Salt ......... C.4 
The work presented in this report was completed and first published in 1982. Certain portions of the report have been modified for the current version to more clearly explain some aspects of the performance assessment methodology and to address review comments and more recently adopted regulatory considerations. 


\section{ACKNOWLEDGMENTS}

Several individuals made valuable suggestions and comments during the development and demonstration of the scenario selection procedure discussed in this report. In particular, the authors would like to acknowledge the suggestions of Joe Pearson, private consultant; Mark Reeves of INTERA Environmental Consultants, Inc.; Herb Shaw of the U.S. Geological Survey; and Fred Donath of The Earth Technology Corp. 


\subsection{INTRODUCTION}

The Waste Management Systems Division of Sandia National Laboratories, (SNL), under funding from the U.S. Nuclear Regulatory Commission (NRC), has developed a methodology for use in assessing the performance of geologic high-level radioactive waste repositories (herein referred to as the Performance Assessment Methodology). An Important part of this methodology includes a procedure for selecting scenarios for use in evaluating disposal sites and facilities. As used in this report, the term scenario will refer to a set of naturally occurring and/or human-induced conditions that represent realistic future states of the repository, geologic systems, and ground-water flow systems that could affect the release and transport of radionuclides from the repository to humans.

Scenario identification is important not only in evaluating the safety of a site but also as a guide to data collection. Identification of scenarios in conjunction with sensitivity analyses can indicate which data are most significant in assessing the performance of a potential disposal site.

\subsection{Purpose of Report}

This report contains that portion of the Performance Assessment Methodology describing a procedure for arriving at a representative set of scenarios for use in evaluating a potential waste disposal site. The use of this procedure has been demonstrated by applying it to the analysis of a hypothetical repository in a bedded-salt formation (Section 2.0). In this demonstration, a set of representative scenarios potentially important to the isolation of radioactive wastes at this site was selected. These scenarios were used in the demonstration of the Performance Assessment Methodology that is described in Cranwell et al. [1987]. Because the site is hypothetical, the scenarios selected in the demonstration may not be the same as those selected in a real site analysis. In fact, the most significant scenarios will undoubtedly vary form site to site and from geologic formation to geologic formation.

\subsection{Summary of Report Contents}

Section 2.0 of this report contains a description of the scenario selection procedure. This procedure includes (1) the identification and classification of events and processes (Sections 2.1 and 2.2.), (2) criteria for screening events and processes (Section 2.3), (3) a method for constructing scenarios from events and processes (Section 2.4), and (4) criteria for screening scenarios (Section 2.5). Section 2.6 discusses the use of expert judgment in the scenario selection procedure. A mathematical description of how scenarios can be used in evaluating compliance with the EPA's containment requirements is given in section 2.7 . Examples of the use of variations of the scenario selection procedure are given in Section 2.8. 
In Section 3.0, the scenario selection procedure is demonstrated by applying it to a hypothetical site with a bedded-salt formation as the host medium for the repository. A description of this site can be found in Sections 3.1 and 3.2 . The final set of scenarios selected for this site can be found in Section 3.9 .

Summary and conclusions are given in Section 4.0. The appendices contain procedures for determining probabilities of various events and processes. 


\subsection{PROCEDURE FOR SCENARIO SELECTION}

The selection of those scenarios considered to be important in the geologic disposal of radioactive waste should be accomplished by means of an objective and consistent procedure. Firm and useful criteria become essential in the selection of relevant scenarios for use in a potential disposal site analysis.

This chapter presents a systematic procedure for arriving at a set of scenarios for use in the analysis of a potential disposal site. Briefly, this procedure consists of the following steps:

1. An initial comprehensive identification of those events and processes felt to be important to the long-term isolation of radioactive waste in deep geologic formations.

2. A clasification of these events and processes to aid in completeness arguments.

3. A screening of these events and processes based on well-defined criteria.

4. The formation of scenarios by taking specific combinations of those events and processes remaining after the screening process.

5. An Initial screening of these scenarios.

6. The selection of a final set of scenarios for use in evaluating a potential disposal site.

Each of these steps is discussed in more detall below. The screening criteria mentioned in Step 3 are discussed in Section 2.3.

Figure 1 provides a simplifled graphical illustration of the scenario selection procedure. A loop connecting classification back to identification is indicated in Figure 1 to point out the fact that classification provides a valuable logical test to ensure that potentially important events and processes have not been overlooked. The procedures and criteria for scenario selection presented here will be demonstrated in Section 3.0 by application to a hypothetical repository in bedded salt. A final set of scenarios, selected for this hypothetical site, will be discussed in Section 3.9. No claim is made that the methods presented are the only methods available for scenario selection, nor that the scenarios selected for the hypothetical bedded-salt site are those that would be selected in a real site analysis. The methods presented can be applied, in principle, to any geologic site being considered for radioactive waste disposal. 


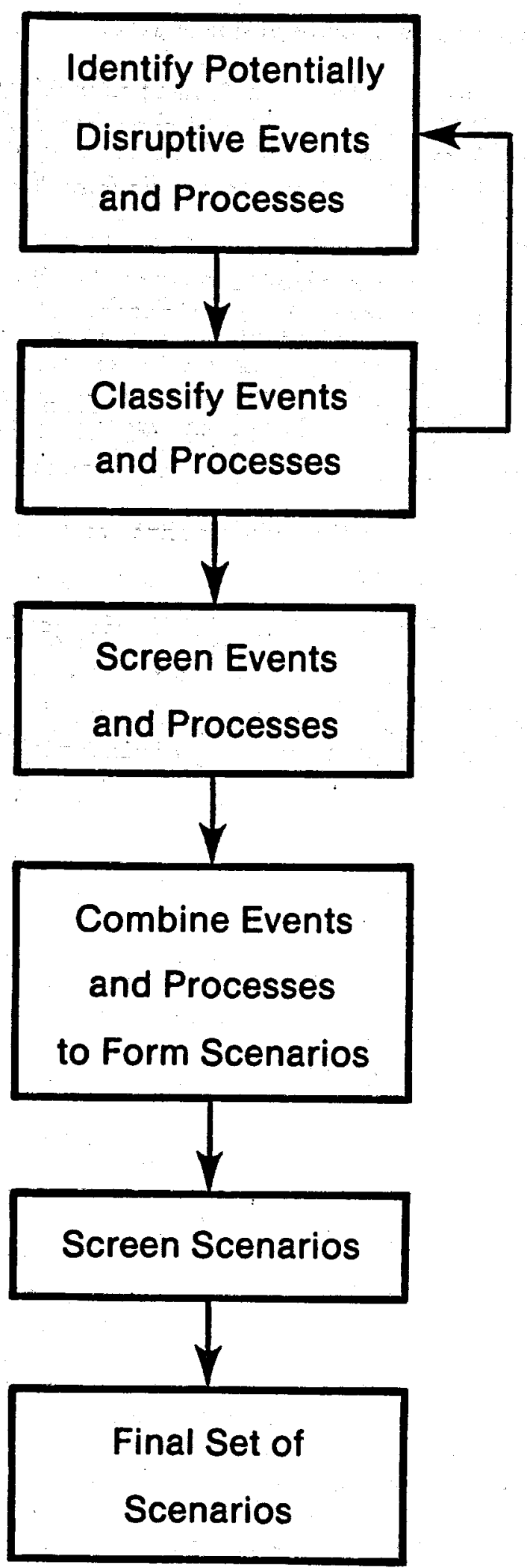

Figure 1. Graphical Illustration of Scenario Selection Procedure 


\subsection{Identification of Events and Processes}

The first step in any scenario selection procedure should be the identification of a comprehensive set of events and processes; both natural and human-induced, believed to be important to the disruption of the isolation of radioactive waste at the site being considered. This identification would generally be accomplished through discussions among persons knowledgeable in the areas of earth sclence and waste-management analyses. The use of knowledgeable and experienced individuals helps ensure that potentially important scenarios are not overlooked. For the demonstration of the Performance Assessment Methodology, a pane1 of knowledgeable earth scientists was convened for the purpose of identifying those events and processes considered to be important to the disruption of the isolation of radioactive waste in bedded salt (see Section 3.3, Table 2).

\subsection{Classification of Events and Processes}

The classification of events and processes provides a logical aid to help ensure that important scenarios will not be overlooked. The initial list of phenomena (see Table 2) was classified into the categories of natural, human-induced, and waste- and repository-Induced. This classification was based on the origin and physical characteristics of these phenomena. A procedure for further classification is presented below. In addition to addressing the question of completeness, this classification also provides the organization needed to begin developing and analyzing scenarios.

Events and processes will also be classified based upon the manner by which they influence the disposal system consisting of the repository and the surrounding geology. Those phenomena in the near vicinity of the repository, whose major effect is to influence the release and movement of radionuclides from the waste packages and engineered barrier system to a nearby aquifer or directly to the land surface, will be referred to as release phenomena. Similarly, those phenomena in the far field whose major effect is to influence the transport of radionuclides in ground water will be referred to as transport phenomena.

The distinction between those events and processes included as release phenomena and those included as transport phenomena is not always obvious. For example, faulting may be classified as either a release or transport phenomenon, depending on the proximity to the site. If the fault should pass through or very near the repository, its primary effect would be to influence the release and movement of radionuclides from the repository to a nearby aquifer. In this:case, the fault would be classified as a release phenomenon. On the other hand, if the fault should occur at some distance away from the repository so that its primary effect is to influence the transport of radionuclides in ground water, then it would be classifled as a transport phenomenon. Regardless of its classification, a given event or process may influence both radionuclide release and transport, depending on its effect on the site 
hydrology. Despite the seemingly arbitrary division of phenomena into release and transport categories, the reasons for this division become more apparent when the one considers the complex thermal, mechanical, geochemical and hydraulic analyses that may be required for near-field (release) phenomena analysis compared to the more straightforward flow and transport analyses required for far-field (transport) phenomena analysis.

While only two classification schemes are used in this example, additional classifications are helpful in developing a comprehensive list of phenomena.

\subsection{Screening of Events and Processes}

Many of the events and processes from the initial 1ist considered for a potential disposal site can be eliminated based on firm and well-defined screening criteria. A screening of these events and processes is not only desirable but also essential if one considers the thousands of scenarios that could be defined by taking specific combinations of these phenomena.

Initial screening criteria should consist of the following:

1. Physical reasonableness of the events and processes being considered.

2. Probability of significant release of radionuclides from these events and processes.

3. Potential consequences associated with the occurrence of these events and processes.

Physical Reasonableness. Events and processes whose occurrence is impossible due to the physical and chemical characteristics of the waste and characteristics of the engineered facility or geologic site can be eliminated by this screening criterion. Some examples of phenomena that could be eliminated based on the test of physical reasonableness are

- A nuclear explosion in an underground facility designed to prevent criticality.

- Formation of dissolution cavities in crystalline rock.

- Tsunamis for a repository far removed from coastal regions.

Clearly, the elimination of phenomena due to this criterion would be largely site specific. Therefore, this step in the screening process should be repeated for each repository site.

Probability. Events and processes with very "small" probability can generally be rejected. The specification of "small" should be the 
responsibility of the regulator or the applicant and should be consistent with the appropriate regulations. Once a value has been selected, judgmental decisions will undoubtedly still have to be made as many probabilities associated with varlous phenomena will have large uncertainties. The value selected in the demonstration analysis of this report was $10^{-8} / \mathrm{yx}$.

In several safety studies, numerical probability criteria have been used to reject scenarios. For example, WASH-1400 [U.S. Nuclear Regulatory Commission, 1975] uses a limit of $10^{-8} / \mathrm{yr}$ to reject accident sequences. Other references [Griesmeyer and Okrent, 1981] suggest larger numbers (e.g., 10-7/yr). The U.S. Environmental Protection Agency (EPA) [U.S. Environmental Protection Agency, 1985] suggests that categories of events and processes with probability of occurrence smaller than $10^{-8} / \mathrm{yr}$ can be ignored.

Consequence. As used in this report, "consequence" can have different interpretations, depending upon the stage of the screening process. For example, in the earlier stages of the screening process, "consequence" generally refers to the effects that a certain event or process might have on the natural properties of the site (e.g., hydraulic head distribution). Thus, only flow and possibly thermomechanical analyses are needed at this point. In the screening of scenarios, "consequence" generally refers to the amount of radionuclides being discharged to the environment and the health effects associated with these discharges. Thus, radionuclide transport and health effects calculations are needed at this point. The reason for this breakdown is that in the early stages of the screening process, detailed transport and health effects calculations should be avoided because of the higher computer and man-power costs associated with these efforts. The total scenarios should be reduced to a reasonable number before undertaking detailed risk calculations.

At any rate, screening based on consequence can occur in several ways. For example, events and processes having similar consequences (e.g., effects on hydraulic head) could concelvably be grouped together provided the probabilities of these phenomena are appropriately combined. Also, events and processes with insignificant consequences (e.g., no apparent effect on hydraulic head) could be eliminated. However, before eliminating phenomena based on insignificant consequences, their potential maximum consequence should be considered.

\subsection{Scenario Construction}

The next step in the scenario selection procedure involves the formation or development of scenarios by taking meaningful combinations of those phenomena remaining after the screening process. Recall that at this point, the events and processes have been classified as to "release" and "transport" phenomena as discussed in Section 2.2. The development of scenarios by taking combinations of the various release and transport phenomena is illustrated by a simple example. 
Consider the simple case of two release phenomena (R1, R2) and three transport phenomena (T1, T2, T3). The possible scenarios that can be created by taking combinations of these phenomena are shown in Figure 2 . There are $2^{5}-32$ possible combinations in this example. The use of a logic diagram as illustrated in Figure 2 ensures that all possible combinations are identified. The base case scenario represents the initial conceptualization of the disposal system including the repository and emplaced waste. All components of the engineered-barrier system are assumed to perform as designed. The other scenarios are perturbations to these basic conditions.

This organizational method is preferable to the classical event-tree, fault-tree techniques frequently used in the analysis of engineered systems. This statement is made for the following reasons.

1. Many of the so-called "events" associated with geologic environments do not represent immediate or abrupt changes in the system but rather slow, continuous changes over hundreds to thousands of years (e.g., dissolution cavities in bedded-salt formations, shaft or borehole seal degradation, etc.). Hence their occurrence cannot be represented by a simple "yes" or "no" statement.

2. Feedback loops frequently appear in the investigation of the processes that could affect the release of radionuclides from the underground facility. Event trees and fault trees do not adequately incorporate interactions between various factors influencing radionuclide movement.

3. For a given set of conditions, many of the processes are basically deterministic. Thus, the question of when and if a certain "barrier" will be breached is answered when a given set of conditions is specified. The real question is, what conditions exist?

4. Event trees and fault trees force artificial divisions in the representation of processes. The important question is how the entire system behaves.

Other studies [Burkholder, 1981; Koplik et al., 1982] have also concluded that event and fault trees are not useful for analyzing geologic processes or their interactions. They recommend the use of simulation techniques with models to describe the evolution over time of a set of variables representing the scenarios. The latter method is used in this study as described in the next chapter. 


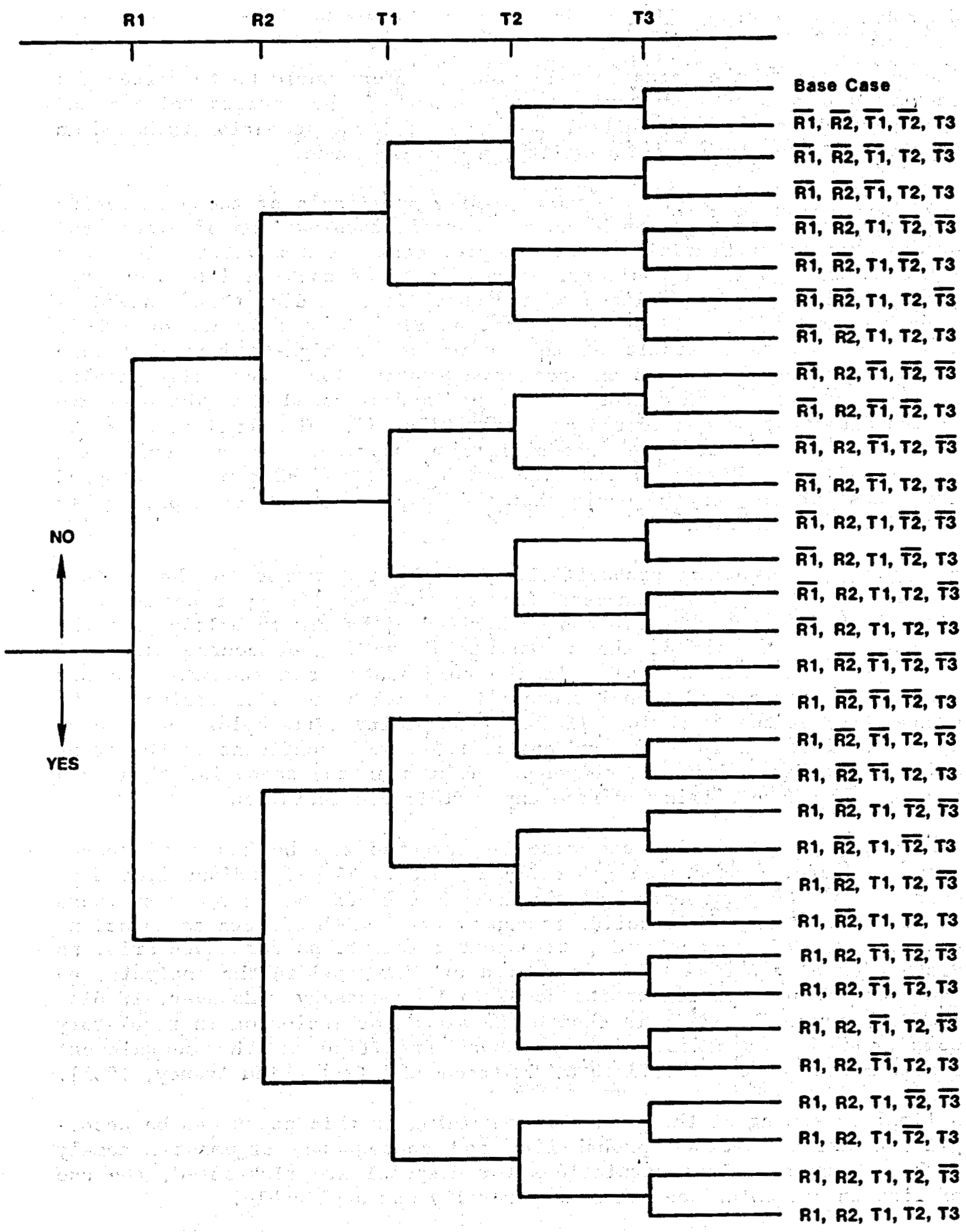

Figure 2. Potential Combinations of Two Release and Three Transport Phenomena 


\subsection{Screening of Scenarios}

The next step in the scenario selection procedure would be to screen the scenarios developed from taking combinations of the various release and transport phenomena. An initial screening of these scenarios is based on physical reasonableness, probability, and consequence.

Phystcal Reasonableness. The most readily applicable of these screening criteria is physical reasonableness. Certain combinations of events and processes are incompatible. For example, consider a basaltic dike that intrudes through the repository. The effects of such an intrusion primarily would be on the release of radionuclides. A dike that behaved as a barrier to flow could be designated as $R 1$. If a fracture or rubble zone occurred as a result of the intrusion, a high-conductivity zone could be formed that would enhance ground-water flow. For this example, the presence of a high-conductivity zone is designated R2. The presence of the dike must be considered as either R1 or R2. The combination R1 R2 requires the dike to have incompatible properties. As a result, all scenarlos (e.g., Figure 2) that include both R1 and R2 could be dropped from consideration on the basis that the components are not a physically reasonable combination.

Probability. Assuming probabilities have been assigned to the various release and transport phenomena (components) comprising a scenario, a probability of that scenario can be arrived at by simply multiplying the probabilities of each of the components (assuming, of course, independence among the components). If the components of a scenario are not independent, then conditional probabilities can be used to arrive at the probability of the scenario. If this probability falls below the agreedupon cutoff $\left(e . g ., 10^{-8} / \mathrm{yr}\right)$, and one is relatively confident in the probability estimates for each component comprising the scenario, then this scenario could be eliminated from any further consideration.

Consequences. Scenarios can also be screened on the basis of consequence. Here, consequence generally refers to either radionuclide discharges to the environment or the health effects resulting from these discharges. Thus, radionuclide transport and health effects calculations are needed. If, in performing transport calculations for a scenario, no discharges are observed for the period of time used in the analysis, no additional consideration of the scenario is necessary. However, if discharges occur, the scenario must be retained for inclusion in regulatory compliance assessments, such as those specified in the containment requirements, 40 CFR 191.13 [U.S. Environmental Protection Agency, 1985].

A final screening of the scenarios remaining at this point can be accomplished using combined probability and consequence arguments, namely risk. However, unless regulations for disposal are risk-based, the use of risk in screening scenarios is generally not applicable. 


\subsection{Use of Expert Judgment in Scenario Selection Procedure}

At various stages throughout the scenario selection procedure, expert judgment must be used to make certain decisions. The basic reasons for using expert judgment instead of another, seemingly more precise, technique are (1) the avallable data may not be of sufficient quality, quantity, or of sufficlent spatial or temporal distribution for the use of other techniques; (2) the system or process may be too complex for other techniques; and (3) an expert's personal experience may make that expert capable of distinguishing between certain options or approaches.

Expert judgment can be obtained efther from an individual expert or from a panel of experts. The use of either of these approaches is dependent on the topic to be considered, the availability of experts, the time avallable, and the cost. A single expert must be knowledgeable about a particular topic or group of related topics. The reasonableness of the results from and rationale used by a single expert should be checked by rigorous peer review. One approach to using a panel is to have several experts with similar backgrounds address an appropriate topic in a narrowly defined area. The panelists would be required to reach a consensus with possible provisions for the presentation of dissenting views. Another approach is to use several panels with each panel consisting of experts from a variety of disciplines. With this type of panel, a decision from each panel is considered as a decision from a "single expert," and the multiple panels provide multiple opinions. Where practical, a formalized methodology should be used in order to elicit the best technical judgment with the least personal bias.

In the implementation of the scenario-selection methodology, expert judgment is required in (1) the identification of an initial set of potentially disruptive events and processes; (2) some aspects of the screening of events, processes, and scenarios based on physical reasonableness; (3) the determination of the probability of occurrence of some events and processes; (4) the definition of the conceptual and mathematical models of the site and the various processes occurring at and near the site; and (5) the identification and the implementation of the computer code(s) to be used in consequence analysis. For a detailed treatment of the use of expert judgments in performance assessment, the reader is referred to the report by Bonano et al. [1990].

\subsection{Use of Scenarios in Evaluating Compliance With the EPA's Contalnment Requirements}

The EPA's containment requirements limit cumulative radionuclide discharge at the accessible environment for a period of 10,000 years. If the future evolution of a repository system is described by a vector of state variables $z$, then evaluating the performance of the repository 
against the EPA's containment requirements involves evaluating Equation (2.7.1),

$$
E=\sum_{1} \frac{1}{L_{1}} \int_{0}^{T} D_{1}(\underline{z}, t) d t
$$

where $L_{i}=$ release limit for isotope 1 ,

$D_{1}$ - time-dependent discharge rate for isotope 1 , and

$T=10,000$ years.

The components of $z$ include binary variables that represent the occurrence or nonoccurrence of various physical phenomena and process variables that affect the magnitude or extent of some physical process. Some of the components of $z$ may be time dependent (e.g., the average temperature in a given area of a high-level waste repository). We assume that such time dependence can be represented by a formula or algorithm involving deterministic functions of time and a limited number of time-independent coefficients. Alternatively, one may discretize time and measure the time-dependent quantity only at discrete times.

While we can identify the components of $z$, there may be substantial uncertainties in the actual values taken on by these components. However, using available data, expert judgment, and computational algorithms, we can generate the joint pdf for the components of $z$. Thus, we can estimate the expected value of $\mathrm{E}$ as follows:

$$
\langle E\rangle=\int_{\Omega_{z}} P(\underline{z}) \sum_{i} \frac{1}{L_{i}} \int_{0}^{T} D_{i}(\underline{z}, t) d t d \underline{z},
$$

where $P(\underline{z})=$ joint pdf of the state variables $\underline{z}$, and

$$
\Omega_{z} \quad-\text { the domain of } P(\underline{z}) \text {. }
$$

It is useful at this point to split the set of state variables $z$ into two subsets $\underline{s}$ and $\underline{r}$, where $\underline{s}$ is the subset of all binary variables in $\underline{z}$, and $\underline{r}$ is the subset of the process variables in $\underline{z}$. Then Equation (2.7.2) can be rewritten as

$$
\langle E\rangle=\int_{\Omega_{s}} \int_{\Omega_{r}} S(\underline{s}) R(\underline{r} \mid \underline{s}) \sum_{i} \frac{1}{L_{i}} \int_{0}^{T} D_{i}(\underline{s}, \underline{r}, t) d t d \underline{r} d \underline{s},
$$


where $s(\underline{s})$ - jolnt pdf of the binary components of $s$, and

$$
R(x \mid s) \text { - joint pdf of the process variables } x \text { and is generally }
$$

For the present, assume that phenomena represented by the binary vartables $E$ occur Independently of each other. Then if $q_{1}$ is the probability that phenomenon 1 occurs, the pdf for $s$ can be written as

$$
p\left(s_{1}\right)=q_{1} \delta\left(s_{1}\right)+\left(1-q_{1}\right) \delta\left(s_{1}-1\right)
$$

where $\delta\left(s_{1}\right)$ is the Dirac delta function which has the following properties:

$$
\int_{X} f(x) \delta(z-x) d x-f(z), \text { if } z<x
$$

and

$$
\int_{X} f(x) \delta(z-x) d x-0 \text {, if } z \neq x
$$

Thus, the flrst term in Equation (2.7.4) represents the probability that phenomenon 1 occurs (arbitrarlily assigned to $s_{1}-0$ ) and the second term Is the probability that phenomenon 1 does not occur (assigned to $s_{1}-1$ ).

Given our earlier assumption of independence of the phenomena represented by $s$, the joint pdf for the components of $\underline{s}$ can be written

$$
s(s)=\prod_{j=1}^{N}\left[q_{j} \delta\left(s_{j}\right)+\left(1-q_{j}\right) \delta\left(s_{j}-1\right)\right]
$$

where $N_{2}$ is the number of components in the vector $s$ (1.e., the number of events and processes under consideration). Equation (2.7.3) now becomes

$$
\begin{aligned}
\langle E\rangle- & \left.\int_{\Omega_{s}} \int_{\Omega_{r}} \int_{j}^{N_{1}^{s}}\left[q_{j} \delta\left(s_{j}\right)+\left(1-q_{j}\right) \delta\left(s_{j}-1\right)\right]\right\} R(\underline{r} \mid \underline{s}) \cdot \\
& \int_{1}^{\frac{1}{L_{1}}} \int_{0}^{T} D_{1}(\underline{s}, \underline{r}, t) d t d \underline{r} d \underline{s}
\end{aligned}
$$


The integration over $\underline{s}$ can now be performed with the following result:

$$
\langle E\rangle=\sum_{\ell=1}^{N} Q_{\ell} \int_{\Omega_{r}} R(\underline{r} \mid \ell) \sum_{1} \frac{1}{L_{i}} \int_{0}^{T} D_{i}(\ell, \underline{r}, t) d t d \underline{r},
$$

where $N_{c}$ is the number of possible combinations of occurrence/non-occurrence of the $\mathrm{N}_{8}$ events and processes under consideration. The quantity $Q_{\ell}$ is the probability of the $l$ th such combination. We now formally identify each of the $\mathrm{N}_{c}$ possible combinations of phenomena as a scenario. Thus, Equation (2.7.8) Indicates that $\langle\mathrm{E}\rangle$ can be estimated by first calculating the expected value of the cumulative, normalized radionuclide discharge for each scenario, then summing over all scenarios weighted by the scenario probabilities.

In developing Equation (2.7.8), we assumed that the phenomena represented by the vector $\underline{s}$ occur independently. However, the possibility of dependencies poses no particular problem in the formalism leading from Equation (2.7.3) to Equation (2.7.8). The real problem, of course, is to Identify and quantify such dependencies. Once quantified, dependencles among the probabilities of individual events and processes can be incorporated into the scenario probabilities $\left(Q_{l}\right)$.

Careful consideration of Equation (2.7.8) leads to some interesting questions. Suppose, for example, that the frequency of occurrence of a particular event is sufficiently high that multiple occurrences might be expected during the regulatory period. For such a case, different numbers of occurrences might be treated as different events. Continuing with the example of exploratory drilling, no drill holes might be considered as one event, one to five drill holes as a second event, and more than five drill holes as a third event.

Another question that arises from Equation (2.7.9) is how to account for the time of occurrence of a particular event or process. A reasonable approach here is to divide the regulatory period into multiple time intervals and consider the possibility of some phenomenon occurring in each time interval as a separate event.

\subsection{Variants to Scenario Selection Procedure}

The scenario selection and screening methodology described in the previous sections has been applied several times. SNL has used the methodology to arrive at scenarios for assisting in the development of performance assessment methodologies for the NRC. These scenarios were developed generically for hypothetical repositories in bedded salt (see Section 3.0 in this report) and tuff [Guzowski, 1987] formations to guide model-development activities, not to analyze a specific repository site. Besides these applications at SNL, the methodology has been used as the basis for scenario selection in the Canadian [Stephens and Goodwin, 1989] and Swedish [Andersson and Eng, 1989] programs. In addition to its use 
In the Canadian and Swedish programs, the methodology has been the subject of the Working Group on Identification and Selection of Scenarios for the Performance Assessment of Nuclear Waste Disposal sponsored by the Organization for Economic Cooperation and Development/Nuclear Energy Agency [Hodgkinson, 1988; Hodgkinson and Summerling, 1989]. It has also been used by Nirex Ltd. In the United Kingdom [Hodgkinson and Summerling, 1989].

In the applications of the methodology outside SNL (1.e., Canada and Sweden) modifications and deviations from the steps in the original methodology have been implemented. These modifications and deviations are referred to herein as "variants." These varlants were necessitated in order to render the methodology applicable to the specific needs and requirements in these programs. The scenario selection methodology provides a general "road map" for arriving at scenarios; the fact that variants of the methodology have been implemented is an indication of the flexibility of the methodology.

\section{SKI/SKB Scenario Development Project}

The Joint SKI/SKB Scenario Development Project [Andersson and Eng, 1989] started from the SNL scenario selection methodology. They implemented the first three steps in the methodology: (1) identification of events and processes, (2) classification of events and processes to increase the likelihood of "completeness," and (3) screening of events and processes based on established criteria. The main deviation from the SNL methodology was the introduction of the "process system." The motivation for developing the process system was twofold: (1) the events and processes belonged to different categories, and (2) a prohibitively large number of scenarios would have resulted by combining all events and processes surviving the screening step. Events and processes belonged to two categories: (1) events and processes that represented external conditions driving other events and processes (i.e., climate change), and (2) events and processes that represented detalled phenomena (1.e., ground-water flow) and that are affected by the external conditions. The latter type of events and processes constituted the process system. Andersson and Eng [1989] defined the process system as the grouping of all phenomena (events and processes) that are required to define the performance of the entire disposal system and that can be predicted. The events and processes that represent external conditions and "driven the phenomena in the process system were the ones combined into scenarios. In this way, the number of scenarios in need of analysis was kept down to a manageable level.

It should be pointed out that to date these events and processes have not been combined into scenarios. A few of the events and processes were Identifled as "Isolated scenarios" and are not to be combined with other events and processes. Using this approach, eleven events and processes were identifled as representing external conditions to be combined into scenarios, and five were identified as isolated scenarios. Several different approaches are currently under investigation for combining the 
external events and processes into scenarios." These approaches are all based on the use of different criteria to restrict the number of possible combinations. Examples are:

(1) the use of the period of time over which a given event or process can occur to estimate a probability of occurrence as a function of time;

(2) the use of time order; that is, the prescribed order in which certain combinations of events and processes can occur; and

(3) the use of the combination of the probability of occurrence of the events and processes in a scenario to screen out scenarios with very small probabilities.

Andersson and Eng [1989] erroneously state that the SNL scenario selection methodology cannot accommodate these approaches or strategies for combining scenarios. At present, there are no inherent attributes of the methodology that would prevent the incorporation of any of these strategies.

Scenario Selection for the Canadian Nuclear Fuel Waste Management Program

Stephens and Goodwin [1989] claim to have refined the procedure in the SNL scenario selection methodology to address their specific requirements for scenarios. The scenarios they selected were not site specific but addressed a specific disposal concept. They defined the terms "factor" and "scenario" to guide the analysis. A factor was defined as anything that could concelvably affect the disposal system over any given time period of interest, while scenario meant a combination of one or more factors that could adversely impact the performance of the disposal system.

Like the Swedes, the Canadian program exercised the first three steps in the SNL methodology. A group of approximately 15 individuals prepared a comprehensive list of factors (identification of events and processes, following the terminology in the SNL methodology). To decrease the number of factors, "general" factors were defined (e.g., the "diet" factor to include all factors referring to food consumption by man). A total of 270 general factors were defined. To increase the likelihood that the list of 270 general factors was sufficiently complete, the group of experts organized and ordered these factors in a variety of ways. Some of the classifications used were (1) type of factor and component of the disposal system affected, (2) origin of factor (i.e., naturally occurring, human-induced, etc.), (3) mode of action of the factor (1.e., biological, chemical, physical), and (4) significant pathways affected by each factor. Following this classification (the second step in the SNL methodology), the group of experts screened out scenarios that, for a variety of reasons, did not warrant further consideration. The reader is referred to the paper by Stephens and Goodwin [1989] for a discussion of the criteria used to screen out factors. After the screening process, 
145 factors were Identifled for qualitative treatment only, and 125 warranted a quantitative evaluation.

The factors in this latter group were used to formulate scenarios. A "central" scenario was formulated that represented the most likely complete mechanism for radionuclides to be released from the engineered facility and transported through the geosphere, and to result in doses to humans. This central scenario contained as many of the 125 factors to be quantitatively evaluated as practicably possible. The "residual" factors (1.e.. those not Included in the central scenario) were grouped in all possible combinations to arrive at a set of "alternative" scenarios. Each of the alternative scenarios contained a given combination of one or more of the residual factors superimposed on all factors in the central scenario, except those factors in the latter that would be physically inconsistent with the alternative scenario. The use of a central scenario and alternative scenarios as perturbations to the former one is similar to the approach used by Bonano et al. [1989] in the demonstration of a performance assessment methodology for a HLW repository in basalt formations. Stephens and Goodwin [1989] do not discuss how the residual factors were combined to form the alternative scenarios; however, it seems likely that they used a logic-tree approach. In formulating the central scenar1o, the group of experts decided that 117 of the 125 factors should be used, leaving elght factors to be combined into alternative scenarios. Before proceeding to form scenarios from these eight factors, the experts screened out two more, deferred one until more information became available, combined four into one, and left one unchanged. This resulted in three alternative scenarios in addition to the central scenario. The work was completed by thoroughly documenting the four scenarios, the consequences of which were to be estimated. This documentation included the assignment of a probability of occurrence. Stephens and Goodwin [1989] do not discuss how the probabilities were estimated.

\section{Formation of Scenarios Using a Top-Down Approach}

The scenario development work for Nirex in the United Kingdom [Billington et al., 1989] has centered around the use of a "top-down" approach, as opposed to the "bottom-up" approach in the SNL methodology. The top-down approach is similar to the use of fault trees in reactor safety studies. In essence, in the top-down approach, possible consequences that may lead to a violation of a specified regulatory 1 imit are hypothesized and the manner in which these consequences can occur postulated. Hodgkinson and Summerling [1989] criticlzed the top-down approach because it tends to result in incomplete sets of scenarios.

Hodgkinson and Summerling [1989] proposed a way to use the top-down approach that, they claim, eliminates the problem of completeness. Their proposed approach divides the disposal system into component elements (i.e., repository, natural environment, and radiological system) which are called "scenario elements." Possible realizations of the alternative 
states that each scenario element can attain are postulated. The steps in the proposed top-down approach are:

(1) define possible scenario elements;

(2) construct an Influence diagram that includes the interdependencies amongst scenario elements;

(3) postulate a comprehensive set of alternative states for each scenario element;

(4) using a state tree, form combinations of states for the scenario elements, with each combination being a scenario;

(5) screen combinations of scenario-element states that are physically unrealistic and/or unimportant to obtain the set of scenarios for consequence analysis; and

(6) assign "degrees of bellef" to each scenario-element state, accounting for the other states through the influence diagram, and, consequently, estimate scenario probabilities.

Scenario elements could be defined, according to Hodgkinson and Summerling [1989], based on their cause (e.g., naturally induced, humanly Induced, repository induced) or on their field of effect (e.g., near field, far field, etc.). These authors claim that this top-down approach, as compared to the more conventional approach of Billington et al., [1989], has the advantage of postulating scenario-element states comprehensively, the degrees of belief of which can be coherently assigned using expert judgment. 
In this section we demonstrate the use of the scenario selection procedure discussed previously by applying it to a hypothetical reference site containing a bedded-salt formation as the host medium for the radioactive waste repository. Because the stratigraphic layering of any disposal site is an important consideration in developing and analyzing the release and subsequent transport of radionuclides to the blosphere, a description of the reference site that provides the geologic setting for the demonstration is given below.

\subsection{The Reference Site}

While the reference site used in the demonstration is hypothetical, the physlographic setting and geologic and hydrologic properties are real in the sense that they were chosen as being representative of several regions in the United States. The site is located in a symmetrical upland valley, half of which is shown schematically in Figure 3. Surrounding the valley is a ridge having an elevation of $6000 \mathrm{ft}$. The crest of the ridge is a divide for both surface drainage and ground-water flow with the result that the only water moving within the valley falls in the valley itself. River $L$ is the major drainage for the valley. The elevation of River $L$ at the point of cross section indicated in Figure 3 is $2500 \mathrm{ft}$. Intermittent tributaries to River $\mathrm{L}$ such as River $U$ exist, but they have no effect on flow and are not modeled. The valley is assumed to receive an average of $40 \mathrm{in}$. of rainfall per year, of which 16 in. are lost by evapotranspiration and the remaining $24 \mathrm{in}$. recharge the ground-water system.

Underlying the valley is a basement of crystalline bedrock that crops out over a narrow width at the ridge crest surrounding the valley. This basement is assumed to be impermeable to ground-water flow and is overlain by a sequence of sedimentary rock as shown in Figure 3 . The layered sequence is typical of sedimentary basins in which shale, siltstone, sandstone, and salt are the dominant rock types. A bedded-salt deposit having a low permeability is located within the sedimentary sequence and is considered to be the host rock for the radioactive waste repository. A detailed description of the reference repository can be found in Campbell et al. [1978].

\subsection{Hydraulic Characteristics of the Reference Site}

Hydraulic properties of the rock units shown in Figure 3 are given in Table 1. The properties of the sandstone and shale units are representative of these rock types [Franke and Cohen, 1972]. However, as the site studied by Franke and Cohen did not contain a bedded-salt formation, the hydraulic conductivity and porosity of the salt were arbitrarily (but conservatively) assumed to be factors of $10^{3}$ and 10 lower, respectively, than those values for the middle and lower shale units. These values are at the upper end of the range of representative salt formations. 


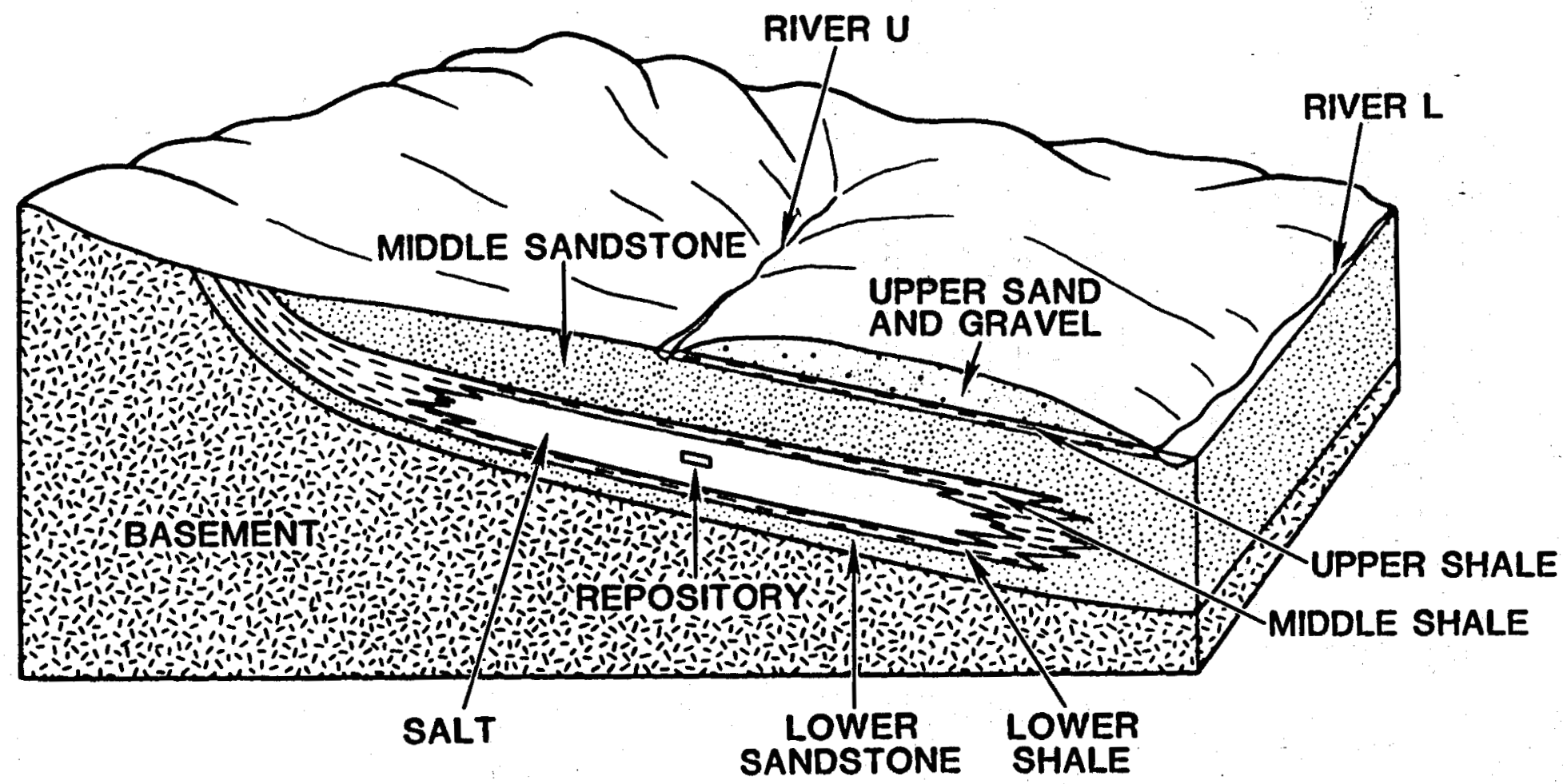

Figure 3. Schematic Diagram of the Reference Site. One side of the symmetric basin is shown. The upper end of the valley is approximately elliptic with the repository located on the minor axis; the sides of the valley are parallel below the repository. The vertical exaggeration of scale is approximately 20. 


\begin{tabular}{|c|c|c|c|c|c|c|}
\hline $\begin{array}{l}\because \\
\because \\
\vdots \\
\because \\
\vdots\end{array}$ & $\begin{array}{l}\text { Upper } \\
\text { Sand } \\
\text { and } \\
\text { Grave1 }\end{array}$ & $\begin{array}{l}\text { Upper } \\
\text { Shale }\end{array}$ & $\begin{array}{l}\text { Middle } \\
\text { Sand- } \\
\text { stone }\end{array}$ & $\begin{array}{l}\text { Middle/ } \\
\text { Lower } \\
\text { Shale }\end{array}$ & Salt & $\begin{array}{l}\text { Lower } \\
\text { Sand- } \\
\text { stone }\end{array}$ \\
\hline $\begin{array}{l}\text { Horizontal } \\
\text { Hydraulic } \\
\text { Conductivity }\end{array}$ & $\begin{array}{r}270 \\
\text { (ft/day) }\end{array}$ & $10^{-2}$ & 50 & $10^{-2}$ & $10^{-5}$ & 40 \\
\hline $\begin{array}{l}\text { Vertical } \\
\text { Hydraulic } \\
\text { Conductivity }\end{array}$ & $\begin{array}{r}27 \\
(\mathrm{ft} / \mathrm{day})\end{array}$ & $10^{-5}$ & 1.4 & $10^{-3}$ & $10^{-6}$ & 7 \\
\hline Porosity & 0.3 & 0.3 & 0.3 & 0.3 & 0.03 & 0.3 \\
\hline
\end{tabular}

The location of the repository, as may be inferred from the elevation contours of Figure 4, is far enough from the head of the valley that ground-water flow near the repository is perpendicular to River $L$ and to the valley axis. This suggests that, for purposes of analyzing conditions around the repository, a two-dimensional simulation of the reference site would be sufficient. Furthermore, three-dimensional analyses of the reference site have shown that a two-dimensional representation of the flow system is adequate.

Contoured hydraulic head data and interstitial velocity fields for the reference site are calculated in two dimensfons using the Sandia Waste Isolation Flow and Transport (SWIFT) model: SWIFT is a three-dimensional, finite-difference code that solves conservation equations for fluid flow, heat transport, (possibly nontrace) solute transport, and radionuclide transport in trace quantities [Reeves and Cranwell, 1981]. Figure 5 shows the two-dimensional representation of the reference site used in the SWIFT simulations.

The distribution of hydraulic head, as calculated by SWIFT, is shown in Figure 6. This figure indicates that flow in the middle and lower sandstone aquifers (also referred to as overlying and underlying aquifers, respectively) is essentially one-dimensional.

A downward gradient exists across the repository, which would be more apparent if not for the vertical exaggeration of scale ( $x 20)$. Thus, should a hydraulic connection be established between the overlying and underlying aquifers, fluid flow would be downward through this connection. 


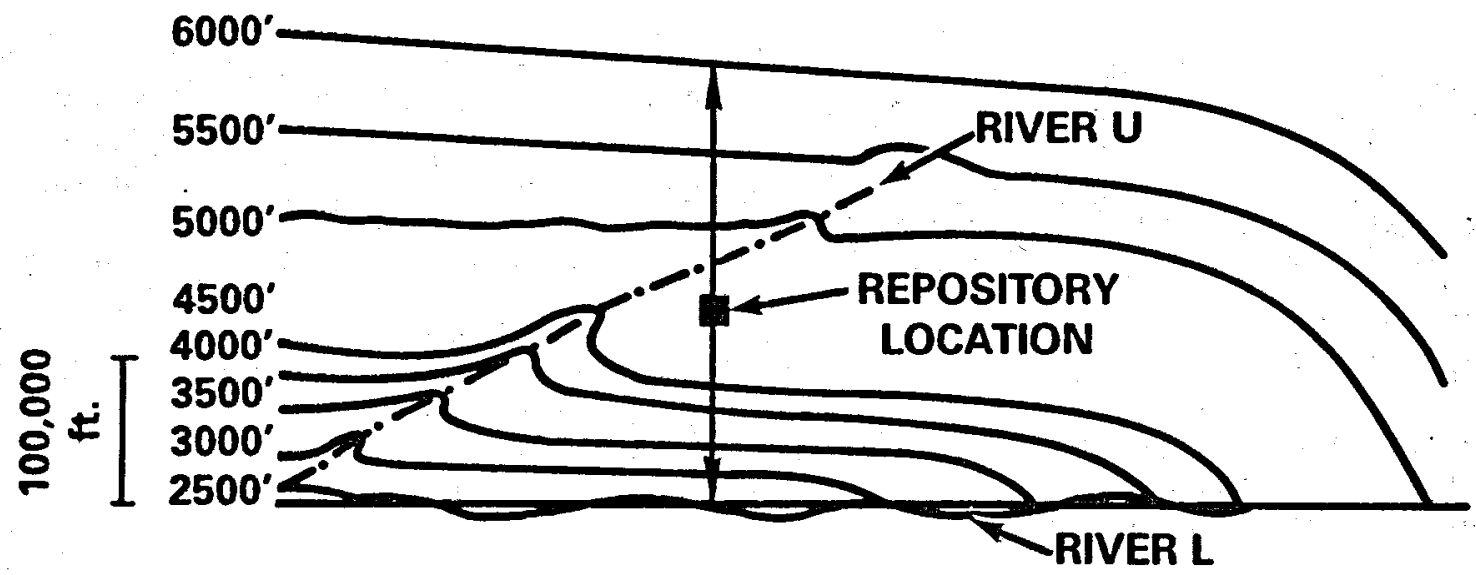

Figure 4. Physlographic Setting of the Reference Site. Lines of Constant Elevation are Shown.

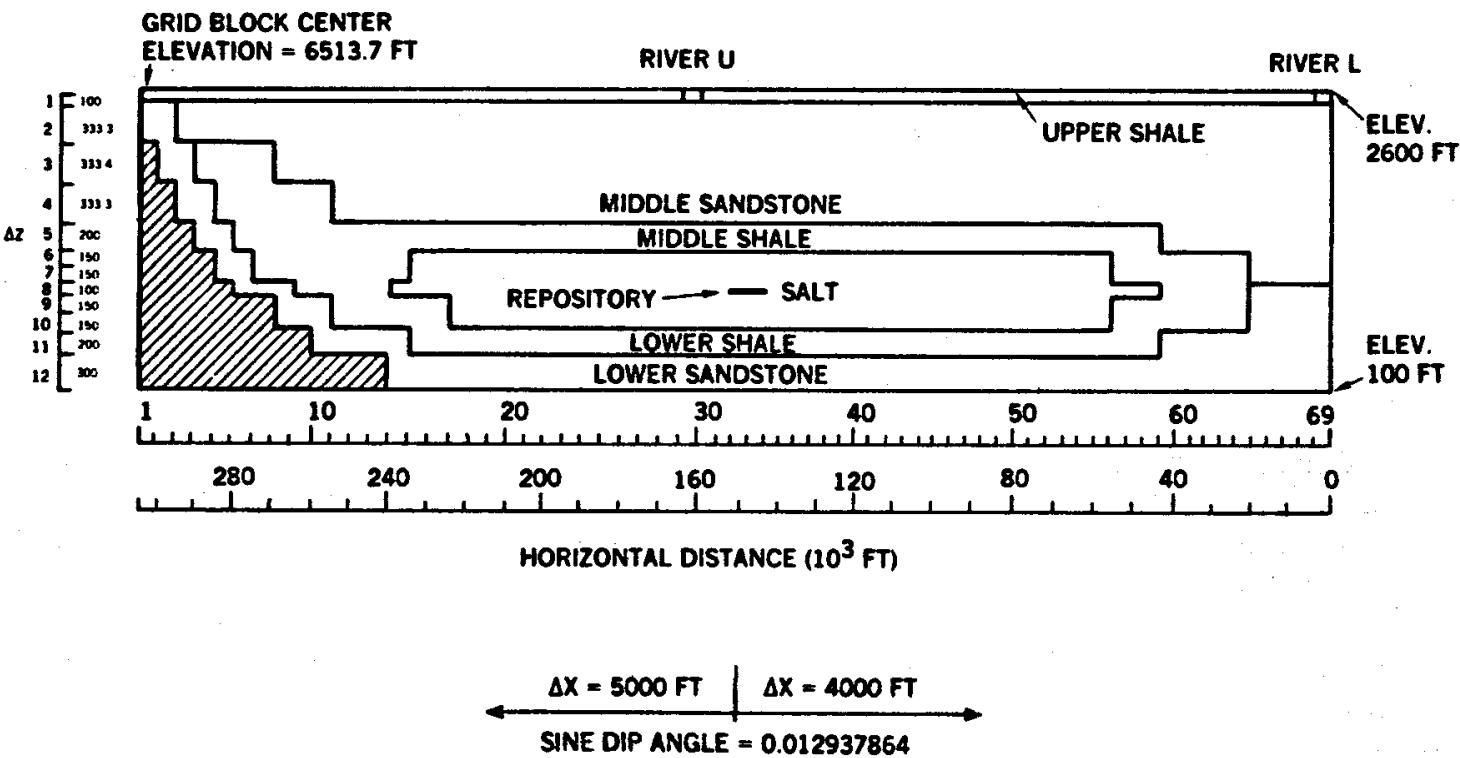

Figure 5. Two-Dimensional SWIFT Setup for the Reference site 


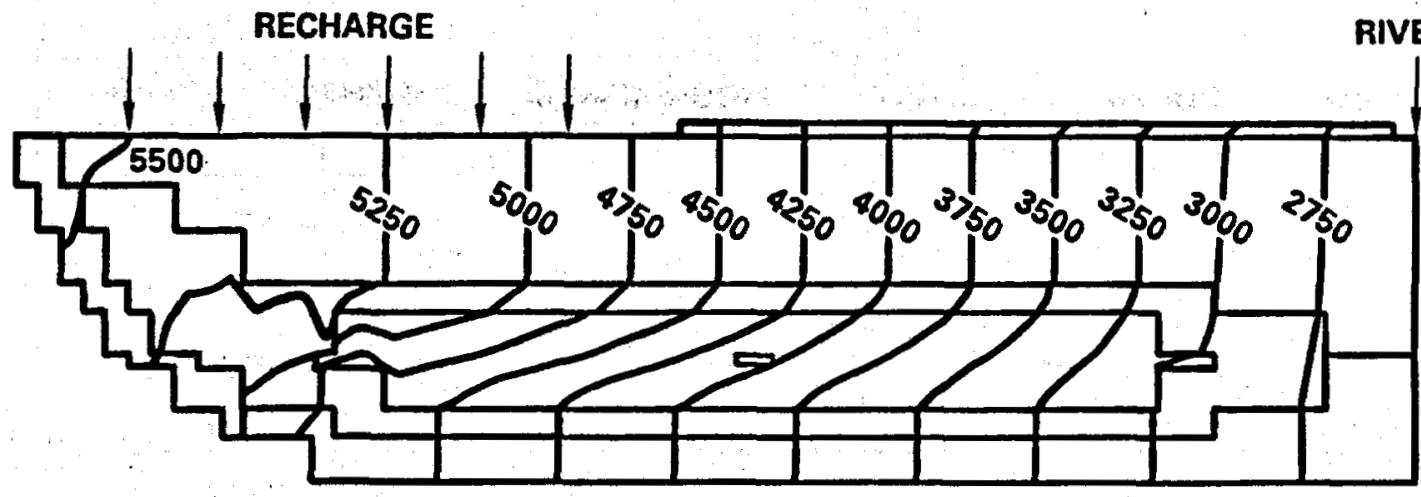

Figure 6. Hydraulic Head Distribution of the Reference Site

Upward ground-water movement exists in the vicinity of River $L$. This upward movement is not apparent in Figure 6 because of the absence of detail in the plotting of the lines of constant potential. (This absence of detail was intentionally incorporated to avoid clutter in the figure.) Figure 7, on the other hand, shows an enlarged isolated segment of the reference site near River L. Here, more detail was incorporated and upward movement of the ground water is apparent.

Fluid velocities, as calculated by SWIFT, are shown in Figure 8 . The one-dimensional nature of fluid flow in the aquifers is clearly shown in this figure. Fluid velocities below $5 \times 10^{-5} \mathrm{ft} /$ day were not plotted, which explains why no vectors are shown in the salt layers. Figure 8 begins to show some movement upward toward River $L$. However, here as in Figure 6, detail was sacrificed to avoid cluttering the figure. To better illustrate this upward movement, velocity vectors were plotted for an enlarged, isolated segment of the reference site near River $L$. These are shown in Figure 9, where the upward movement to River $L$ is more evident.

Plots of both the distribution of hydraulic head and fluid velocity field w11I be used in the next chapter to show the effects of various features on the natural flow patterns of the reference site. However, in most cases, changes in the ground-water flow pattern are illustrated adequately by the fluid velocity field. Thus, plots of the hydraulic head distribution will be used only to show changes in flow trends that are not necessarily obvious from the fluid velocity field plots. For example, certain geologic features could change the direction of flow from downward across the salt and shale to upward across these units (see e.g., 


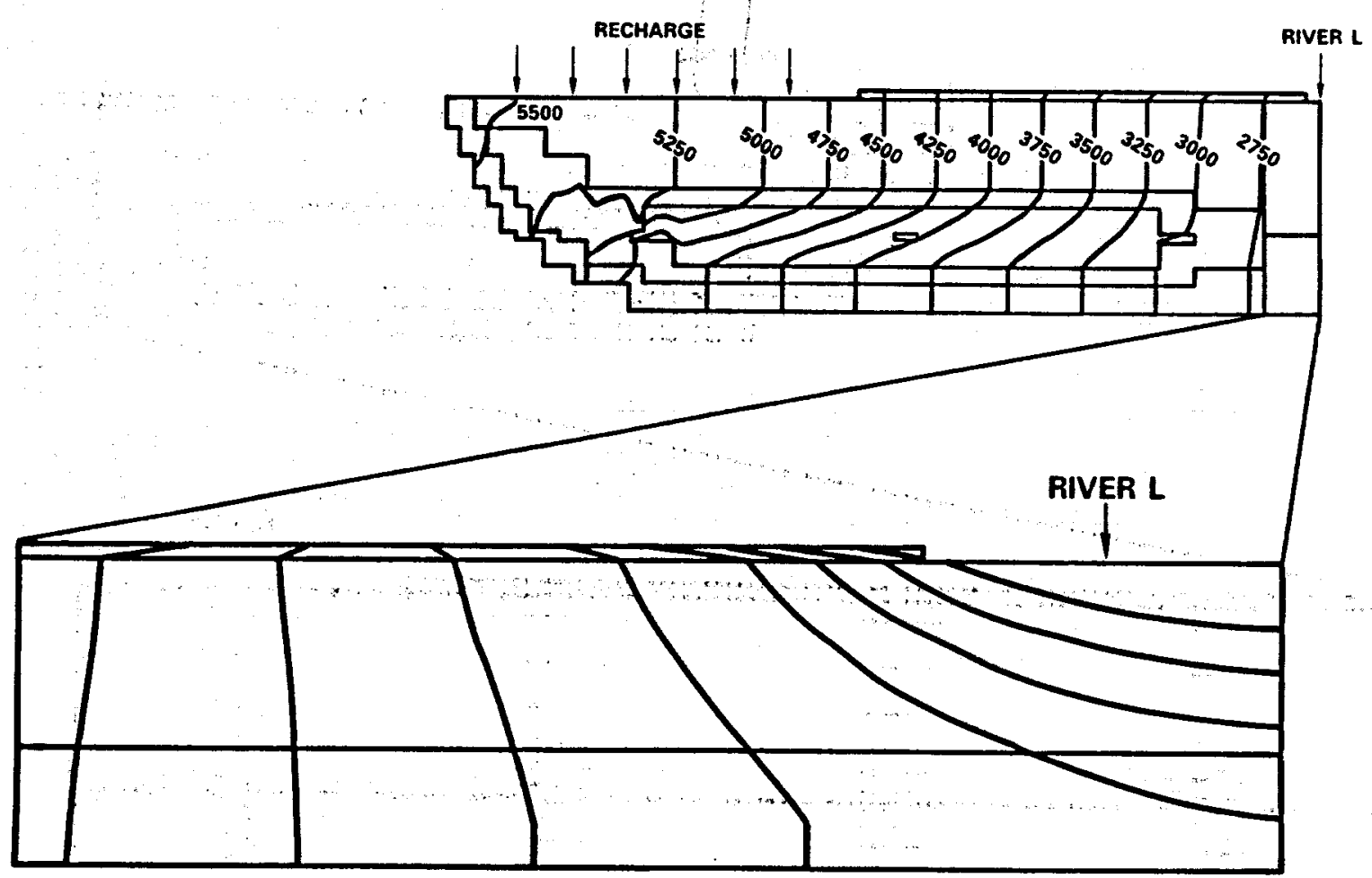

Figure 7. Hydraulic Head Distribution Near River L. Enlargement was more in the horizontal direction than in the vertical. Thus, the vertical exaggeration of the two figures is not equivalent.

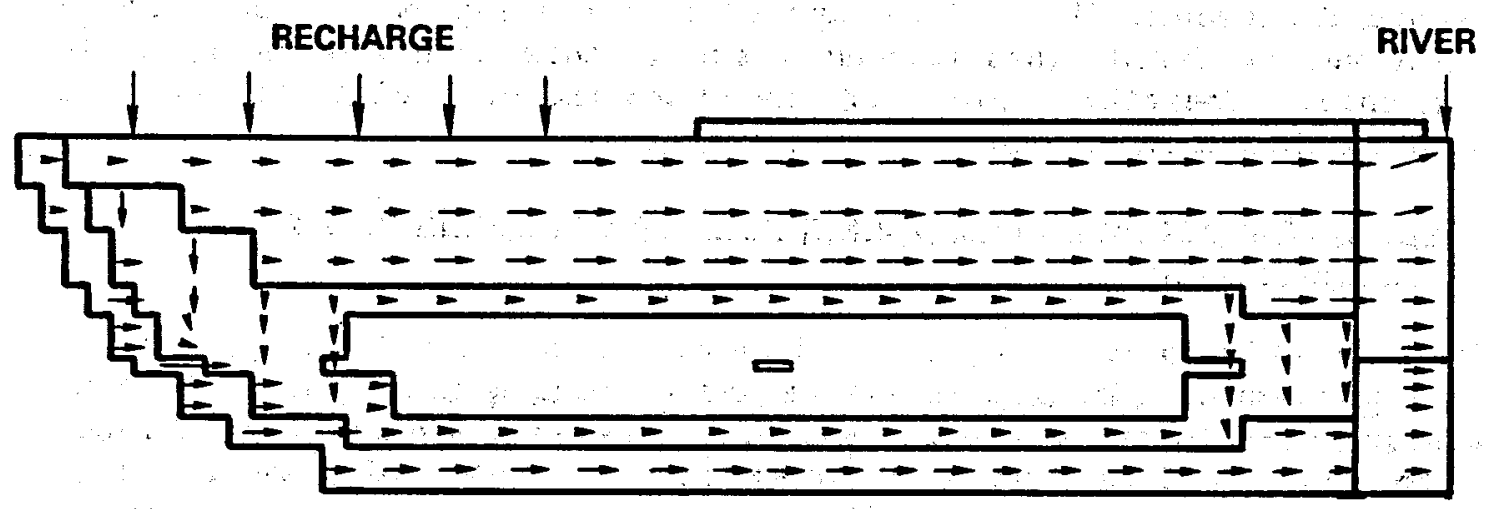

Figure 8. Fluid Velocity Vectors of the Reference Site 


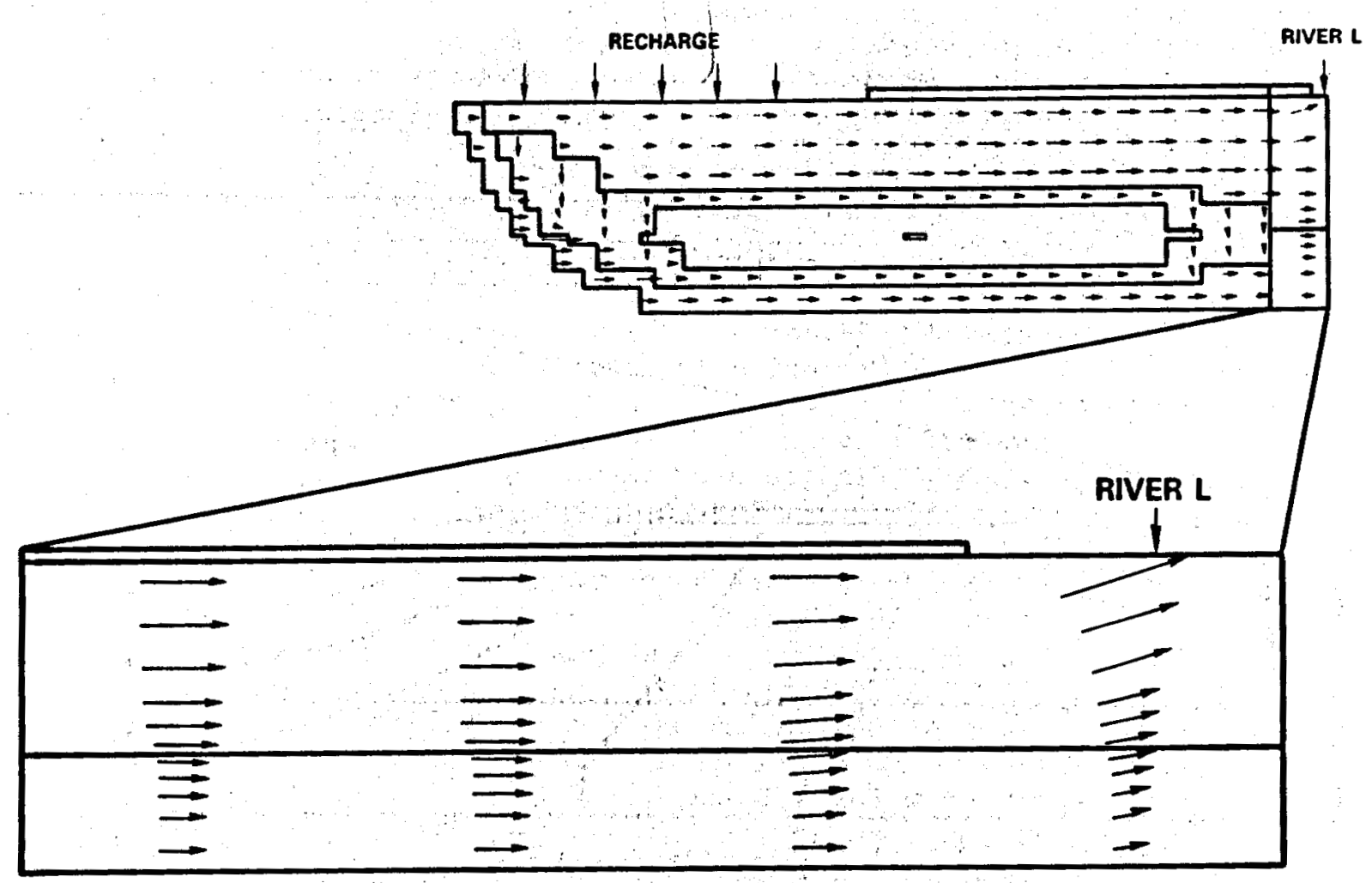

Figure 9. Fluld Velocity Vectors Near River L

Transport Phenomenon T11). This upward movement may not be seen in the velocity vector fleld plots because these vectors do not normally appear in the salt. Therefore, plots of the hydraulic head distribution would be used to show this change in the head gradient.

\subsection{Identification and classification of Events and Processes for Reference Site}

In 1976 to 1977, a panel of knowledgeable earth scientists was convened for the purpose of identifying events and processes that could potentially disrupt a radioactive waste repository [Scenario Identification Panel, 1976 to 1977]. Other studies [Arnet et al., 1980; Bingham and Barr, 1979; IAEA, 1983; and WIPP, 1979] have been reviewed to compare the relative completeness of the list. Phenomena Identified by the panel are Iisted in Table 2 and are classifled into the following categories: natural, human-Induced, and waste and repository-1nduced. This Iist Includes a varlety of events and processes and represents an attempt to establish a comprehensive base from which a final set of scenarios will be selected. As the list is somewhat general, it could probably be shortened in a site-specific analysis. 
Table 2.

Potentially Disruptive Events and Processes

Natural Eyents and Processes

Celestial Bodies

Meteorite Impacts

Surficlal Events and Processes

Erosion/Sedimentation

Glaclation

Pluvial Periods

Sea Level Varlations

Hurricanes

Seiches

Tsunamis

Regional Subsidence or Uplift

(also applies to subsurface)

Landslides

Subsurface Events and Processes

Seismic Activity

Volcanic Activity

Magmatic Activity

Formation of Dissolution Cavities

Formation of Interconnected Fracture Systems

Faulting

Human-Induced Events and Processes

Inadvertent Intrusions

Explosions

Drilling

Mining

Waste Disposal (Injection We1ls)

Withdrawal Wells

Hydrologic Stresses

Irrigation

Damming of Rivers

Waste- and Repository-Induced Events and Processes

Subsidence and Caving

Shaft and Borehole Seal Degradation

Thermally-Induced Stress/Fracturing in

Host Rock

Excavation-Induced Stress/Fracturing in

Host Rock 
A classification of these events and processes into release and transport phenomena is discussed in Section 3.5 .

\subsection{Initial Screening Based on Physlcal Reasonableness and Probability Arguments}

The inftial screening of the list of phenomena presented in Table 2 can be accomplished by using straightforward elimination procedures such as probabilistic and physical justification arguments. For example, many of the surficial phenomena and processes listed in Table 2, with the exception of those having long-term hydrologic effects, have 1ittle meaning for an inland site with a repository located at least $2000 \mathrm{ft}$ below the ground surface. Furthermore, certain geologic and natural phenomena and processes, such as meteorite impacts are shown to have small enough probability of occurrence that their contribution to repository performance assessment is of Iittle importance.

The following paragraphs contain arguments for eliminating certain of the phenomena listed in Table 2. These arguments represent the first step in the screening procedure to arrive at a list of phenomena that portray the most significant scenarios. To the extent possible, the arguments apply to the generic aspects of geologic waste disposal. However, in certain instances, reference will be made specifically to bedded salt and to the hypothetical reference site used in the methodology demonstration.

As was mentioned in Section 2.0 , a probability of $10^{-8} / \mathrm{yr}$ is used as the cutoff for the elimination of phenomena based on probabilistic arguments. A 105 year period of performance was used in the demonstration of Performance Assessment Methodology [Cranwell et al., 1987].

\section{Meteorite Impact}

Large meteorite impacts occur with such infrequency that these phenomena are of no importance with respect to the performance assessment of a deep geologic repository. Several estimates have been made of the probability that a meteorite impact could either excavate a repository located at varying depths below the land surface or severely fracture the overlying protective rock strata, Hartmann [1979] estimates that the probability of a catastrophic impact completely exhuming part of a repository is $6 \mathrm{x}$ $10^{-13} / \mathrm{yr}$. The repository is assumed to have an area of $10 \mathrm{~km}^{2}$ and to be buried 600 m deep. The Swedish KBS study. [Karnbranslesakerhet, 1978] determines a rate of $10^{-13} / \mathrm{km}^{2}-\mathrm{yr}$ for craters at least $100 \mathrm{~m}$ deep. Logan and Berbano [1978] estimate a probability of $1 \times 10^{-13} / \mathrm{yr}$ for a direct strike by a meteorite of enough energy to exhume material from a depth of $800 \mathrm{~m}$ for a $10 \mathrm{~km}^{2}$ repository. Claiborne and Gera [1974] estimate the chances of excavation to be $2 \times 10^{-13} / \mathrm{yr}$ for an $8 \mathrm{~km}^{2}$ repository located $600 \mathrm{~m}$ below the land surface. 
The Sandia hypothetical waste repository is approximately $8 \mathrm{~km}^{2}$ and located at a depth of about $625 \mathrm{~m}$ [Campbel1 et al., 1978]. The probability of excavation for this repository has been estimated as $8 \times 10^{-13} / \mathrm{yr}$ (see Appendix A). This probability value, as well as the others 1 isted above, is several orders of magnitude smaller than the cutoff value $\left(10^{-8} / \mathrm{yr}\right)$. Therefore, this event is rejected based on its small probability of occurrence.

\section{Erosion/Sedimentation}

Because of the depths being considered for deep geologic waste repositories, erosion is generally not considered to be important as a potential mechanism for releasing radionuclides from the repository. Erosion alone, at a U.S. average of approximately $2 \times 10^{-4} \mathrm{ft} / \mathrm{yr}$ [Judson and Ritter, 1964], is unlikely to be a hazard for emplacements ranging from 2000 to $3000 \mathrm{ft}$ below the land surface. In areas dominated by limestone and having a relatively high rainfall, the average erosion rate, predominantly the result of chemical weathering, is approximately $5 \times 10^{-4} \mathrm{ft} / \mathrm{yr}$ [Bloom, 1969]. The more resistant rocks of the Columbia River drainage system which undergo primarily mechanical weathering have an average erosion rate of $1 \times 10^{-4} \mathrm{ft} / \mathrm{yr}$ [Gilluly et al., 1968]. Mountainous regions typically have erosion rates of approximately $3 \times 10^{-3} \mathrm{ft} / \mathrm{yr}$ [Bloom, 1969]. The average rate of downcutting of the Colorado River in the Grand Canyon, one of the highest for any major river system, has been from $5 \times 10^{-4} \mathrm{ft} / \mathrm{yr}$ to $3 \times 10^{-3} \mathrm{ft} / \mathrm{yr}$ [Gilluly et al., 1968]. Even at these accelerated rates, it would take over $700,000 \mathrm{yr}$ to remove the overburden above a repository located at depths of $2000 \mathrm{ft}$.

Because the principal effect of sedimentation is to increase the thickness of the overburden above the repository, this process is, in most cases, beneficial. Sedimentation can, however, have certain negative effects. For example, sedimentation can influence the distribution of surface waters and increase the static loading over the repository. This increase in loading could induce fracturing or plastic deformation of the protective rock units encompassing the repository. Such effects are, however, considered in other scenarios in this study. Sedimentation is also a factor in diapirism, a process that could result in upward movement of waste. However, certain conditions need to exist before this process can occur. For example, model studies of salt dome formation have shown that an overburden of about $3300 \mathrm{ft}$ and a thickness of at least $900 \mathrm{ft}$ of salt were necessary to initiate the salt-flow process [Halbouty, 1979]. The thickness of the salt layer in the reference site used in this demonstration is only $700 \mathrm{ft}$, with an overburden of approximately $2050 \mathrm{ft}$. Because only the overburden can increase, it is felt that sedimentation, as a potential mechanism for containment fallure, can be neglected in this analysis. Thus, both erosion and sedimentation are eliminated from any additional consideration based on the criteria of physical reasonableness. 
During the Pleistocene Epoch, four mafor glaclal advances covered the northern portion of North America. The latest advance began about 70,000 years ago and, after several pulses, finally retreated from the United States about 10,000 years ago. Considerable controversy surrounds what conditions cause continental glaciation, whether the present climate is post-glacial or interglacial, and what long-term effects industrialization will have on world climate. Based on the history of glaciation in the Pleistocene, renewed growth of continental glaciers is expected within the next 100,000 years [Bloom, 1969]. Thus, depending on its location and the period of time considered to be of concern, the effects of glaciation on a geologic radioactive waste repository could be realized.

For those sites that would be overridden, the effects of glaciation are uncertain. For example, the deposition of glacial till beneath the glacier could result in a positive effect, because this material tends to be relatively impermeable, On the other hand, glacial movement can result in erosion of the land surface beneath the glacier. The rate of this erosion, however, depends upon several factors: (1) the thickness and rate of movement of the glacfer; (2) the abundance, shape, and hardness of the rock particles within the base of the glacier; and (3) the erodibility of the rocks beneath the glacier. Furthermore, the depth of erosion can vary depending on the local topography and climatic conditions. For example, it is believed that glacial scour deepened the large valleys of northern British Columbia and southern Alaska by at least 1960 ft [Flint, 1971]. Ried [1982] concluded that the average erosion rate beneath the Muir Glacler in southern coastal Alaska amounted to $6 \times 10^{-2}$ $\mathrm{ft} / \mathrm{yr}$. At this rate, $2000 \mathrm{ft}$ of overburden could be removed in about 32, $000 \mathrm{yr}$. However, these regions provide optimum conditions for glacial erosion. They are high and steep and have climates that, during a glacial period, would provide abundant snowfall. The Canadian Shield is an example of the other extreme. Here, evidence indicates that glaciation did little more than modify the details of the existing relief [F1int, 1971].

In addition to the erosional effects of the glacier itself, increased fluvial erosion in advance of the ice can result from the increase in precipitation often associated with interglacial periods. Furthermore, the tremendous weight of the glacier itself and the presence of ice and accompanying water could result in fracturing and renewed movement on existing faults as well as alterations in the surface-water and groundwater hydrology.

Any long-term risk from glaciation could probably be controlled by selecting repository sites some distance from the glaciated areas of the Pleistocene Epoch. The reference site described in Section 3.1 and used in this analysis is assumed to be located in a region not affected by 
future glaciation. Thus, glaciation is ellminated from additional con: sideration based on the criteria of physical reasonableness and/or probability.

\section{Rluvial Perlods/Sea-Level Variations}

Pluvial periods and sea-level variations could be important for disposal in unsaturated zones (arid lands) and in rock structures showing evidence of dissolution. Pluvial periods could increase the amount and rate of aquifer recharge, thus increasing hydraulic gradients in drainage systems. In fully saturated systems, such as the reference bedded-salt site, increased rainfall would probably not have adverse effects except to increase runoff and thus erosion. In Instances of disposal in unsaturated zones, pluvial perlods must be assessed on a site-specific basis. In the analysis of the reference site, the problem of pluvial periods is handled in part by varying the hydraulic properties of the overlying and underlying aquifers. That is, allowing for uncertainty in aquifer hydraulic conductivity has the effect of allowing for variation in aquifer recharge rates.

Sea-level variations can alter processes such as erosion, sedimentation, and the regional hydrology. However, most effects from sea-level variations would not be felt by a repository located inland. A substantial rise in sea level would flood coastal areas. This flooding could affect a repository located in the salt-dome regions of the Gulf Coast, depending on its depth of burial above the present sea level. Extrapolation of recorded sea-level fluctuations indicate that between 10,000 and 9000 years ago the sea level was rising at an average rate of approximately 3 $x 10^{-2} \mathrm{ft} / \mathrm{yr}$, whereas during the last $3000 \mathrm{yr}$ the average rate has slowed to approximately $1 \times 10^{-3} \mathrm{ft} / \mathrm{yr}$ [Flint, 1971]. At this latter rate, the sea level could rise as much as $115 \mathrm{ft}$ in the next 100,000 years. Considering the elevation of the reference repository (approximately $2800 \mathrm{ft}$ above sea level), the effects of such sea-level changes would be minimal.

Based on the above arguments, the phenomena of pluvial periods and sealevel variations can be eliminated because of physical reasonableness and/or probability of occurrence.

\section{Hurricanes/Seiches/Tsunamis}

These phenomena may be Important to the safety of disposal sites located on the margins of the Gulf of Mexico or on the coastal regions of the United States during the operational phase. In the postclosure phase, adverse effects from these phenomena might conceivably arise from alteration of ground-water flow patterns and from imposed hydrostatic loading on the site. However, such effects are likely to be transient and of no long-term consequence.

As the reference site is not located near coastal regions, the phenomena of hurricanes, seiches, and tsunamis are eliminated based on physical reasonableness and/or probability of occurrence. 
Regional uplift or subsidence is of little consequence to the integrity of a bedded-salt repository. One reason for this lack of effect is the long times required to produce significant uplift or subsidence. Furthermore, the expected epelrogenic nature of the movement would probably not cause faulting and folding.

Uplift could result in an increase in stream gradients, and therefore an increase in rates of stream erosion. With the exception of active orogenic belts and recently deglaclated areas, the maximum rate of uplift in the United States 15 approximately $5 \times 10^{-2} \mathrm{ft} / \mathrm{yr}$ [Press and siever, 1974], with most areas of uplift experlencing substantially lower rates. Even at lower rates of uplift, stream erosion will not match uplift for most rock types.

Subsidence could result in a decrease of stream gradients and erosion rates. Deposition of sediments in the region may contribute to the 1solation of the repository. Maximum rates of epeirogenic subsidence are approximately $3 \times 10^{-2} \mathrm{ft} / \mathrm{yr}$ [Press and Siever, 1974]. Most subsiding areas have rates substantially lower than this.

The bedded-salt locations under consideration for nuclear waste disposal sites are in regions undergoing epelrogenic uplift at rates of $3 \times 10^{-3}$ to $2 \times 10^{-2} \mathrm{ft} / \mathrm{yr}$ [Press and Siever, 1974]. Because of the low rate of movement, along with the limited amount or absence of folding and faulting associated with the movement, regional uplift and subsidence are not expected to result in significant effects on the reference site system. Thus, these phenomena are eliminated based on physical reasonableness and/or probability of occurrence. It should be noted that 10 CFR 60 [U.S. Nuclear Regulatory Commission, 1988] classifies uplift and subsidence as potentially adverse conditions and, thus, requires that the applicant demonstrate that these conditions do not impair significantly the ability of the repository to isolate the waste.

\section{Landslides}

In certain areas, a landsilde could conceivably divert or dam a river, resulting in the presence of water above the repository. Impounded water behind the dam could exert sufficient pressure to result in displacement along fractures and faults. However, for the reference site used in this analysis, diversion of water or damming by a landslide resulting in surface water being present above the repository would require the diversion or impoundment of water a distance of about 25 miles laterally from an existing river (River $L$ ). No evidence of the diversion or impoundment of a body of water by landsilde for a distance this great can be found in the Ilterature. Thus, for the site considered in this demonstration, landslides can be eliminated based on physical reasonableness and/or probability of occurrence. However, this phenomenon should be considered 
for different sites. 10 CFR 60 classifies landslides as a potentially adverse condition and requires the applicant to demonstrate that this condition does not impair significantly the ability of the geologic repository to isolate the waste.

\section{Seismic Activity}

The frequency and magnitude of earthquakes in a region may affect the stability of a repository during the operational phase. After closure of the repository, ground motion caused by earthquakes will affect the repository by possibly contributing to the fallure of waste packages, borehole seals, and shaft seals. Movement along faults, formation of fractures, and changes in rock properties could affect ground-water flow, thereby influencing radionuclide release and transport. The NRC's rule on high-level waste disposal (10 CFR 60$)$ lists earthquakes as a potentially adverse condition and requires a careful analysis from the applicant to demonstrate that it does not significantly impair the ability of the geologic repository to isolate the radioactive waste. Nevertheless the effects of earthquakes (e.g., faulting) are considered in other sections of this report.

\section{Volcanic and Magmatic Activity}

Volcanic activity occurs primarily in tectonically unstable areas. These areas are rift zones, spreading centers along plate boundaries, subduction zones and locations above deep-mantle plumes. The Quaternary volcanism evident throughout much of the western United States probably is the result of the North American Plate overriding a previously active spreading center.

Areas underlain by bedded salt are generally either tectonically stable or undergoing epeirogenic uplift. Volcanic activity would not be expected in either of these settings. In the areas of uplift, occasional fractures may provide pathways for intrusion of magma resulting in the formation of dikes or sills. Areas of possible future dike intrusion should have anomalously high heat-flow associated with magma at depth. Such anomalies would probably be detected during site evaluation.

The formation of a dike or sill could disrupt the ground-water flow system of the site. Because these features generally have low permeability, such a feature would act as a low-conductivity "dam," resulting in the redirection of the flow of ground water. The effects of the change in ground-water flow on the reference site depend in part on the orientation and size of the feature and the geologic setting into which the feature intrudes. These features and their effects on the reference site flow patterns are investigated in the next section.

The low probability of volcanic activity in bedded-salt regions essentially eliminates this geologic process from additional consideration. Several estimates have been made as to the probability of this process 
disrupting a repository site. Logan and Berbano [1978] estimate the probability of volcanism affecting a $10 \mathrm{~km}^{2}$ repository in the Delaware Basin to be from approximately $8 \times 10^{-11}$ to $8 \times 10^{-12} / \mathrm{yr}$. Arthur $D$. Little, Inc. [1980], arrived at estimates ranging from $1 \times 10^{-8}$ to $1 \times$ $10^{-10} / \mathrm{yr}$. For a repository with the dimensions of those of the reference repository used in this analysis, a probability of $6 \times 10^{-9} / \mathrm{yr}$ was est mated using a model described in Beckman and Johnson [1982]. For reasons given in Appendix B, this estimate 18 conservative. Thus, probabilities discussed above indicate that this phenomenon can be eliminated based on probabilistic arguments.

\section{Explosions}

Because of repository-design technology and the understanding of radionuclide-host rock interactions, a nuclear explosion originating in the repository is considered impossible. Furthermore, 10 CFR 60 requires that the system be designed for nuclear-criticality safety.

The possibility of a disruption of the repository owing to the effects of nuclear warfare is highly speculative, as much of this subject requires subjective judgments concerning the actions of humans in the future. In the event of nuclear warfare, empirical relations between crater dimensions and explosive yield [Glasstone, 1962] Indicate that a surface explosion of 635 MT yield would be required to excavate a crater $2063 \mathrm{ft}$ deep (the repository is $2050 \mathrm{ft}$ below the land surface). Excavating through the shale layer ( $1700 \mathrm{ft}$ depth) would require a $365 \mathrm{MT}$ yield. Most thermonuclear weapons of the $k$ ind that might be deployed against strategically important targets would have a yield of $200 \mathrm{KT}$ to $10 \mathrm{MT}$.

The more likely scenario would be the explosion (either accidental or in the event of war) of one or more nuclear weapons in the $10 \mathrm{MT}$ yield range on or near the surface of the reference site. These explosions could cause some fracturing in the middle shale layer allowing the infiltration of water to the salt layers and the formation of a dissolution cavity that may in time reach the repository. The possibility of this phenomenon is considered in a later section of this report (see Phenomenon R4).

Sabotage needs to be considered only during the operational phase of the repository. After closure, access to the radioactive waste requires a massive drilling and excavating program. For this reason, sabotage is not considered in this report. Furthermore, an explosion caused by combustible material (e.g., gas) after closure of the facility is highly improbable. Although $10 \mathrm{CFR} 60$ prohibits combustible material unless its presence w111 not compromise the performance of the repository, it is still possible for combustible material to exist in the repository. However, the existence of such material would undoubtedly be detected during the operational phase of the programs and, therefore, be adequately compensated for as required by 10 CFR 60 . 


\section{Irrigation and Damming of Rivers}

Irrigation by well water in a region presupposes the presence of aquifers with sufficient yield and water of adequate purity to support such activity. In bedded-salt areas, the aquifers beneath the salt beds tend to be saline, whereas the aquifers above the salt usually contain relatively pure water. As a result, irrigation would affect the aquifers above the repository horizon. The pumping and infiltration of water could alter the hydraulic properties of the region. However, these changes are considered in the analysis by varying the hydraulic properties of the aquifer. A large-scale irrigation project could decrease hydrostatic pressure in the pumping area. Such changes in pressure may result in minor displacements along fractures in the underlying units. This movement would be small and have no effect on the repository or the ground-water flow system. Furthermore, large irrigation projects for the reference site used in this analysis are not considered due to the relatively large rainfall assumed $(40 \mathrm{in} / \mathrm{yr})$. Irrigation wells are considered as shortened paths to the surface environment (see Transport Phenomenon T1) and also are used in the Pathways Model [Helton and Kaestner, 1981] to determine surface concentrations for use in estimating health effects. The effects of irrigation on radionuclide transport in ground water (other than varying the hydraulic properties of the site) are not considered. In a real site analysis, estimates should be made as to the potential impact of large irrigation projects on the hydrologic system.

Regional changes in the ground-water system associated with dam construction could alter the hydraulic properties of the aquifers. These variations are included in the analysis by varying the hydraulic properties of the aquifer. Other than varying these properties, it is assumed that no dams exist or are constructed at some later date at the reference site. It should be noted that $10 \mathrm{CFR} 60$ requires that the applicant demonstrate that these phenomene do not impair significantly the ability of the repository to isolate the waste.

\subsection{Additional Screening Using Consequence Arguments}

In the previous section a preliminary screening of the initial list of events and processes was performed based on straightforward physical reasonableness and probabilistic arguments. A detailed analysis of their effects on the flow properties of the reference site was not required. In this section, consequences are examined for several of the remaining events and processes 1isted in Table 2. Here, consequence is in terms of the effects that these phenomena have on the natural properties of the reference site. Additional screening is then performed based on consequences and probability.

The discussions of the events and processes in this section are in the context of release (R) and transport ( $T$ ) phenomena. 
Release Phenomenon R1. Release Phenomenon R1 consists of a highpermeability region extending from the ground surface to the repository having a horizontal cross-sectional area ranging from a few square feet to a few tens of square feet (Figure 10). This feature is meant to represent a drill hole or shaft, present at time of repository closure or emplaced at some future time, that was never sealed or in which the sealing material has deteriorated. The effects of such a feature on the flow system are shown in Figure 11. This figure indicates that water in the middle sandstone aquifer would tend to migrate through the feature to the repository. It is assumed that the width of the feature in the direction of the hydraulic gradient is sufficiently small so as to avoid the formation of a $\mathrm{U}$-tube connection of the middle sandstone aquifer (see Release Phenomenon R3).

Drilling into the repository could result in release of radioactive material directly to the ground surface if a waste canister is penetrated or leached radionuclides are encountered. However, the small amount of material that would be transported to the surface under these conditions would result in little change in cumulative release. It should be noted that any doses resulting from this material are not relevant to the containment requirements. The more significant long-term effects from a drill hole or mining shaft emplaced to the repository level would come from the dissolution and transport of radionuclides in ground water. Large scale releases to circulating ground water would have to be preceded by dissolution of all or portions of the salt layers surrounding the waste. Heat generated by the radioactive waste would tend to enhance salt dissolution along this feature. Thermal convection and thermally enhanced diffusion provide mechanisms for movement of dissolved salt away from the repository thereby allowing further salt dissolution. However, heated fluid rising in the drill hole or shaft will cool as it moves away from the repository. Thus, salt may precipitate in the upper portions of the drill hole or shaft and reduce the effective permeability of the feature.

Salt creep is another mechanism that would tend to reduce the long-term effects from a drill hole or mine shaft. Without the offsetting process of salt dissolution, salt creep would have the effect of closing such a feature in the salt. Thus the predominant risk from this phenomenon appears to be the inadvertent drilling into a waste canister or leached radionuclides and transportation of the materlal directly to the surface. Despite the limited release from this event, Phenomenon $R I$ retained for further analysis. 


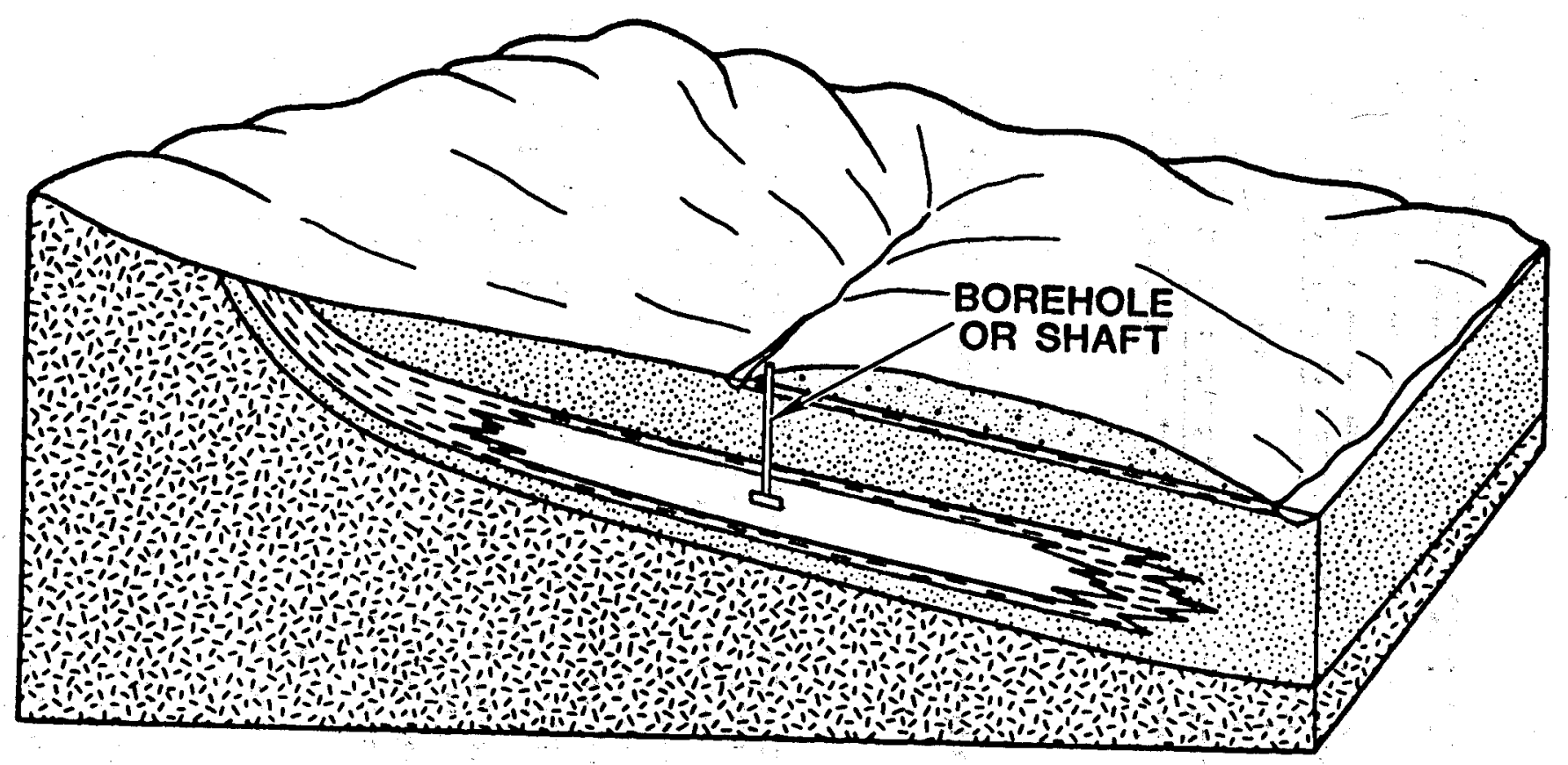

Figure 10. Release Phenomenon Rl 


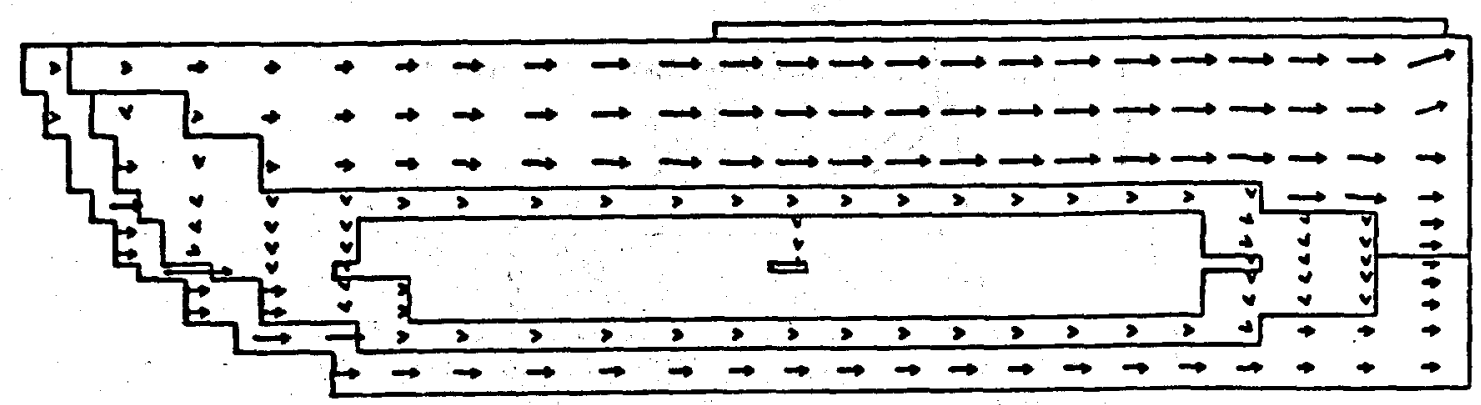

Figure 11. Fluid Veloclty Vectors for R1

Release Phenomenon R2. Release Phenomenon R2 is similar in structure to R1 with the exception that the high permeability region extends to the lower sandstone aquifer (see Figure 12). This feature represents a drill hole or shaft extending from the ground surface to the lower sandstone aquifer and passing through the repository. This high-permeability region would result in flow downward into the lower sandstone aquifer (FIgure 13). Any radionuclides dissolved at the repository would be transported to the lower aquifer for eventual discharge at River $L$. Should this feature be combined with a transport phenomenon that causes an upward hydraulic gradient across the salt and shale, transport of dissolved radionuclides would be upward into the middle sandstone aquifer. The fact that the drill hole or shaft is completed through the repository to the lower sandstone aquifer means that radionuclide migration times to the aquifer will be substantially shorter for R2 than for Rl. The migration pathway is along the lower sandstone aquifer to River L.

This phenomenon cannot be eliminated based on physical reasonableness and/or probabilistic arguments as the probability of inadvertent intrusion is above the $10^{-8} / \mathrm{yr}$ cutoff (see Appendix C). The effects of this feature on the overall flow properties of the site are minimal. However, depending on the size and number of boreholes considered, drilling could result in substantial releases of radionuclides to circulating ground water. Thus R2 is retained to perform additional analysis of the possible discharges to the surface environment and health effects resulting from these discharges. 


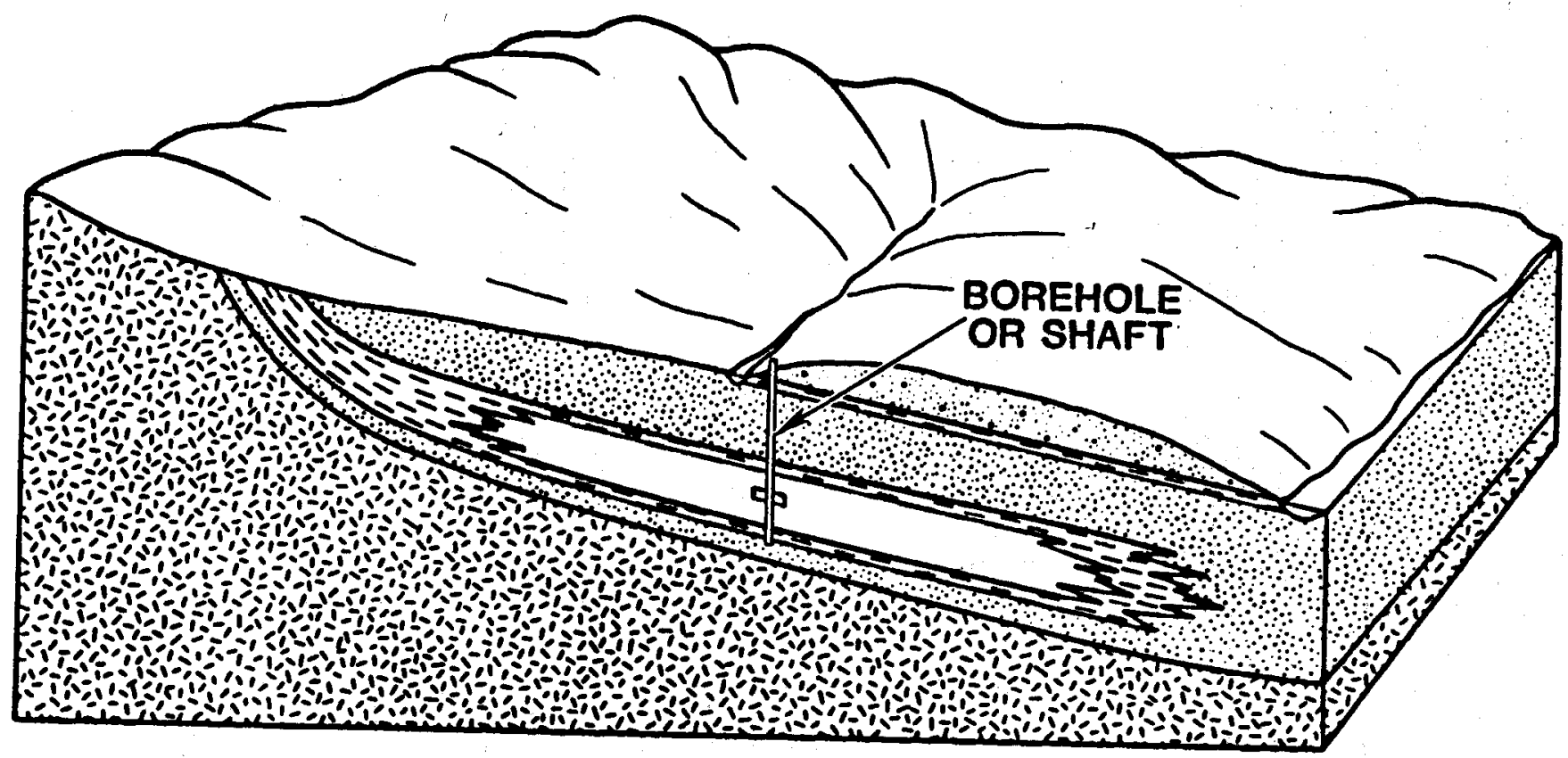

Figure 12. Release Phenomenon R2 


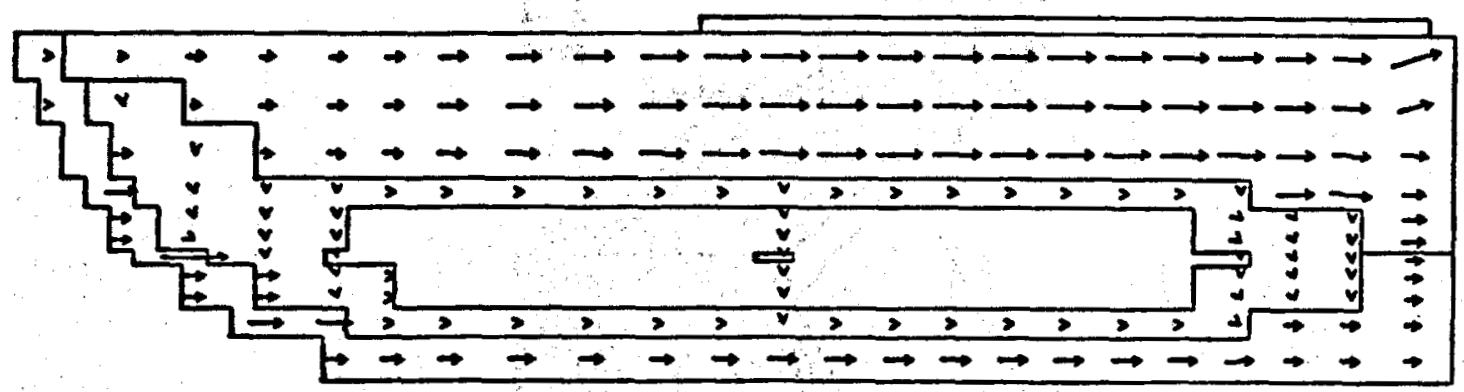

Figure 13. Fluid Velocity Vectors for R2

Release Phenomenon R3. Release Phenomenon R3 postulates the existence of two hydraulic communications between the middle aquifer and the repository with one down gradient from the other (Figure 14). The horizontal cross-sectional area of each zone is on the order of a few square ft to a few tens of square $f t$ as in $R 1$ and $R 2$, these features could be drill holes or shafts, present at the time of repository closure of emplaced at some future time. Because of the density difference between fresh water and brine, the hydraulic gradient will not be sufficient to drive water through the repository and out the downdip comminication unless a minimum separation distance (approximately $3000 \mathrm{ft}$ for the reference site) between the two communications is exceeded.

Assuming the horizontal conductivity of the repository is higher than the intact salt, the presence of these two hydraulic communications results In ground water circulating from the middle sandstone aquifer through the repository and returning to the middle aquifer (Figure 15). Such a communication is generally referred to as a "U-tube " Radionuclides transported to the middle aquifer could reach the surface environment through withdrawal wells placed into the middle sandstone aquifer downdip from the repository or discharged at River L. Design criteria could reduce the probability of this feature by requiring that the separation, in the direction of the gradient, of exploratory holes of shafts emplaced during repository construction, be sufficiently small so as to avold formation of a U-tube. 


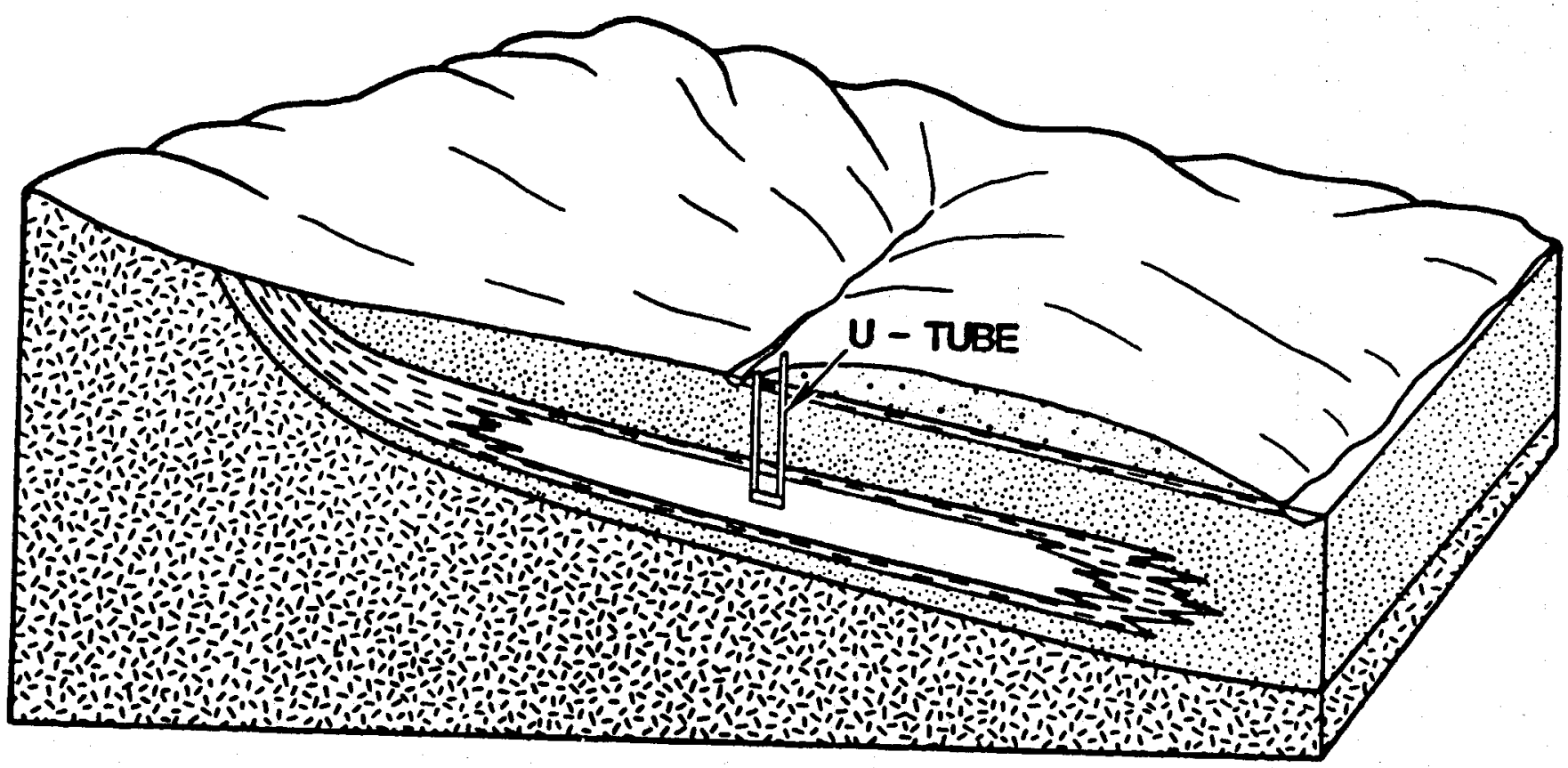

Figure 14. Release Phenomenon R3 


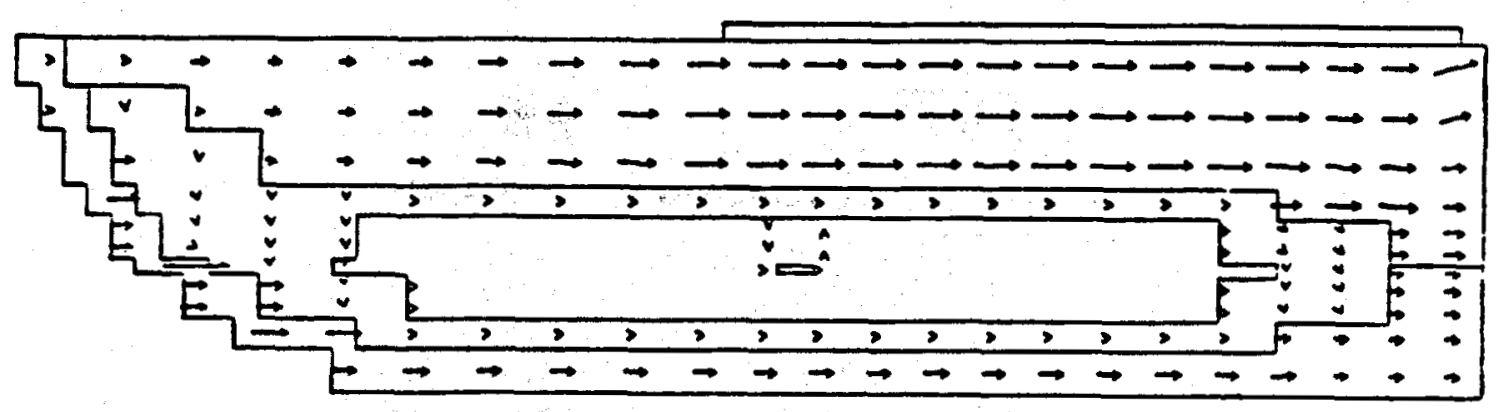

Figure 15. Fluid Velocity Vectors for R3

The consequences of such a feature could be significant, particularly if other features, such as withdrawal wells into the middle sandstone aquifer, provide a shortened path to the surface environment. Travel times from the repository to withdrawal wells located 1 mile downdip from the repository can be as short as a few tens to hundreds of years.

As was mentioned earlier, this feature could be formed by failure of the sealing material in two or more of the access shafts emplaced at the time of construction of the repository or from future drilling or mining. Very few data exist on the long term integrity of sealing materials for boreholes or shafts. Therefore, it is extremely difficult to arrive at a probability that this feature will occur from failure of sealing materials. Probabilities associated with inadvertent intrusions due to drilling are, however, above the 10-8/yr cutoff imposed on this demonstration. Thus this phenomenon cannot be eliminated based on probability arguments. Therefore, based on the potential consequences, R3 will be retained for further analysis.

Release Phenomenon R4. This release phenomenon postulates a massive dissolution cavity having a horizontal cross-sectional area approximately equal to that of the repository (Figure 16). Formation of such a cavity could result from the development of a hydraulic communication between the middle aquifer and the salt followed by dissolution of the salt layers above the repository. Events that might lead to a dissolution of the salt above the repository are (1) Induced fracturing of the overlying shale, (2) driling or mining at some future date after repository closure, and (3) degradation of the sealing material in shafts or boreholes emplaced at the time of repository excavation. 


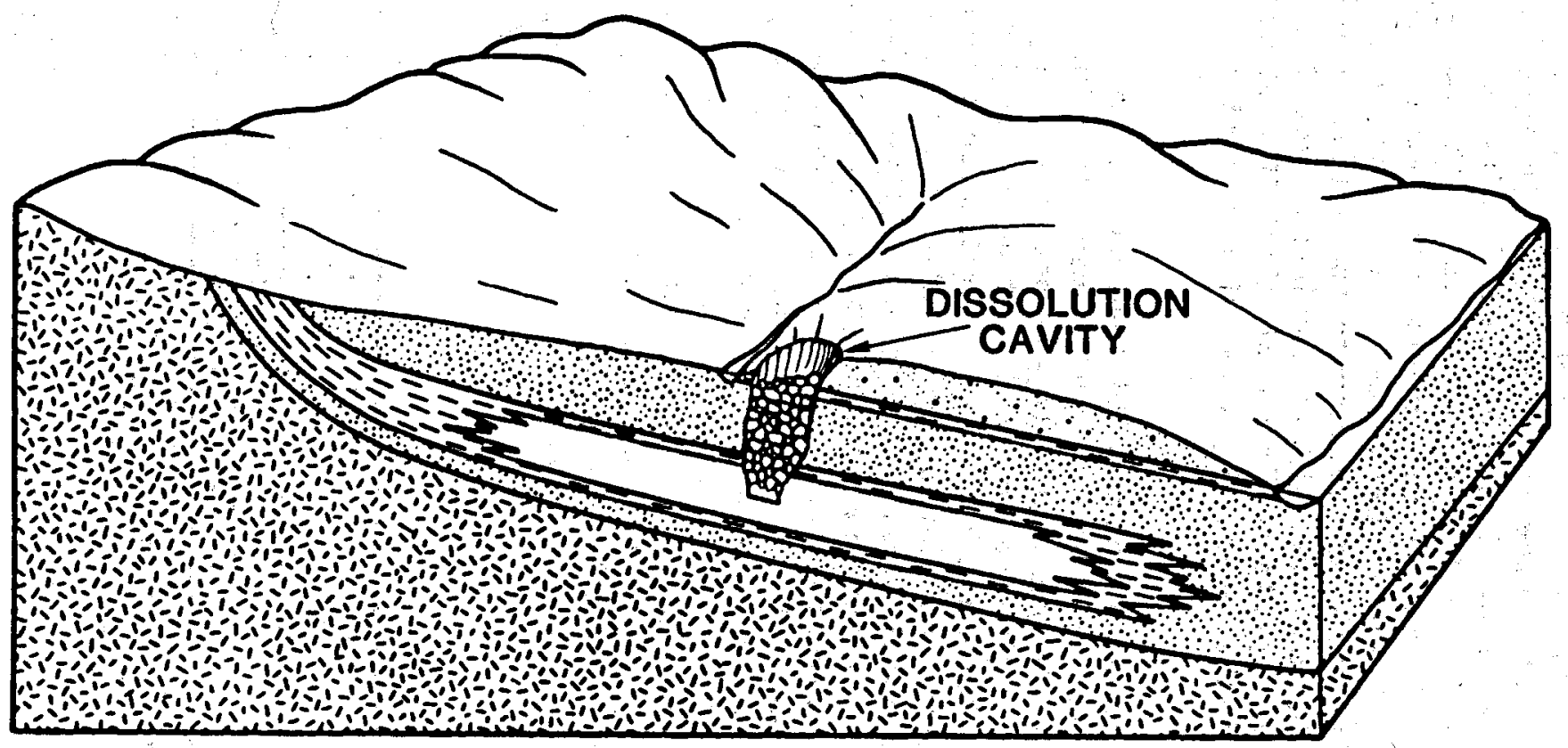

F1gure 16. Release Phenomenon R4 
Fracturing of the overlying shale would provide a communication for water from the middle sandstone aquifer to flow downward into contact with the salt. If the width or separation of the communication in the direction of the gradient is large, interstices at the salt/shale interface could allow for convective flow along this interface forming a dissolution cavity in the salt (Figure 17). ... Subsequent growth of the cavity to the depth of the repository would result in radionuclides being dissolved in circulating ground water. These radionuclides would then be transported in the middle sandstone aquifer where release to the surface could result from water wells placed into the middle sandstone aquifer or from discharge at River $L$. The projected size of this disruptive feature ensures that collapse of the overlying rock will extend to the land surface.

Because of the several mechanisms that could lead to a disruption of the middle shale above the repository and the subsequent dissolution of the overlying salt layers (e.g., thermal effects, impact fracturing, inadvertent intrusions, etc.), this phenomenon should not be eliminated based on probabilistic arguments. Given the existence of hydraulic communications between the middle sandstone aquifer and the salt, rates of growth of dissolution cavities were modeled using the Dynamic Network (DNET) model [Cranwell et al., 1982]. Varying the properties of the hydraulic communications and the middle sandstone aquifer, and considering offsetting effects such as salt creep, it was found that dissolution cavities reached the depth of the repository about 50 percent of the time over a 10-yr period. The consequences of this phenomenon (in terms of discharge rates to the blosphere and health effects) could potentially be large because of the size of the disruptions and the inventory accessed. Therefore, R4 is retained for further analysis.

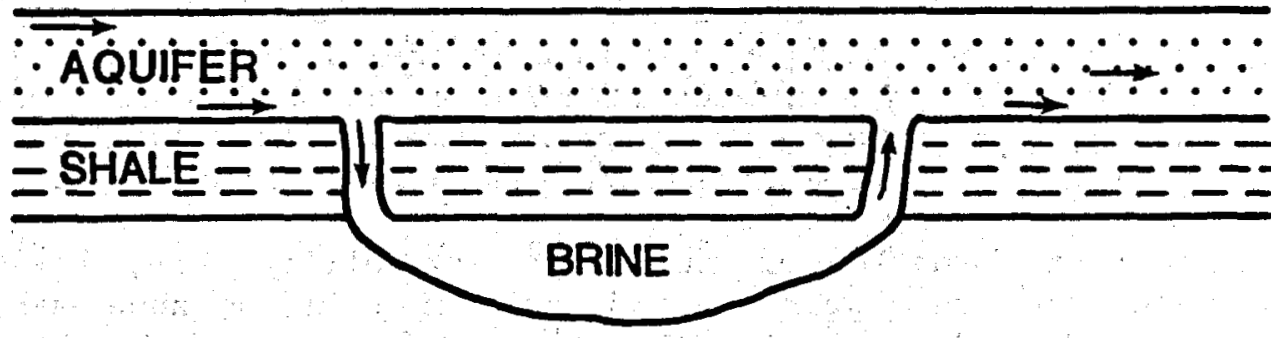

SALT

Figure 17. Dissolution Cavity at Salt/Shale Interface 
Release Phenomenon R5. This phenomenon is similar in nature to R4 with the exception that the disrupted region is below the repository (Figure 18). Such a region would require extensive fracturing of the shale beneath the repository allowing water in the lower sandstone aquifer to flow upward into contact with the salt and then return to the lower aquifer (Figure 19). Long-term dissolution of the salt could result in a dissolution cavity extending into the repository with a subsequent release of radionuclides to circulating ground water.

Release Phenomenon R5 is included here for completeness. However, it is difficult to identify physically reasonable mechanisms that could cause this type of disrupted zone. Drilling or falled seals on shafts would affect the shale both above and below the salt, not just the lower shale. Thermal expansion of the shale is a possibility, but results from thermomechanical calculations indicate that the shale beneath the repository undergoes little thermal stress. Any horizontal thermal expansion meets the resistance of the surrounding rocks and results in compressional stresses such that, even if fractures were to develop, the compressive forces would keep them closed. Expansion downward would be prevented by the greater confining pressure in that direction, whereas expansion upward would be insufficient to cause fracturing of the shale.

Based on the physical reasonableness arguments discussed above, Release Phenomenon R5 is eliminated from any additional consideration.

Release Phenomenon R6. This phenomenon assumes the presence of a relatively narrow planar structure oriented parallel to River $L$ and located directly below the repository (Figure 20). The feature represents a high permeability fault plane terminating at the contact between the lower shale and salt.

A disturbed zone in this location having a high hydraulic conductivity has very little, if any, effect on either the head distribution or velocity field. This can be seen in Figures 21 and 22 , where the vertical and horizontal conductivities for the disturbed zone were arbitrarily set at three orders of magnitude higher for that portion in the shale and one order of magnitude higher for the sandstone. Thus units already having a high conductivity are assumed to be influenced less by this high-conductivity zone than those with a lower conductivity.

At the time of formation of this high-permeability zone, low-salinity ground water from the lower aquifer could rise in the zone and come in contact with the salt. Density differences between the brine at the salt contact and the underlying less-saline water could initiate a convective current, thus resulting in salt dissolution. This process could be enhanced by temperature increases resulting from the emplacement of hot waste in the repository. Furthermore, if this feature is combined with a transport phenomenon that results in an upward hydraulic gradient, salt dissolution could be enhanced. However, analyses of salt dissolution rates have shown that formation of a cavity of any significant size is extremely difficult in this situation. 


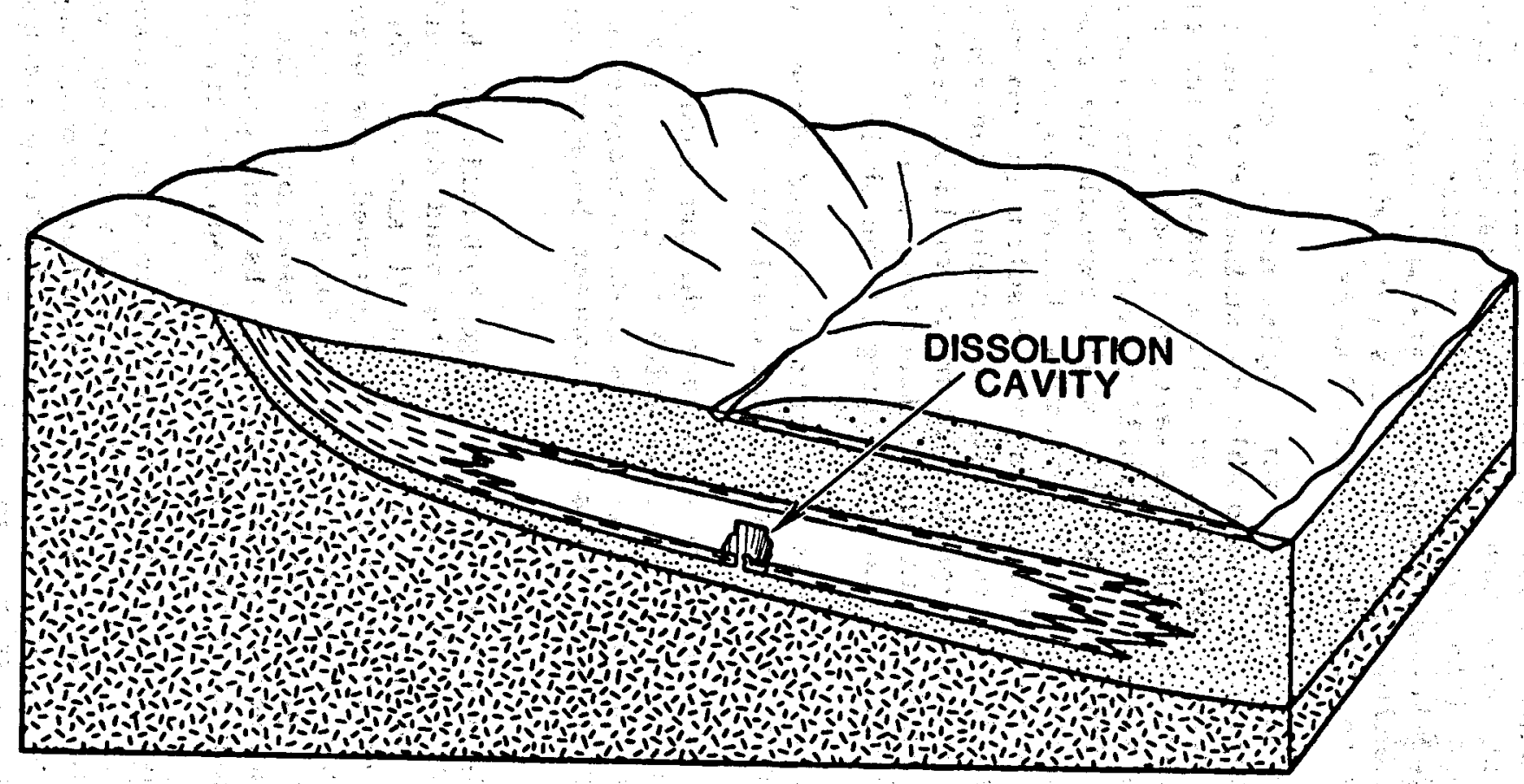

F1gure 18. Release Phenomenon R5 

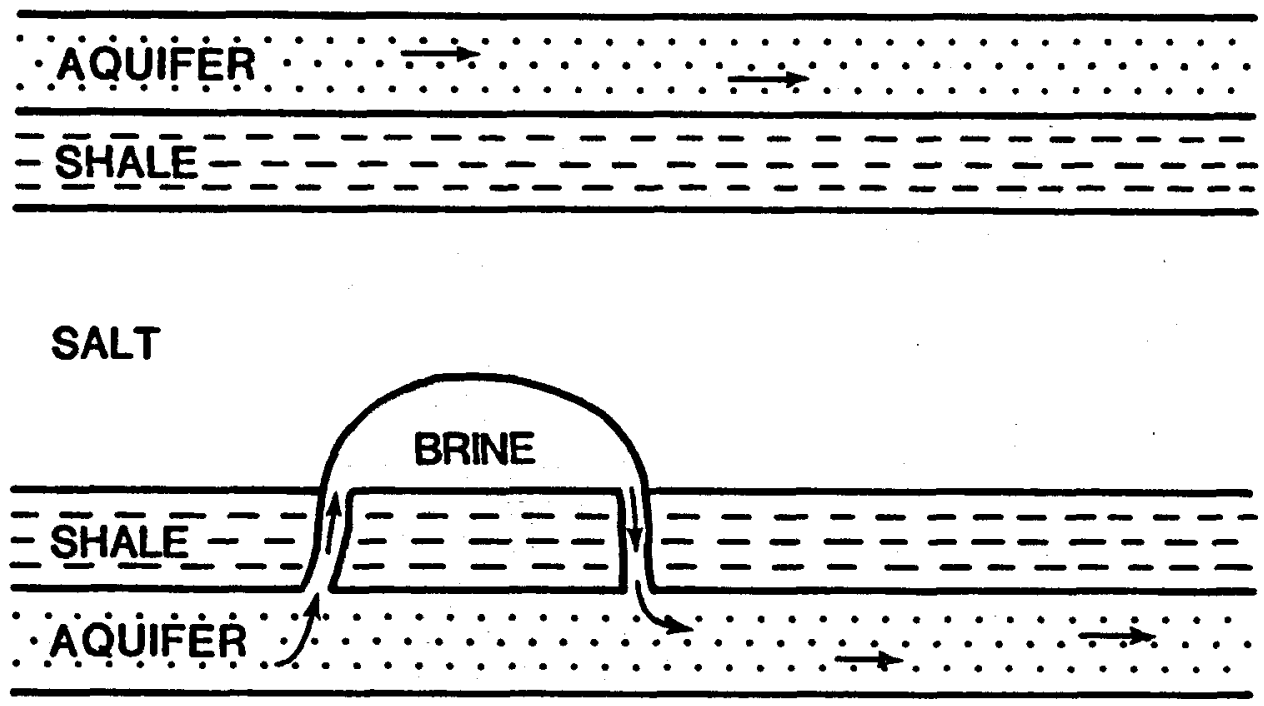

Figure 19. Formation of a Dissolution Cavity Below the Repository

If a fault existed in this position prior to repository excavation, any extensive salt dissolution resulting from it would probably be detected during site-suitability studies. Thus the assumption would be that either the fault was present prior to excavation and extensive salt dissolution had not occurred or the disruptive feature occurred subsequent to repository closure. The probability that an existing undetected fault lies directly below the repository depends on the density of faults in the area (see Appendix D). The probability of a new fault developing directly below an area the size of the repository is extremely small [see Bonilla, 1979]. Furthermore, existing data typically show that bedded-salt deposits generally exist in regions of low seismic activity (e.g., Johnson and Gonzales, [1978]) and, thus, the probabllity of movement of a pre-existing fault would be small [Donath and Cranwell, 1980]. Using data on faulting rates from the Delaware Basin in New Mexico [Claiborne and Gera, 1974] or the Palo Duro Basin in Texas [Stone and Webster, 1981], it can be shown (see Appendix D) that the probability of a fault developing directly below the repository is on the order of $10^{-11} / \mathrm{yr}$. This falls below the $10^{-8} / \mathrm{yr}$ cutoff imposed on this demonstration.

Based on the probabilistic and physical reasonableness arguments above, R6 will not be retained for further analysis. 


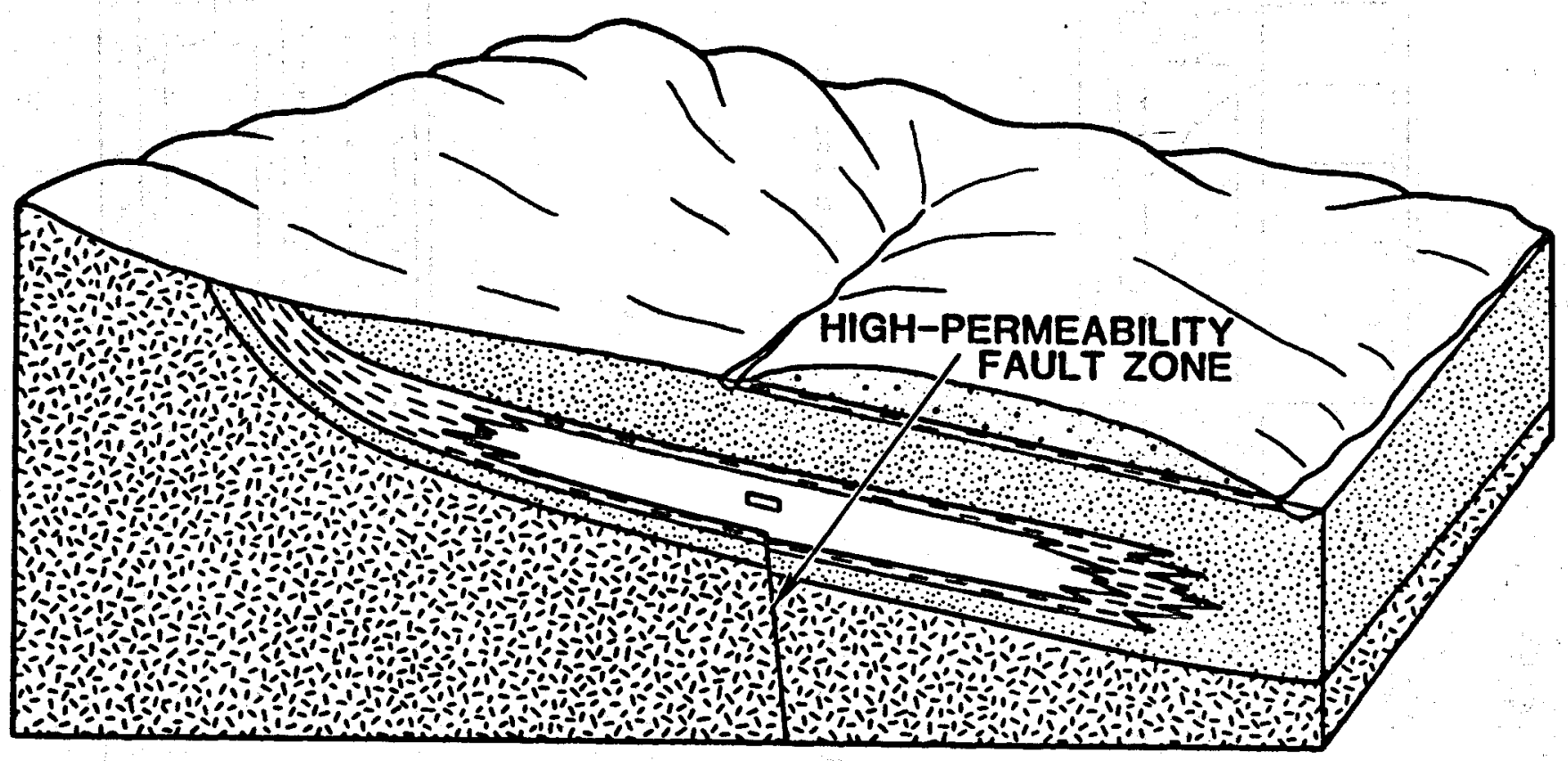

Figure 20. Release Phenomenon R6 


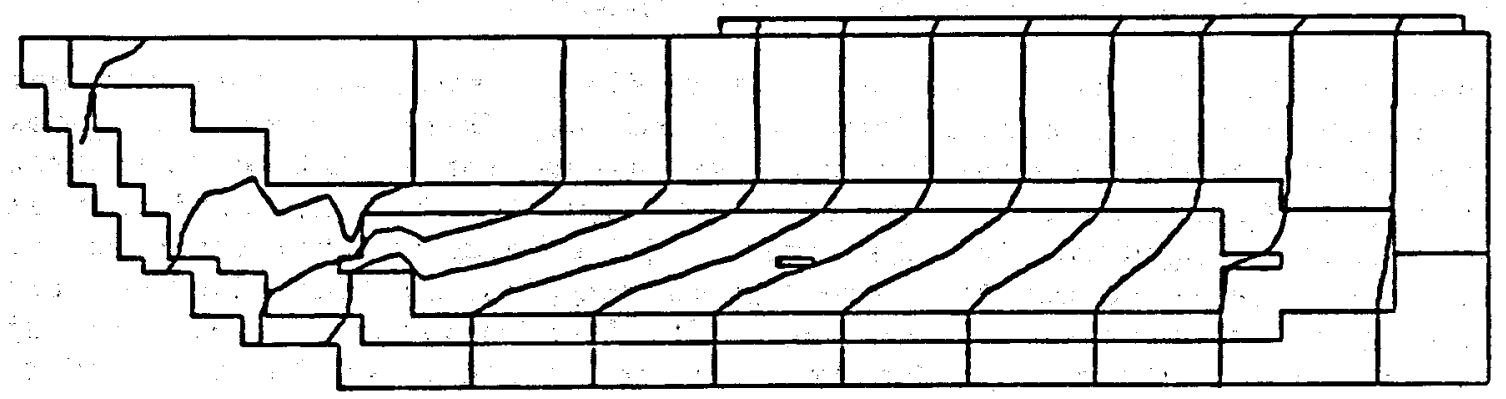

Figure 21. Hydraulic Head Distribution for R6

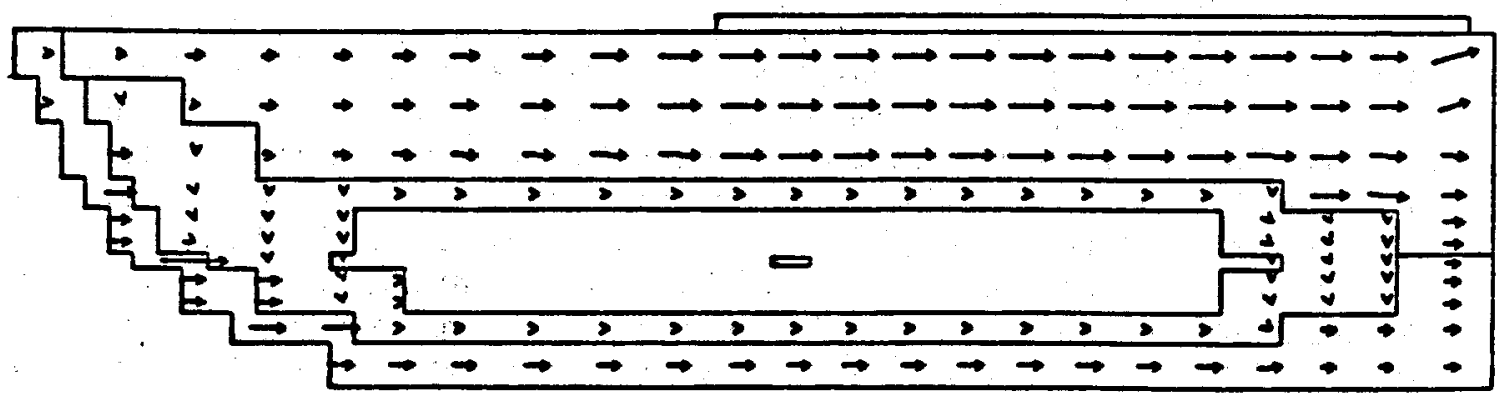

Figure 22. Fluid Velocity Vectors for R6 
Release Phenomenon R7. Th1s phenomenon assumes the presence of a planar structure similar in orientation and location to that of R6 with the exception that the region disturbed by the structure has low permeabil1ty. Here, the structure represents a fault or Igneous dike terminating at the contact between the lower shale and salt.

The effects of this feature on the flow system are somewhat more apparent, as can be seen In Figures 23 and 24. These figures were generated by arbitrarily decreasing the vertical and horizontal conductivities of the disturbed zone by two orders of magnitude for the sandstone and one order of magnitude for the shale. The effects of this structure are to form a low-conductivity "dam," thus reducing the flow in the lower sandstone and increasing the tendency for fluid movement up into the salt and over the obstruction. However, the low vertical conductivity of the shale would eliminate any extensive salt dissolution above the obstruction. On the other hand, if vertical, high-conductivity fractures should develop adjacent to this obstruction, the flow of water from the lower sandstone aquifer could be enhanced, resulting in a continuous convective current of brine and low-salinity water from the lower sandstone. If this process should continue, the eventual outcome could be similar to that discussed in R5, the formation of a dissolution cavity below the repository.

The probability of $R 7$ is simflar to that of $R 6$. However, if the lowconductivity zone is formed by the intrusion of magma into a fault zone, the probablilty of R7 would be even smaller [Schneider and Plath, 1974]. Therefore $R 7$ is eliminated based on probabilistic arguments.

Release Phenomenon R8. Release Phenomenon R8 assumes the presence of a narrow planar structure that is orlented parallel to River $L$ and that passes through the repository (Figure 25). As was the case with R6, the structure represents a high-permeablitty fault zone. Geologically, the presence of this high-permeability zone in the salt unit probably would be rare. It is generally accepted that faulting of thick salt formations does not lead to the formation of permeable zones; on the contrary, the plastic deformation of salt is known to heal any fracture or opening in the salt (e.g., Thurston, [1961]). In fact, most of the known faults in salt formations confirm the self-healing behavior of halite. Fault breccias, which are common in brittle rocks, are unknown in salt formations. However, it might be argued that permeable fracture zones could be found in salt but would eventually be obliterated by salt dissolution or recrystallization. Therefore, the lack of documented examples would not prove the impossibility of the event. Jones [1974] has cited a possible example of faulting resulting in salt dissolution in eastcentral New Mexico. 


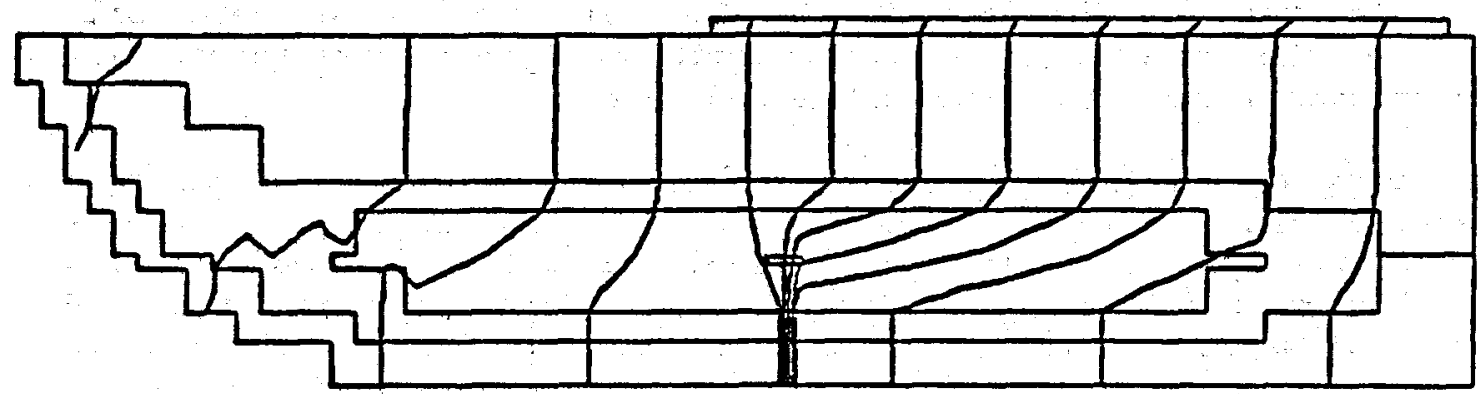

Figure 23. Hydraulic Head Distribution for R7

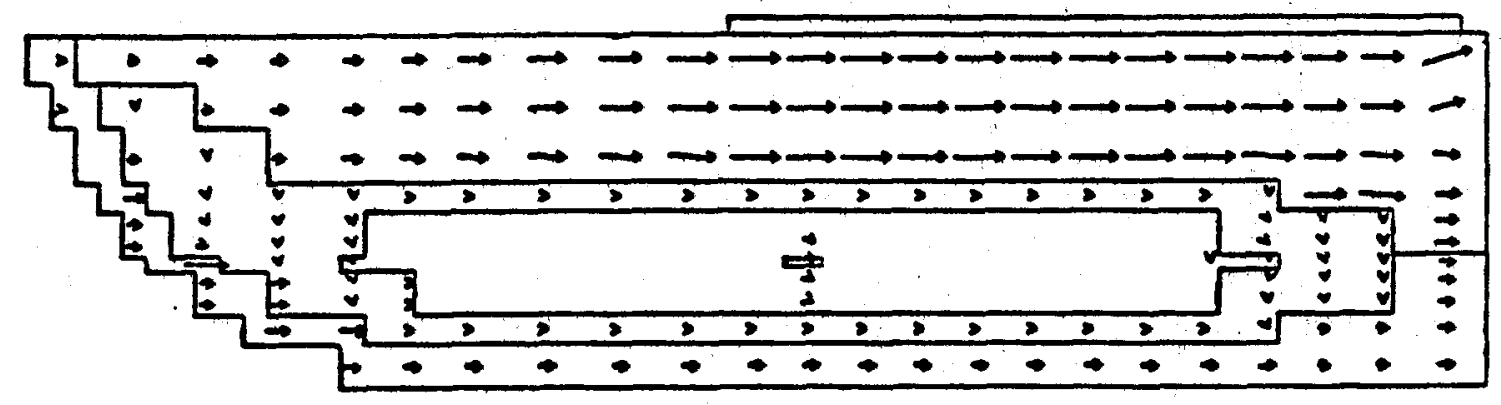

Figure 24. Fluid Velocity Vectors for R7 


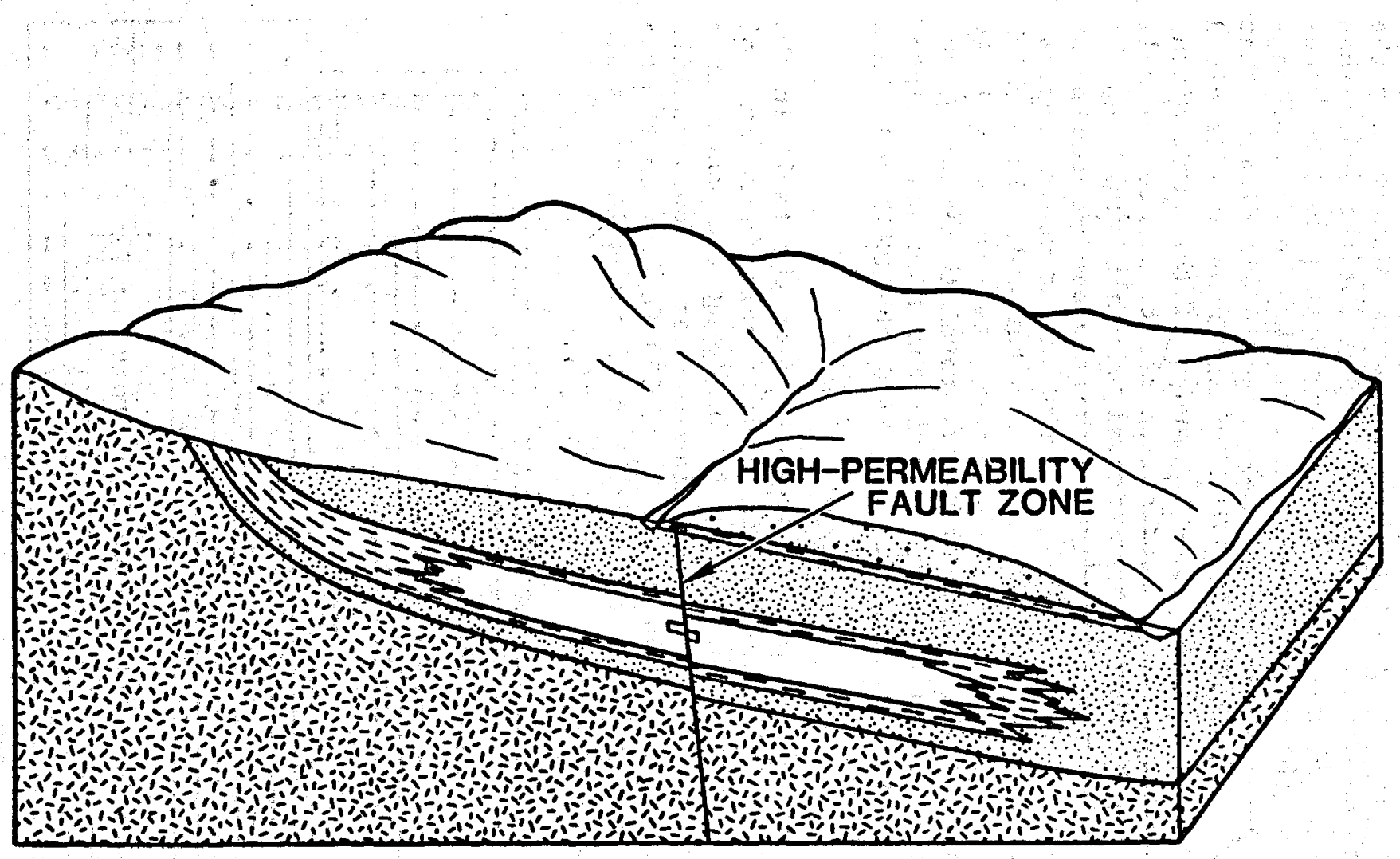

Figure 25. Release Phenomenon R8 
The effects of this high-permeability zone on the ground-water flow patterns of the reference site are shown in Figure 26. Here, as in R6, the vertical and horizontal conductivities of the region disturbed by the structure were set at three orders of magnitude higher for the shale than in the undisturbed system and one order of magnitude higher for the sandstone. Conductivities of the salt also were set at three orders of magnitude higher than in the undisturbed system. Figure 26 indicates that this high-permeability zone provides a path for migration of dissolved radionuclides to the lower sandstone. The permanency of the water circulation through the repository would depend on the relative rates of salt dissolution and fracture healing. The removal of salt would not be uniform along the fault. Salt removal would be highest at the point where the unsaturated water enters the salt formation and would progressively decrease as the circulating brine becomes saturated. In a thick evaporite sequence such as that in the reference site, it is unlikely that salt dissolution would extend throughout the total thickness of the salt. Thus, plastic flow would eventually close the fracture and stop circulation of water. In fact, calculations with the DNET code have indicated that this would occur.

If no permeable zone were formed along that portion of the fault in the salt formation, offsetting along the fault could result in release of radionuclides to circulating ground water by bringing the waste into contact with either an overlying or underlying aquifer. However, this would require vertical displacement of at least $550 \mathrm{ft}$ between the two sides of the fault, because this is the thickness of the salt and shale units above and below the repository.

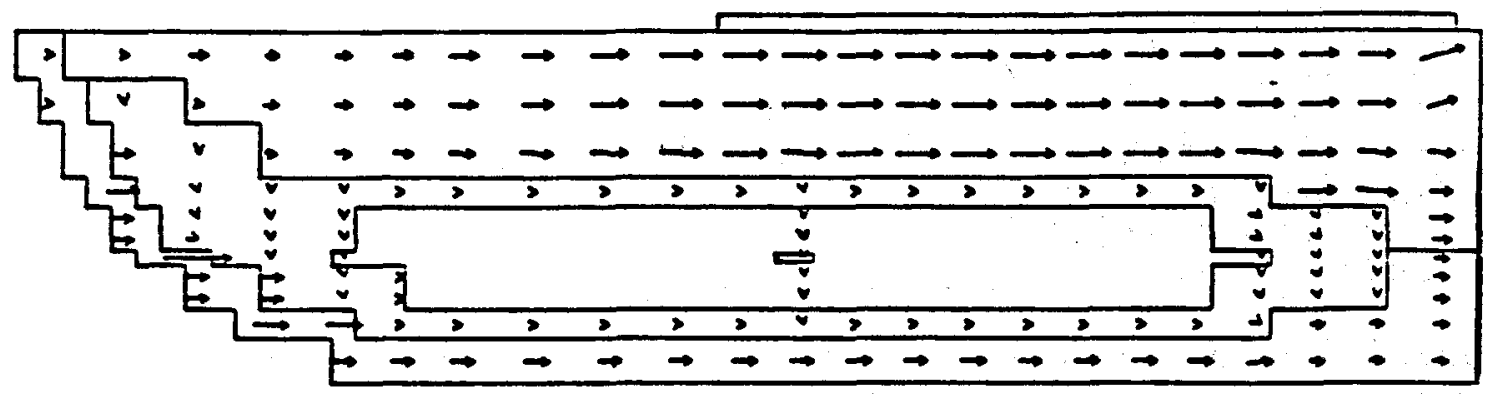

Figure 26. Fluid Velocity Vectors for R8 
Movement along fault planes can occur suddenly or in a more or less continuous creep. The greatest displacement known to have taken place in a single event was an offset of almost $50 \mathrm{ft}$ during the Alaskan earthquake of 1899. The slow, continuous rates of vertical movement along a fault plane can be fairly extensive, but this usually occurs over very long periods of time. For example, the only faults in the Texas Panhandle known to have affected the Upper Permian salt beds have been reported by Johnson [1976]. These faults are located along the Amari11o Uplift and offset the salt by as much as $600 \mathrm{ft}$. Tectonic activity that formed the Amarillo Uplift began in late Mississipplan and early Pennsylvanian time [Stone and Webster, 1981]. Earthquake activity in historic time along this uplift indicates that a least some of the faults in this region continue to be active [Stone and Webster, 1981].

Assuming that movement along the faults began at the end of the Permian (225 milition years ago), Permian beds being the youngest units offset, and continued to the present, and that the maximum offset of the salt beds is $600 \mathrm{ft}$, the rate of movement along these faults is $2.6 \times 10^{-6}$ $\mathrm{ft} / \mathrm{yr}$. This would result in only about $0.3 \mathrm{ft}$ of offset in $105 / \mathrm{yr}$.

A fault intersecting the repository horizon and present at the time of excavation would obviously be detected. Thus, the only other alternative would be that development of the fault occurred subsequent to repository closure. This could be the result of either the formation of a new fault (1.e., the occurrence of faulting where no fault existed previously) or renewed movement on a pre-existing fault below the repository. As was mentioned previously, the probability of a new fault developing is, in itself, very small ( $\left(<10^{-8 / y r}\right)$, let alone that it also intersects the repository. Thus, the more likely occurrence would be renewed growth on a pre-existing fault below the repository. The probability of a preexisting fault lying directly below the repository is on the order of $10^{-3}$ to $10^{-2}$ depending on the density of faults (Appendix D). The possibility of renewed movement on such a fault would make the probability of this phenomenon even smaller. Thus, R8 is eliminated from additional consideration based on the probability arguments discussed above.

Release Phenomenon $R 9$. R9 is nearly Identical to $R 8$, the exception being that the disturbed zone is assumed to have a low permeability. Here, the structure represents a fault plane or an Igneous dike passing through the repository.

The effects of this low-permeability zone on the hydraulic head potential are shown in Figure 27. These equipotential lines were generated by decreasing the vertical and horizontal conductivities of the disturbed zone by three orders of magnitude for the sandstone.

Conductivities of the salt also were set at one order of magnitude lower than in the undisturbed system. Updip from the repository, ground water now moves generally upward through the salt and shale into the middle sandstone aquifer. However, downdip from the repository the flow is still downward across the salt and shale units. These flow patterns 


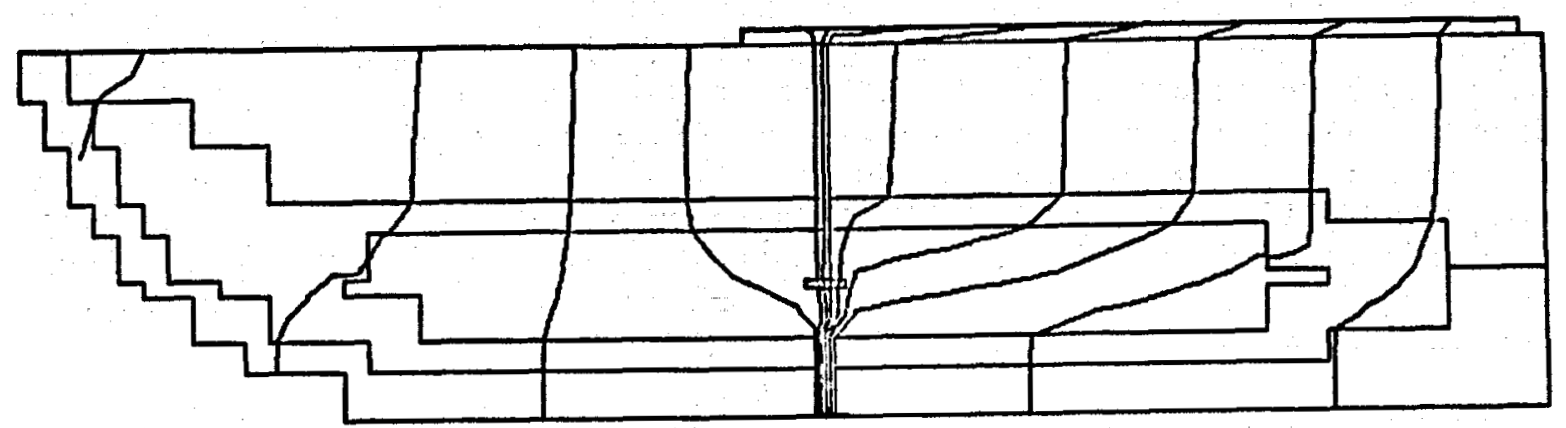

Figure 27. Hydraulic Head Distribution for R9

suggest the possibility of a significant variability in the confining capabilities of the salt. For example, depending on the deformational history of the area, high-permeability fractures may develop parallel to a low-permeability fault plane or dike. As a result, vertical flow along the fault or dike could be enhanced by the presence of these fractures.

Such upward, vertical movement can be observed in Figure 28, where a high-permeability zone was assumed to exist updip and adjacent to the low-permeability zone. Conductivities for this high-permeability zone were increased three orders of magnitude for the salt and shale units and one order of magnitude for the sandstone units. For a fault or dike passing through the repository, the increased vertical flow could intensify the dissolution of released radionuclides in circulating ground water and result in transport of this aqueous solution along the lowpermeability zone. If the fault plane or dike should extend to the land surface, dissolved radionuclides could be discharged directly to the biosphere.

A fault or dike that would cause a disruption of the flow system to the extent shown in Figure 27 would obviously be detected during sitesuitability analyses, provided it existed prior to repository excavation. Thus, one would assume that development occurred subsequent to repository closure. As was discussed in R8, the probability of this alternative is small $\left(\ll<10^{-8} / \mathrm{yr}\right)$ and would be even smaller if such a feature resulted from intrusion of magma into a fault zone. Therefore, $R g$ is eliminated form further consideration based on probabilistic arguments. 


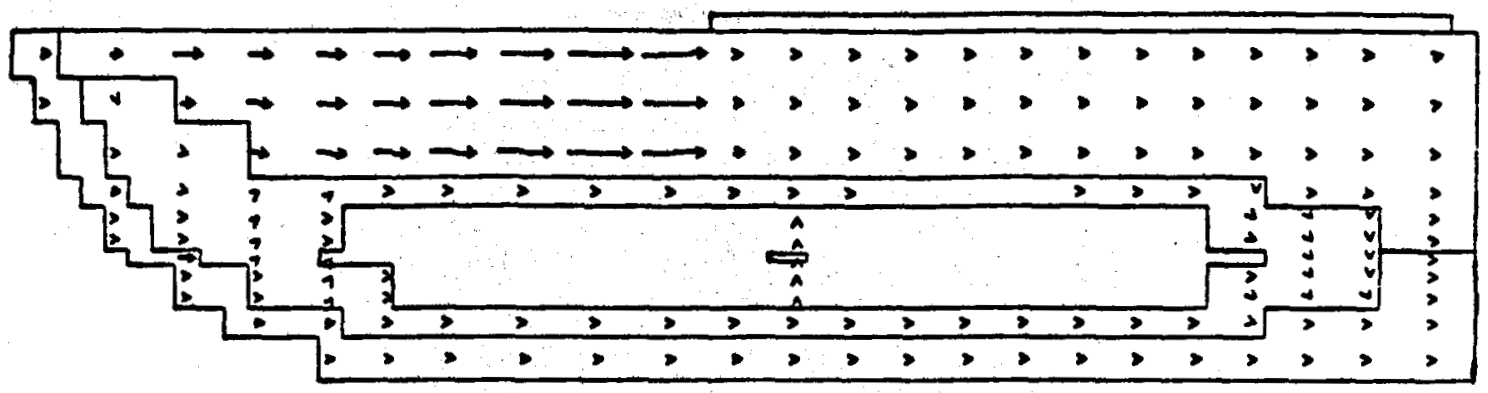

Figure 28. Fluid Velocity Vectors for R9

\section{Transport Phenomena}

Transport Phenomenon T1. T1 represents the existence of a field of withdrawal wells completed into the middle sandstone aquifer and located downdip from the repository (Figure 29). These wells represent sources of water for either an Individual or a municipal water supply and for irrigation. Such wells could be contaminated by dissolved radionuclides discharged into the middle sandstone aquifer through several release phenomena (see, e.g., R3). For purposes of analysis, the fractional discharge of released radionuclides via the wells is taken to be the same as the fractional withdrawal of water from the aquifer over the entire well field. To determine concentrations, the radionuclide discharge is distributed to those wells within the width of the contaminant plume.

For release phenomena in which the migration path from the repository to the overlying or underlying aquifer has a small cross-sectional area (e.g., a single shaft or drill hole), the width of the contaminant plume at distance $X$ downdip in the aquifer is taken as

$$
w_{p}-2.5 \sigma_{y}
$$

where

$$
\begin{aligned}
& \sigma_{y}=\sqrt{2 \alpha_{T} X}, \text { and } \\
& \alpha_{T}=\text { transverse dispersivity. }
\end{aligned}
$$




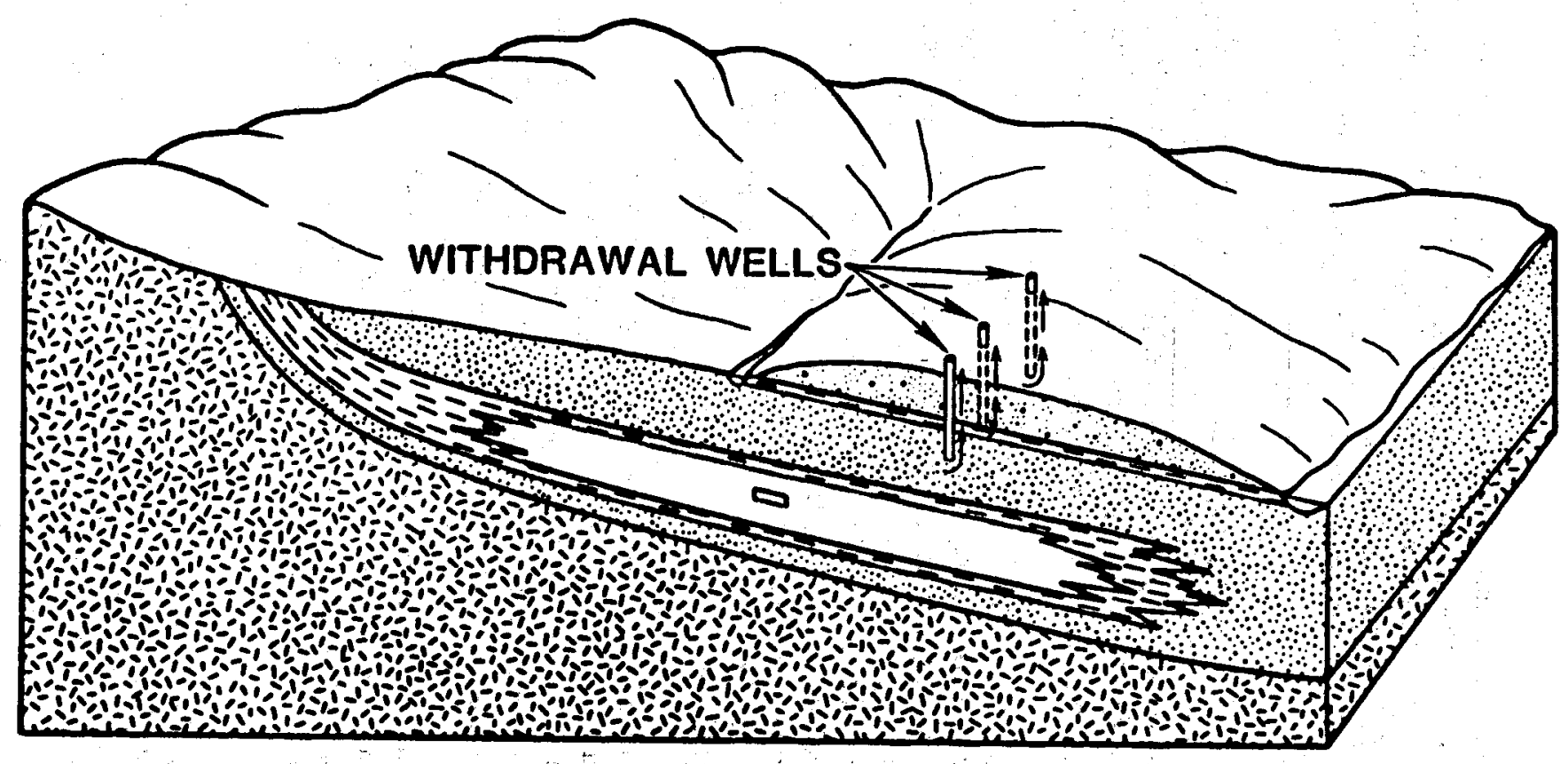

Figure 29. Transport Phenomenon T1 
Ignoring longitudinal dispersion, this plume width will preserve the peak or centerline concentration as the peak concentration is proportional to $1 /\left(\sqrt{2 \pi \sigma_{x}}\right)$.

For release phenomena such as faulting or other major disruptions that extend the full width of the repository, the plume width is taken as the width of the repository. For reasonable values of the transverse dispersivity and downdip distance up to about $10,000 \mathrm{ft}$, it can be readily demonstrated that the repository width is a good approximation for the plume width.

The probabllity of wells being emplaced into the middle aquifer at some time in the future after repository closure is larger than $10^{-8} / \mathrm{yr}$ (see Section 3.8). Furthermore, these wells would provide a shortened path to the surface environment for radionuclides released into the middle sandstone aquifer. Thus, T1 will be retained for further analysis.

Iransport Phenomenon $T 2$. T2 is nearly identical to $T 1$, the exception being that the wells are completed into the lower sandstone aquifer (Figure 30 ). These wells could be contaminated by radionuclides released into the lower aquifer (see, e.g., R2). There are several reasons, based on our hypothetical reference site, why this phenomenon could be eliminated from further analysis. First, because there is some downward movement of ground water through the salt, water in the lower sandstone aquifer is likely to be saline. Second, because wells to the lower aquifer would be drilled through the salt, there is the likelihood of further increasing the salinity. Finally, the lower sandstone is about 2000 ft below the land surface, whereas an abundant water supply (the middle sandstone aquifer) is avallable much nearer the land surface. Nevertheless, there are reasons for retaining T2. For example, the mere fact that the lower sandstone is $2000 \mathrm{ft}$ below the ground surface cannot be taken to preclude 1 ts use as an aquifer sometime in the future.

Furthermore, in our analysis of withdrawal wells, salinity of the aquifers was not considered to be high enough to eliminate possible use of the water. Thus, the possibility of the presence of withdrawal wells into the lower aquifer necessitates the inclusion of $T 2$ for further analysis.

Transport Phenomena $\mathrm{T} 3$ and $\mathrm{T4}$. These transport phenomena are Identical to $T 1$ and $T 2$, respectively, with the exception that the wells are located updip from the repository (Figures 31 and 32 ). The effects on the flow system of withdrawal wells located updip from the repository would be significant only if the amount of water withdrawn were sufficient to alter the hydraulic gradients in the flow system significantly, and then only if these altered gradients were maintained for very long periods of time. Furthermore, assuming wells are just as likely to be drilled downdip from the repository as updip, consequences from $T 3$ and $T 4$ would clearly be dominated by wells located downdip from the repository, i.e., $\mathrm{T} 1$ and T2. Finally, the effects of wells updip from the repository could possibly be beneficial as they could somewhat reduce fluid velocities near the repository. 


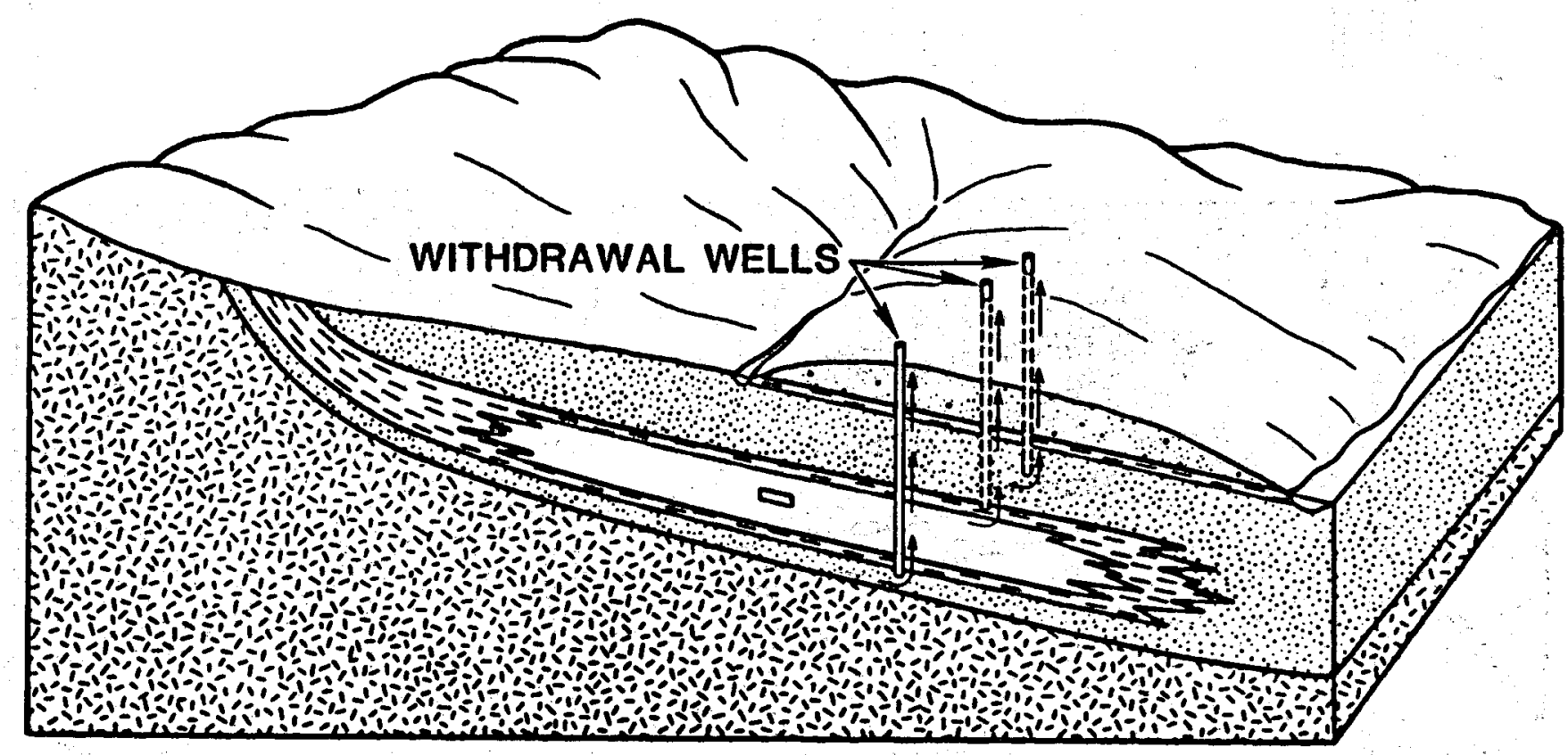

Figure 30. Transport Phenomenon T2 


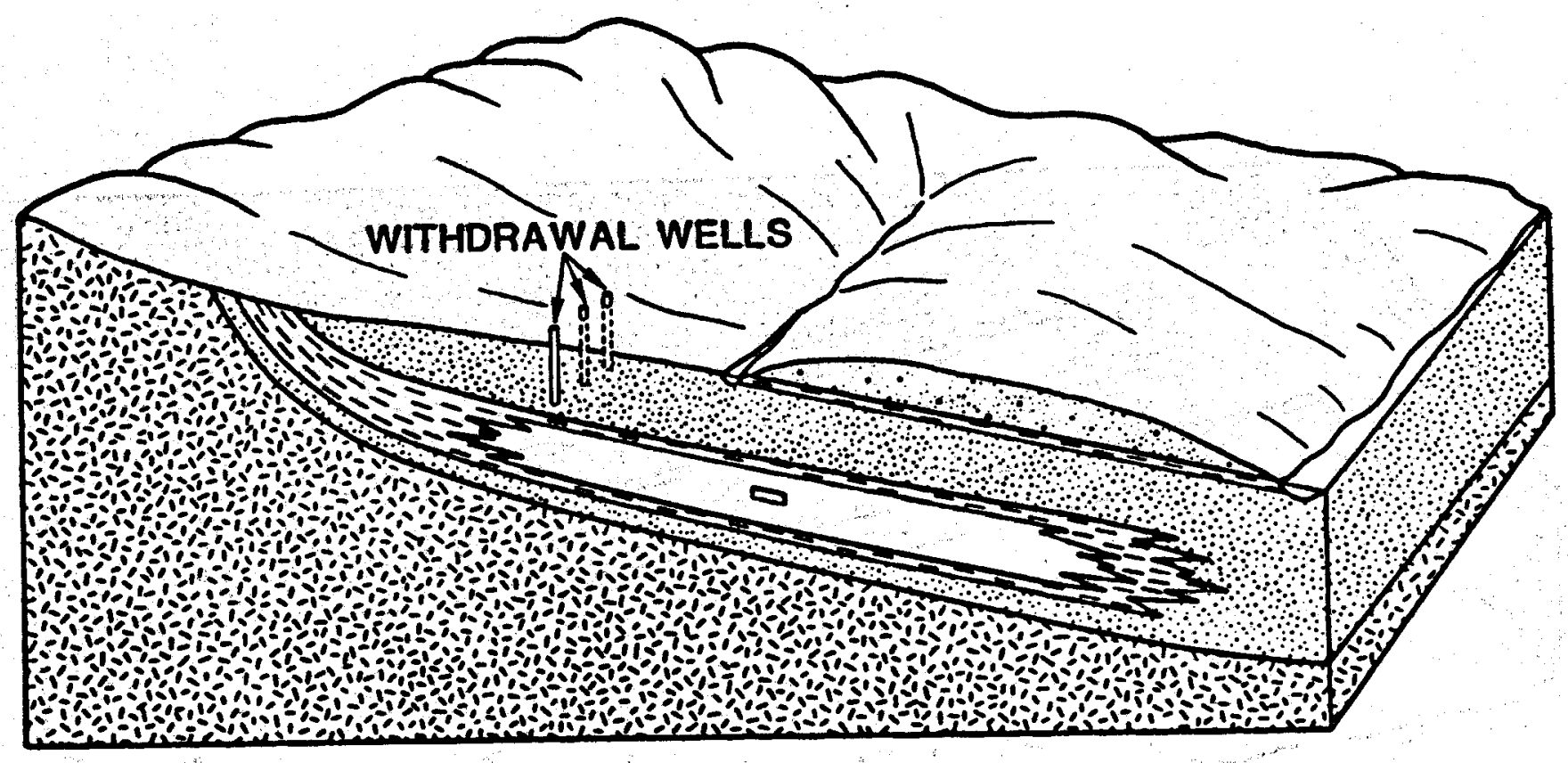

Figure 31. Transport Phenomenon T3 


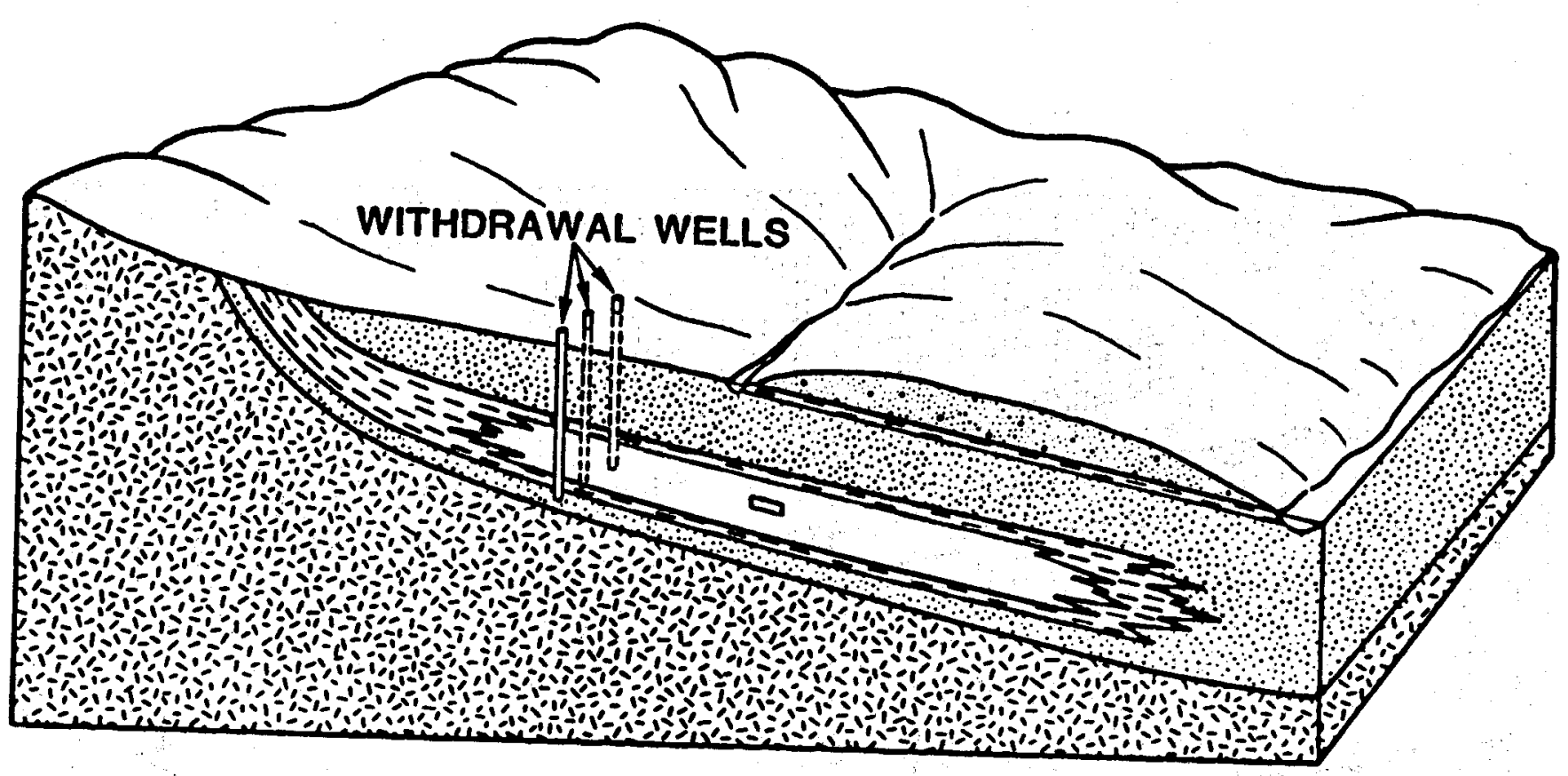

Figure 32. Transport Phenomenon T4 
Based on the arguments presented above, T3 and T4 will be eliminated from any further analysis.

Transport Phenomenon T5. T5 represents a field of injection wells completed into the lower sandstone aquifer downstream from the repository.

Injection wells for disposal of chemical waste or other purposes are likely only into the lower sandstone. The effects could alter the transport of released radionuclides if the amount of the material injected and the periods of injection were sufficient to alter the hydraulic gradients in the flow system for long perlods of time. In addition, the infected fluids could alter the aquifer geochemistry and thus affect radionuclide sorption. Figure 33 shows the hydraulic head distribution plots, where an injection well, Injecting fluid at the rate of $1000 \mathrm{ft}^{3} /$ day, has been completed into the lower sandstone aquifer. This figure shows no significant change in the hydraulic head distribution from the base case. Furthermore, the effects on radionuclide retardation are accounted for in scenarios involving transport through the lower aquifer by varying the retardation factors over wide ranges. Thus, T5 is eliminated from further analysis based on low consequence.

Transport Phenomenon T6. T6 is Identical to T5 with the exception that the injection wells are updip from the repository. T6 is eliminated on the same basis as $\mathrm{T} 5$.

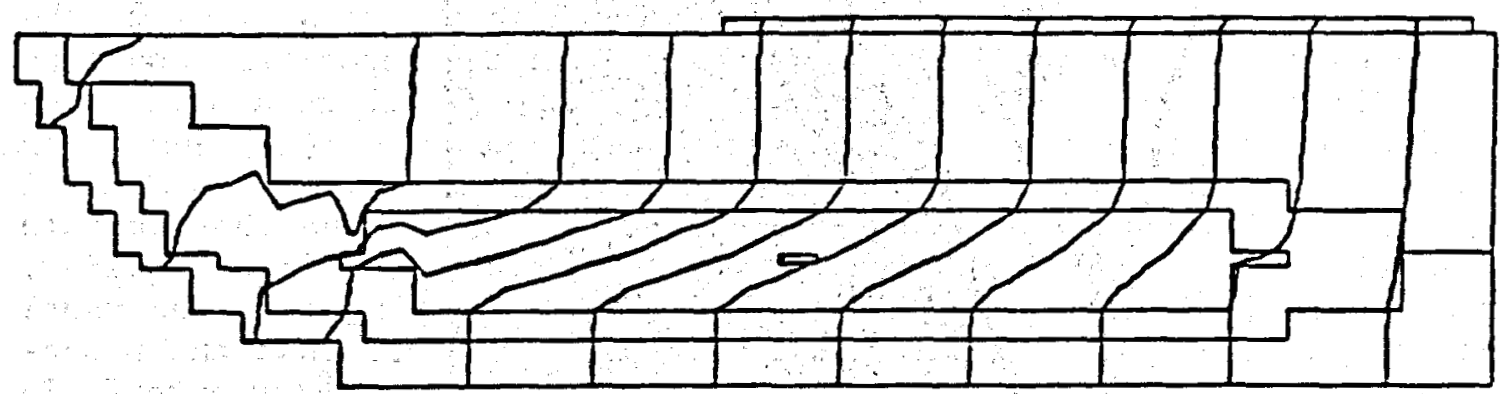

Figure 33. Hydraulic Head Distribution for TS 
Transport Phenomenon I7. T7 assumes the existence of a narrow, highpermeability planar structure oriented parallel to River $L$ and located downdip form the repository and extending through the lower sandstone and shale (Figure 34). The feature represents a fault plane terminating at the contact between the lower shale and salt. T7 is identical to R6 with the exception of location. The feature in $R 6$ is located directly below the repository whereas the feature here is located downdip from the repository. A distinction is made between the two because a fault plane directly below the repository would have a greater influence on release of radioactive material from the repository than on its transport in an aquifer once released to that aquifer, whereas a fault located downdip would have a greater influence on transport of radionuclides in the aquifer.

As was the case the R6, a high-permeability zone in this location could result in some long-range effects on the reference site, such as the formation of a dissolution cavity in the bedded salt above the zone. However, the size of this cavity would not be significant enough to alter the transport of radionuclides released to the lower aquifer. Thus, T7 can be eliminated based on consequence arguments.

Transport Phenomenon T8. T8 is simflar to $T 7$, except that the disturbed zone is one of low permeability. Thus, T8 is similar to R7 with the difference being location. The effects of this low-permeability zone on the flow system are similar to the effects produced by $R 7$, namely, to reduce the flow in the lower sandstone and to develop flow around and over the obstruction (Figures 35 and 36). Furthermore, the hydraulic gradient on the updip side of the disruption is now upward across the salt and shale.

Arguments used to eliminate $R 7$ also could be used to eliminate T8. However, should this feature be combined with a high-permeability zone passing through the repository and connecting both aquifers, flow in the lower sandstone would be diverted upward through the repository and into the middle sandstone. This can be seen in Figure 37, where a drill hole through the repository and into the lower sandstone (R2) has been combined with the low-permeability feature of $T 8$. The placement of withdrawal wells into the middle sandstone aquifer and the shorter path for discharge at River $L$ (1000 ft less than through the lower aquifer) could result in larger consequences than those resulting from the usual discharge to the lower aquifer. Thus, despite the fact that the probability of this scenario is likely to be less than the $10^{-8} / \mathrm{yr}$ cutoff, T8 is retained for further analysis. 


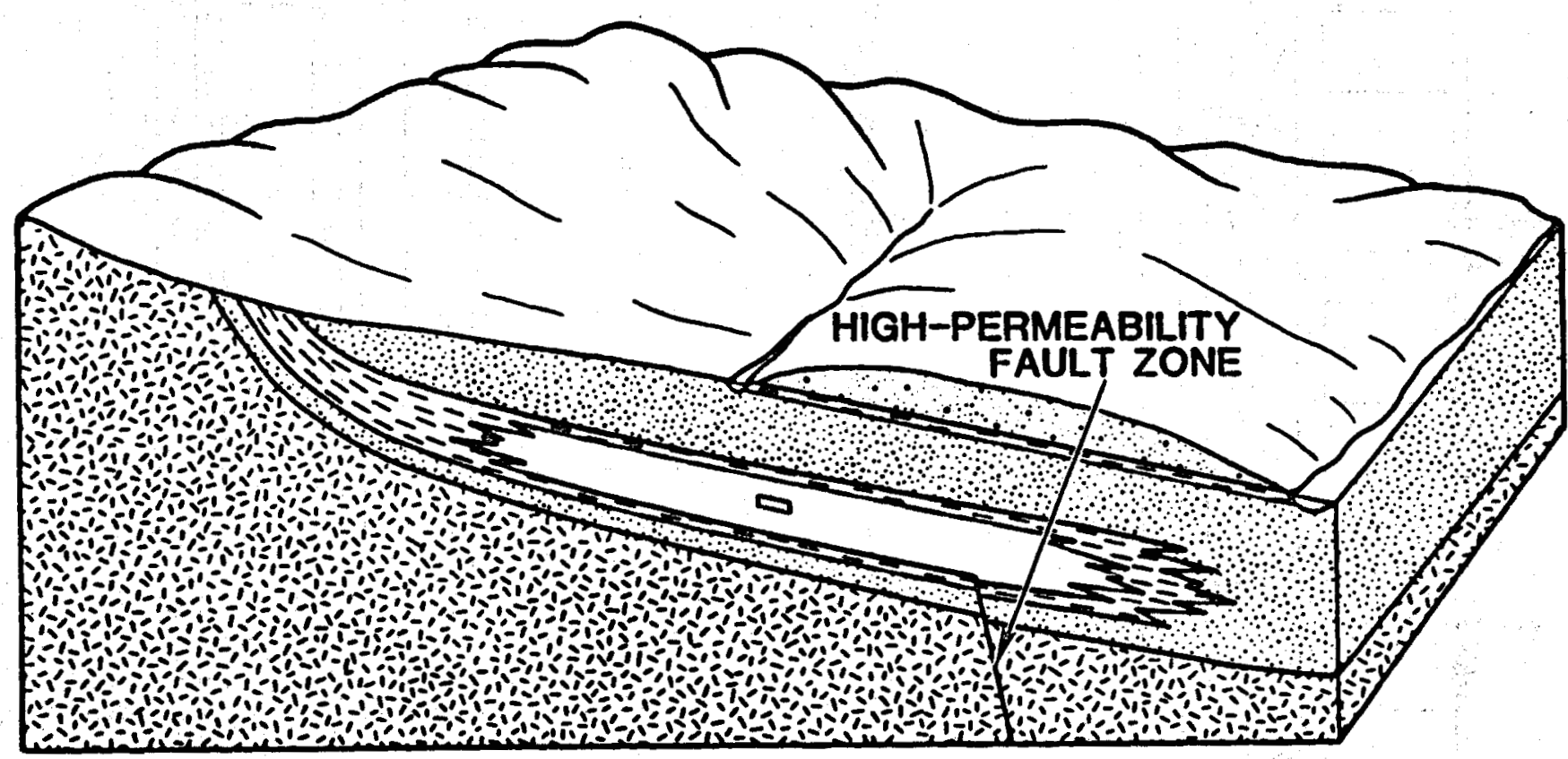

Figure 34. Transport Phenomenon T7 


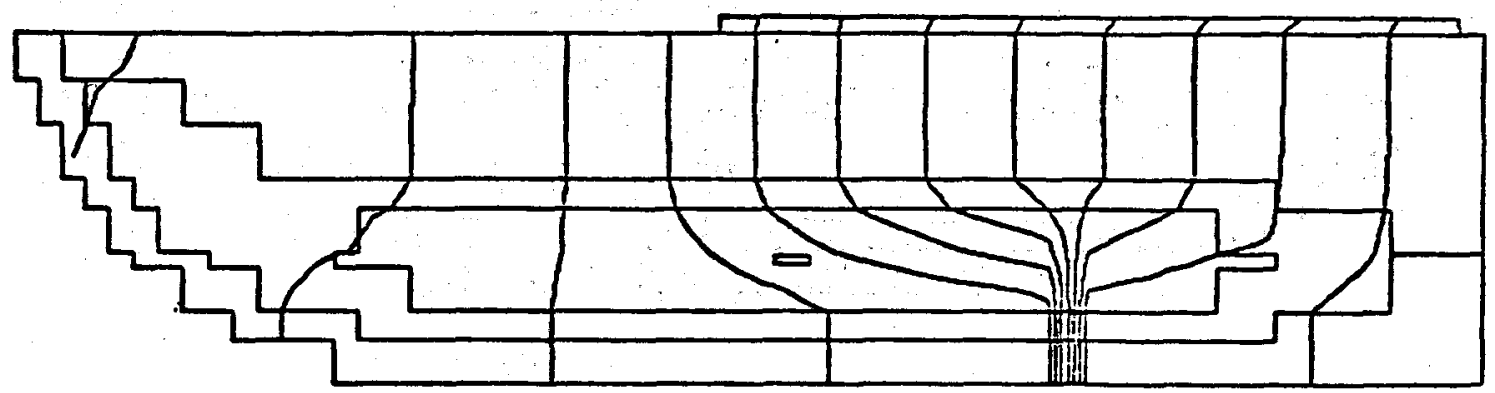

Figure 35. Hydraulic Head Distribution for $T 8$

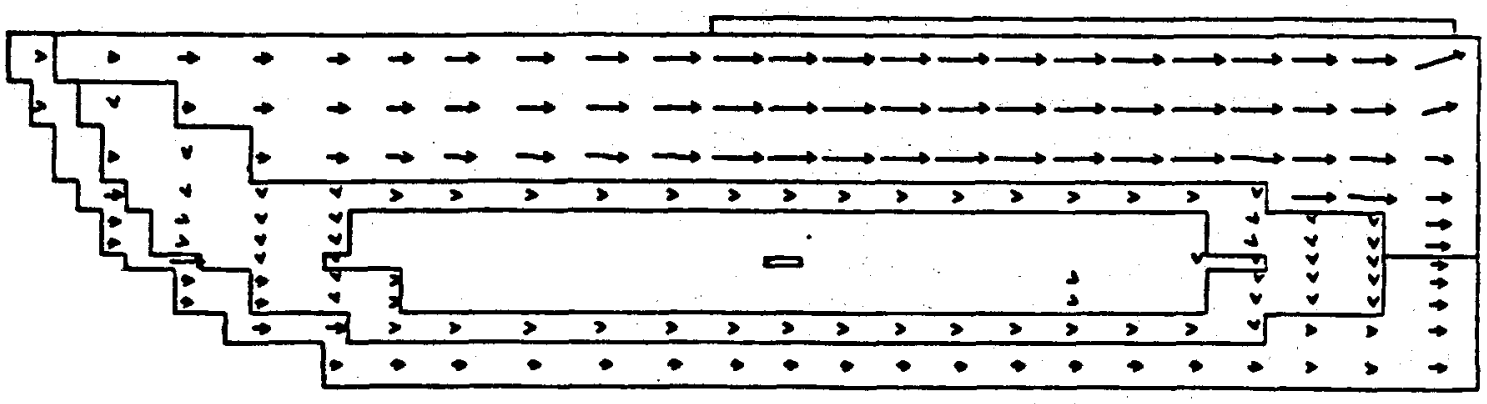

Figure 36. Fluid Velocity Vectors for T8 


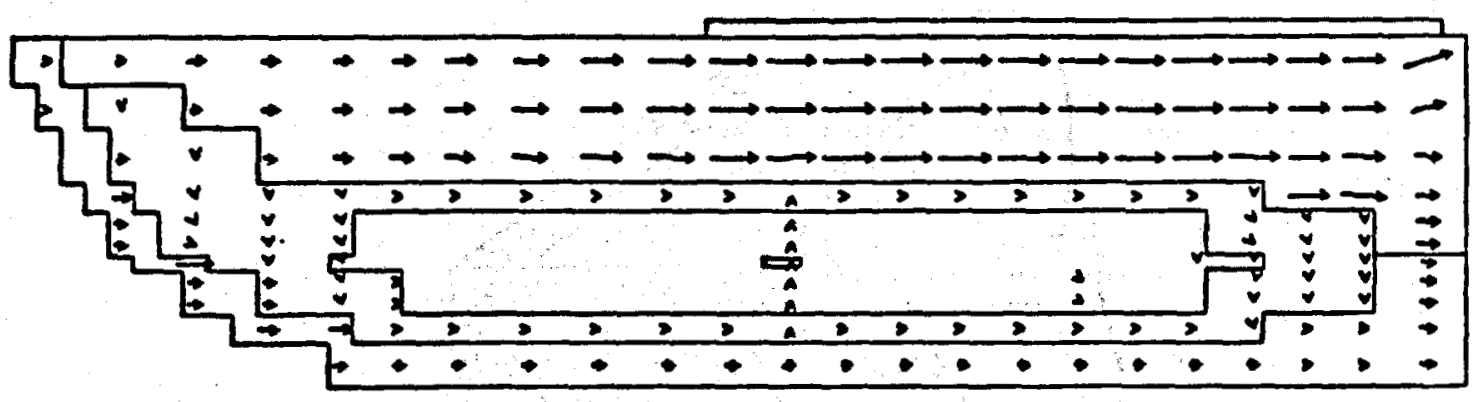

Figure 37. Fluid Velocity Vectors for R2, T8 Combination

Transport Phenomenon T9. T9 represents the presence of a highpermeability fault plane located downdip from the repository and passing through both the lower and middle sandstone aquifers (Figure 38). T9 is similar to R8 with the exception of location. Thus, the effects on the flow system of such a feature would be essentially the same. Large-scale salt dissolution along such a high-permeabllity zone prior to repository construction would probably be detected by site characterization studies, thus eliminating the site from consideration. Furthermore, the probability of postclosure faulting on this scale is small and can be minimized by selecting a site with low seismic activity.

In addition to large-scale salt dissolution, a high-permeability zone in this position could act as a condult between aquifers, and therefore spread any released radionuclides from one aquifer to another, depending on the direction of the hydraulic gradient. For releases to the middle sandstone, dissolved radionuclides could be transported to the lower sandstone through this high-permeability zone, resulting in a longer path length for discharge at RIver $L$. Thus, In this case, the presence of this zone could actually be beneficial. If release occurred to the lower sandstone, movement to the middle sandstone through this highpermeability zone could occur if a blockage or cementation occurred in one or both of the aquifers downdip from the high-permeability zone. However, the probability of $k$ scenario involving the combination of a release of radionuclides to the lower sandstone, a high-permeability zone downdip connecting both aquifers, and a low-permeability blockage downdip from the high-permeability zone is extremely small $\left(\ll<10^{-8} / \mathrm{yr}\right)$. Thus, T9 is eliminated based on probability and arguments. 


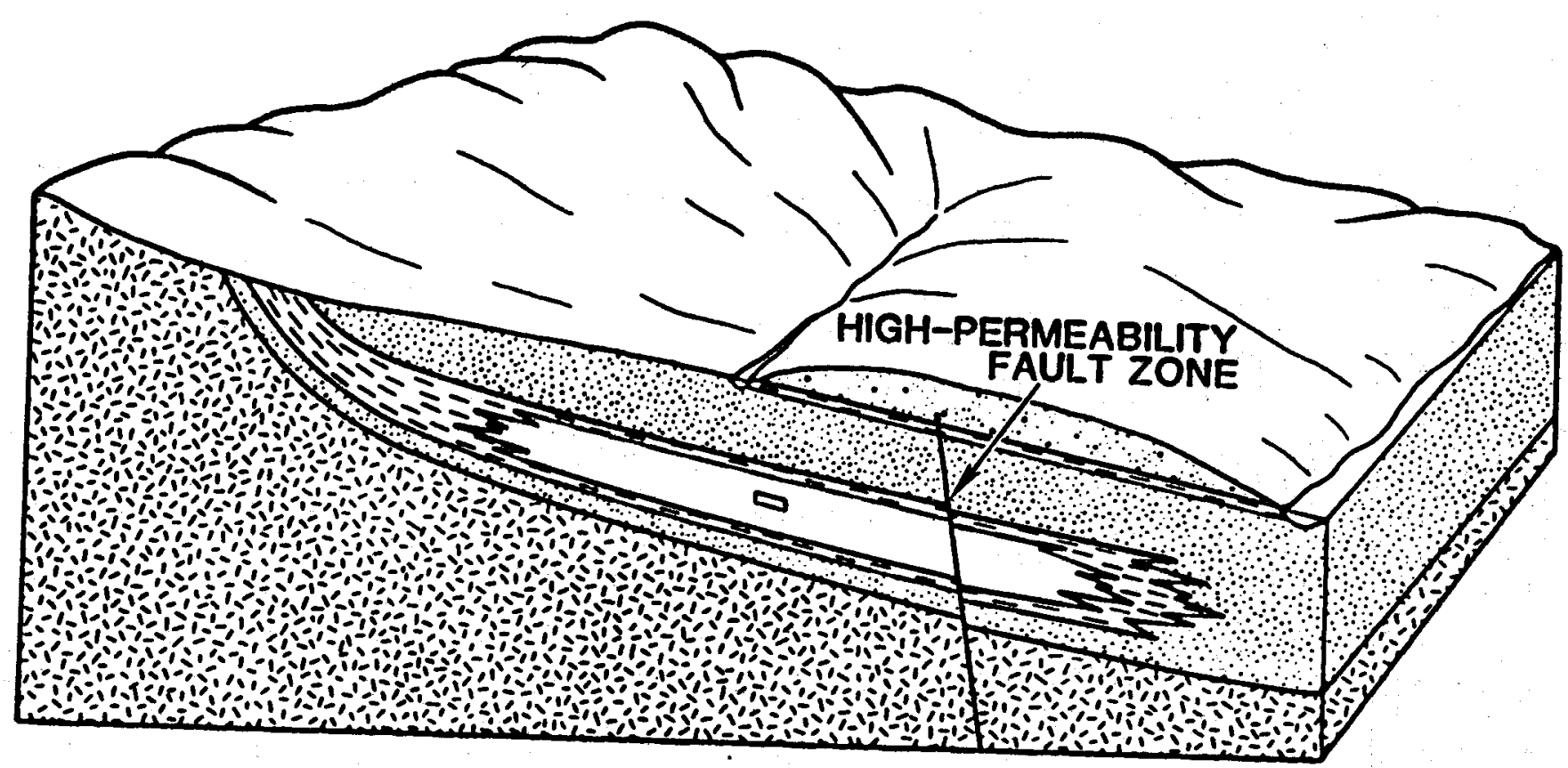

Figure 38. Transport Phenomenon T9 
Transport Phenomenon T10. T10 is similar to T9 with the exception of the hydraulic properties of the disturbed zone. Here, the zone is one having a low permeability and represents a fault plane or igneous dike located downdip from the repository. The effects on the flow system are similar to those for R9. As this feature would create an upward hydraulic gradient across the repository (Figure 39), the primary concern would be the combination of T10 with a high-permeability zone passing through the repository (e.g., R2). In this case, upward vertical flow could occur through the high-permeability zone with dissolved radionuclides being discharged either to the middle sandstone aquifer or directly to the land surface. This upward movement can be observed in Figure 40 , where a drill hole form the surface to the lower sandstone and passing through the repository has been combined with the low-permeability zone of T10.

The probability of a new fault occurring in the reference site downdip from the repository is on the order of $10^{-10} / y r$. If this lowpermeability zone is formed by the intrusion of magma into a fault zone, the probability of such a feature would be even smaller. Nevertheless, with the potential for direct release to the land surface when T10 is combined with $\mathrm{R} 2$, $\mathrm{T} 10$ is retained for further analysis.

Transport Phenomenon T11. T11 assumes the existence of high-permeability planar structure in the lower sandstone and shale oriented parallel to River I and located updip from the repository (Figure 41). The feature represents a fault plane terminating at the contact between the lower shale and salt. It is similar to $T 7$ and $R 6$ with the exception of location.

As was the case with $R 6$ and $T 7$, the effects of this high-permeability zone on the flow system are felt to be negligible. Thus, Iike R6 and T7, T11 is eliminated based on consequence arguments.

Transport Phenomenon T12. T12 is similar to T11, the difference being that the disturbed zone is one of low permeability. Here, the feature represents a fault plane or an igneous dike terminating at the contact between the lower shale and salt.

The effects of this feature on the flow system are similar to those of R7 and T8. However, because the feature is located in the updip portion of the flow system, the increase in the tendency for downward flow downdip from the zone is more apparent than it was in R7 and T8 (Figure 42). This could have the effect of increasing the rate of migration of radionuclides from the repository to the lower sandstone. However, this effect would be offset by the decrease in fluid velocities in the lower sandstone that is caused by this low-permeability zone. Therefore, T12 is eliminated based on consequence arguments. 


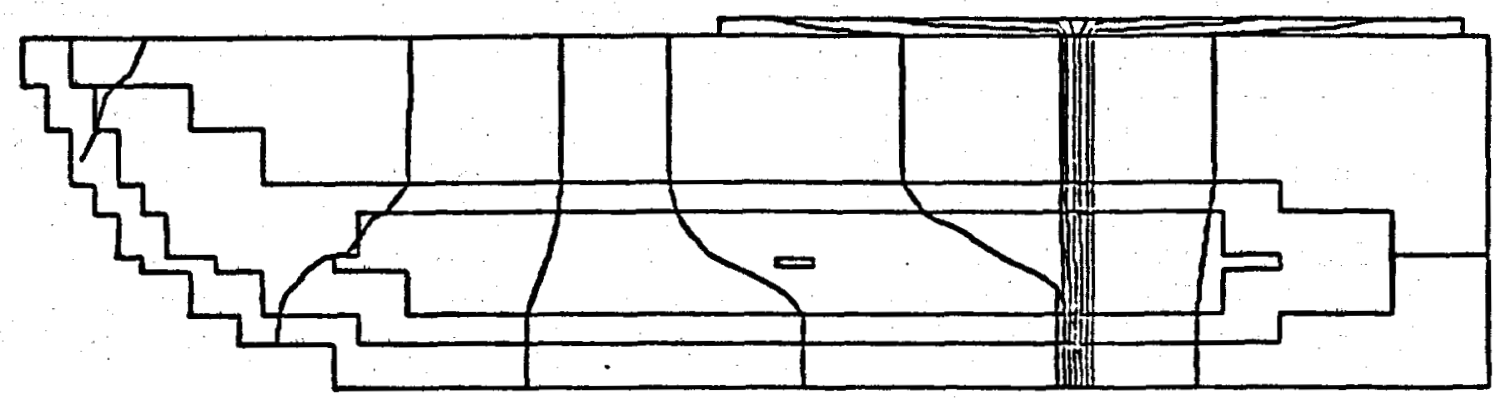

Figure 39. Hydraulic Head Distribution for T10

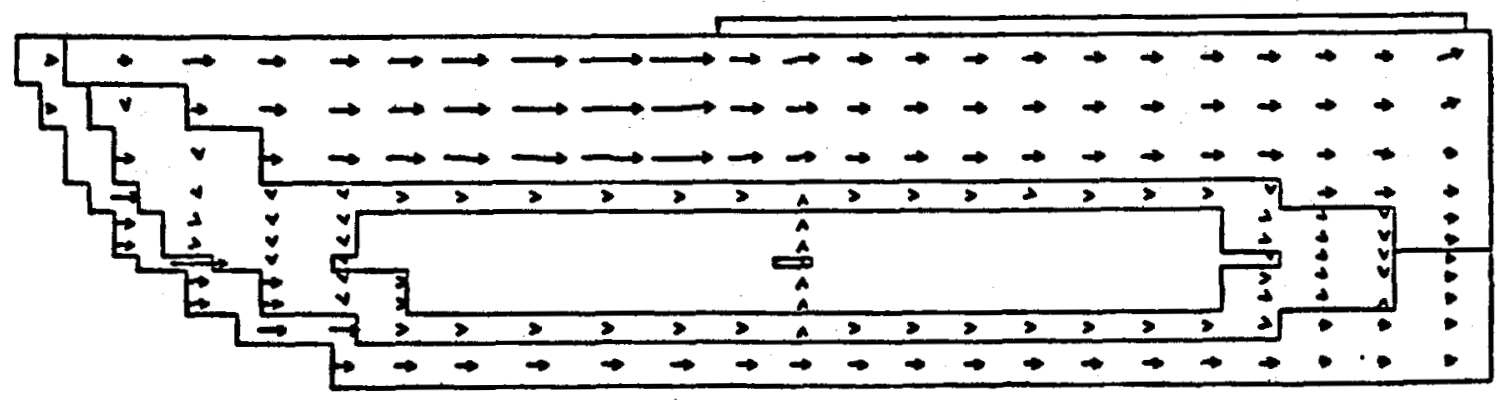

Figure 40. Fluid Velocity Vectors for R2, T10 Combination 


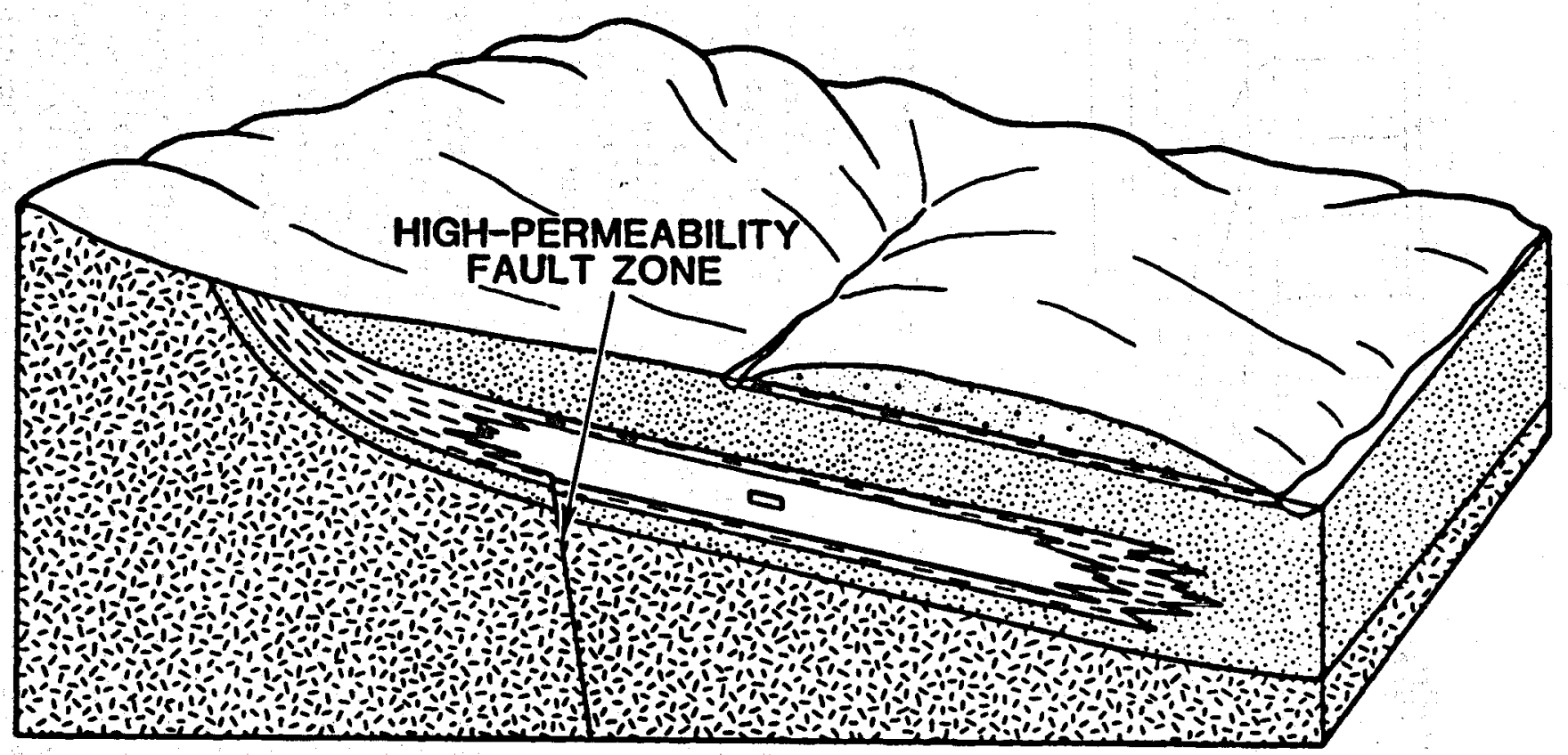

Figure 41. Transport Phenomenon T11 


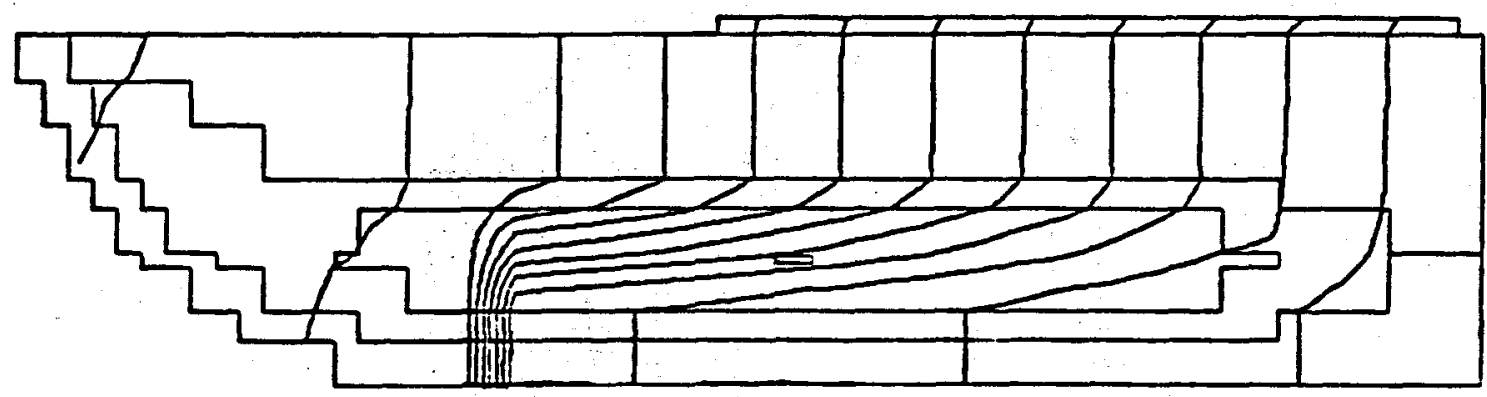

Figure 42. Hydraulic Head Distribution for T12

Transport Phenomenon T13. T13 represents the existence of a highpermeability fault plane on the updip site of the repository, oriented parallel to River $L$, and extending to the land surface (Figure 43). Because it extends to the land surface, it would probably be detected during site-characterization studies. The probability of such a feature occurring at some later date is less than the $10^{-8} / \mathrm{yr}$ cutoff imposed on this demonstration (approximately 10-10/yr). Thus, T13 is eliminated based on probabilistic arguments:

Transport Phenomenon T14. T14 is similar to T13, the difference being that the disturbed zone is now one of low permeability: This feature represents a fault plane or igneous dike extending to the land surface. Because it extends to the land surface, and because of its effects on the flow system (see Figure 44), it would probably be detected during sitecharacterization studies. Thus, the assumption would be that development occurred subsequent to repository closure.

The effects of this low-permeability zone on the flow system are similar to those of $R 9$ and T10. However, because of its location, the increase in the downward flow downdip from this feature is more apparent than it was in R9 and T10 (Figure 44). As was discussed in T12, this could have the effect of increasing the rate of migration of radionuclides from the repository to the lower sandstone. On the other hand, this effect would be offset by the decrease in fluid velocities in the lower sandstone that is caused by this low-permeability zone. Furthermore, the probability of this feature occurring, let alone subsequent to repository closure, is less than the $10^{-8} / \mathrm{yr}$ cutoff. Thus, $\mathrm{T} 14$ is eliminated from further consideration based on probabilistic arguments. 


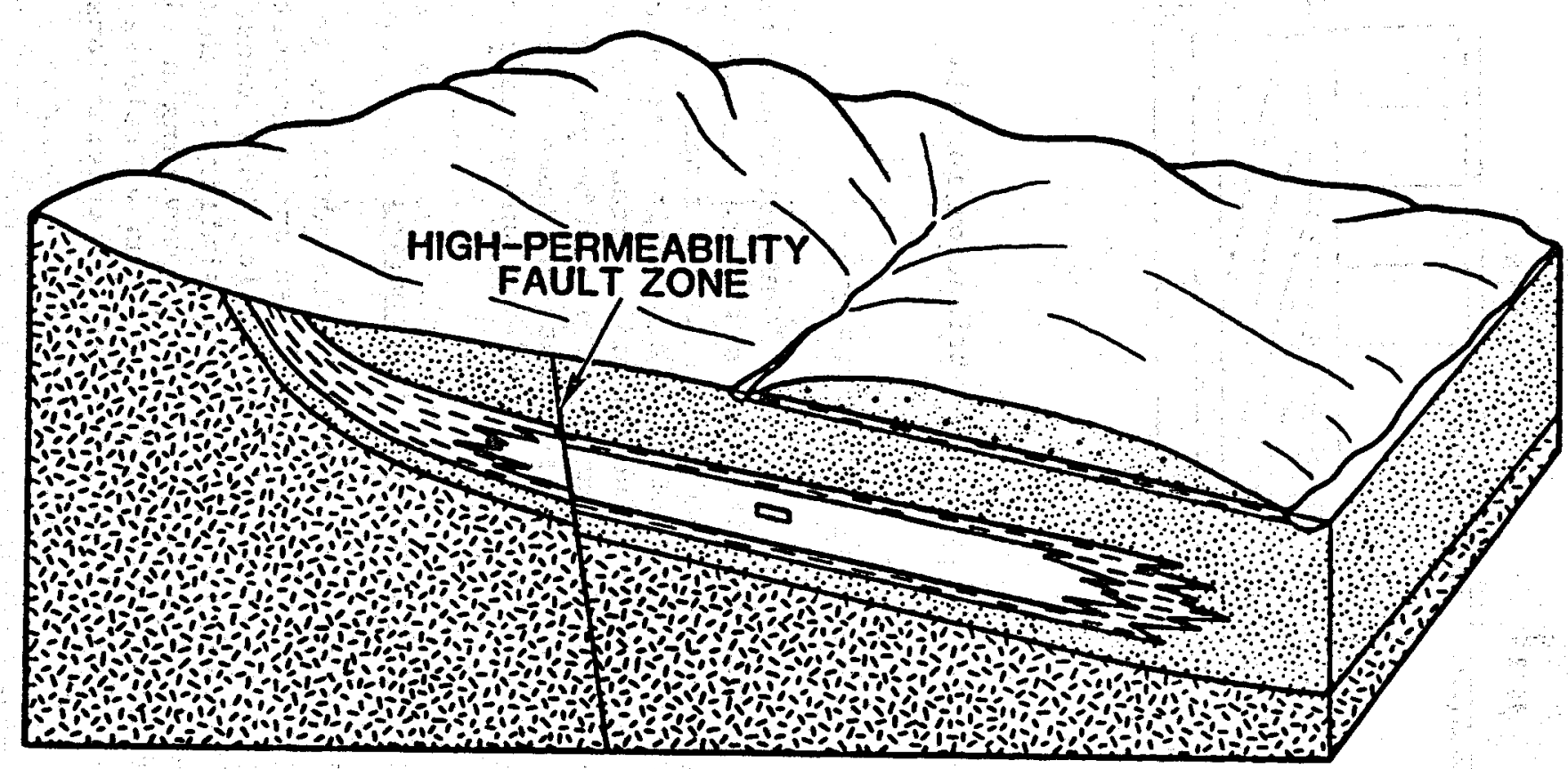

Figure 43. Transport Phenomenon T13 


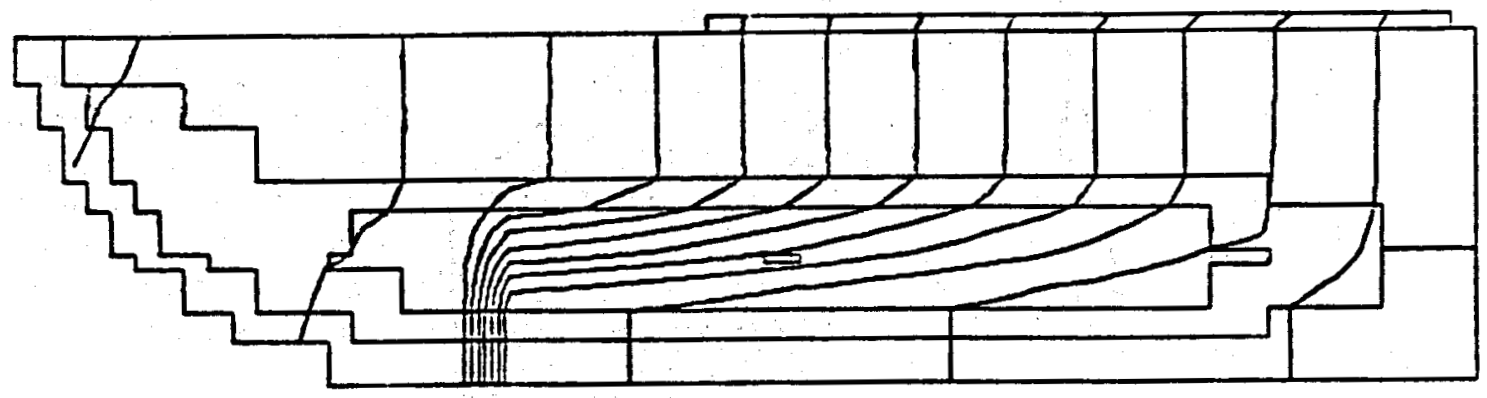

Figure 44. Hydraulic Head Distribution for T14

\subsection{Final Set of Release and Transport Phenomena}

Table 3 below lists the set of Release and Transport Phenomena remaining after the elimination procedures of Sections 3.4 and 3.5. Scenarios will be formed by taking meaningful sequences, either singly or in combinations, of these phenomena (Section 3.7). An initial screening of these scenarios can be carried out based on criteria listed in Section 2.3. A final screening of the remaining scenarios can then be performed based on consequence and risk estimates. Recall that consequences at this point refer to radionuclide discharges to the environment and the health effects resulting from these discharges.

\subsection{Construction and Initial Screening of Scenarios}

The next step in the scenario selection procedure is to construct scenarios by taking combinations of the release and transport phenomena listed in Table 3. One means of lllustrating this construction of scenarios is by the use of a logic diagram similar to that shown in Figure 2. This technique has the benefit of providing a diagrammatic representation of each of the various combinations of release and transport phenomena used and aids in assuring that all combinations have been considered.

A logic diagram, including every possible combination of release and transport phenomena 1 isted in Table 3 , would contain $2^{8}-256$ outcomes. Initially, many of these combinations can be eliminated. For example, R1 (borehole or shaft to repository) could be considered in combination with 
R2 (borehole or shaft to lower aquifer), and the scenario (R1, R2) analyzed in terms of radionuclide transport and health effects.* However, to avoid the complexity of performing transport calculations for scenarios involving multiple transport paths, consequences resulting from scenario (R1, R2) could be determined by adding the consequences from each of $R 1$ and R2. The same reasoning could be applied to any combination of release phenomena involving multiple transport paths. Furthermore, release phenomena involving releases to the upper aquifer would probably be dominated by $\mathrm{R} 4$ (massive dissolution cavity to repository). In fact, the long-term outcome of release phenomenon such as $R 3$ (U-tube) would probably lead to a disruption such as that described in $R 4$. Thus, these phenomena do not necessarily need to be considered in combination. In the demonstration presented here, none of the release phenomena are considered in combination.

Table 3 .

Final Set of Release and Transport Phenomena

Number

R1

R2

R3

R4

T1

T2

T8

T10
Description

Borehole or shaft to repository

Borehole or shaft through repository to lower sandstone

U-tube to middle sandstone

Dissolution cavity from middle sandstone to repository

Withdrawal wells completed into middle sandstone downdip from repository

Withdrawal wells completed into lower sandstone downdip from repository

Low-conductivity fault or dike in lower sandstone downdip from repository

Low-conductivity fault or dike through both aquifers downdip from repository

For the sake of simplicity, scenario notation will be as follows. The scenario in which only R1 and R2 occur, for example, will be denoted as $(R 1, R 2)$, not as the more rigorous ( $R 1, R 2, \overline{R 3}, \overline{R 4}, \overline{T 1}, \overline{T 2}, \overline{T 8}, \overline{T 10})$. Thus, it is important to keep in mind that denoting this scenario as (R1, R2) implies that R3, R4, T1, T2, T8, and T10 do not occur. 
Recall that $R 1$ (borehole or shaft to repository) was retained only because of the potential of inadvertent drilling into a waste canister or leached radionuclides and transporting this material directly to the land surface. Thus, in this demonstration, R1 is not considered in combination with any transport phenomena. This eliminates the sequences (RI, $T 1),(R 1, T 2),(R 1, T 8)$, and (R1, T10). Furthermore, T10 (10w permeabi1ity fault or dike downdip from repository) was retained only because of its potential of direct release to the land surface when combined with R2. Thus, T10 is not considered by itself.

Some scenarios are included only for completeness of the logic diagram. For example, consequences from (R2, T1) would be no different than those from R2, because withdrawal wells completed into the middle sandstone would not alter the consequences from a release to the lower sandstone. The combination (R2, T1) was necessary in construction of the diagram in order to arrive at (R2, T1, T8). The same is true of $\mathrm{T} 1$. The hydraulic gradient in the undisturbed system is downward, and there is assumed to be ample fluid in order for convection to dominate molecular diffusion. Thus, any radionuclides released in the base case (BC) scenario would be discharged to the lower aquifer with eventual transport to River $L$. Withdrawal wells into the middle sandstone would not significantly alter the consequences form the BC scenario. T1 was necessary in order to arrive at (T1, T8). Thus, scenarios $T 1$ and (R2, T1) can be eliminated.

Probabilistic Evaluation of Scenarios

The probabilities of occurrence of the scenarios are based on the probabilities of occurrence and nonoccurrence of the events and processes that compose the scenarios. Four basic techniques are available for determining the probabilities of occurrence. If the avallable data for an event or process are assumed to be randomly distributed in time and location, a Poisson probability model, possibly in conjunction with geometric probability theory, would be appropriate. For data sets that contain a recognized frequency of recurrence, a frequentist approach would be used. In cases where mathematical models can reasonably represent a physical process, the modeling approach can be used. Where data are sparse or unreliable, the use of expert judgment may be the only technique available to estimate reproducible probabilities.

Probabilities determined by the above techniques are for the occurrence of an event or process during some period of time, usually determined by regulations. An implicit assumption of these probabilities is that the occurrence of other events and processes during the same time period is not excluded. To determine the probability of occurrence of a scenario, the probabilities of occurrence of the events and processes in the scenario are combined along with the probabilities of nonoccurrence of the events and processes that were not part of the scenario. The probability of nonoccurrence is the complement of the probability of occurrence. Only those events and processes that are to be used in the logic 
diagram to construct scenarios need to be considered. To simplify this process, a complete logic diagram incorporating all of the events and processes that survived their screening process can be used with the "yes" direction of a branch at each event and process being assigned the appropriate probability of occurrence and the "no" direction being assigned the probability of nonoccurrence. By combining the probabilitles along each pathway through the logic diagram, the probability of occurrence for each scenario can be determined.

\subsection{Einal Screening of Scenarios}

Because only 13 scenarlos remain after screening based on physical reasonableness and consequence, and because this number of scenarios does not require substantial time and effort for analysis, all of these scenarios were retalned for the demonstration of the methodology. If several tens to hundreds of scenarlos remained, screening based on probabilities would be required.

Transport calculations may not have to be performed on all the remaining scenarios if it is felt that certain ones will result in similar consequences. For example, transport calculations performed on the BC scenario resulted in no discharges at River $L$ for the $10^{5}$-year pertod used in these analyses [Cranwell et al., 1987]. Because a downward gradient exists in the undisturbed system, radionuclides released from the repository in the BC scenario would move to the lower aquifer and be transported along this aquifer and discharged to the surface environment at River $L$. Scenario $T 8$ results in a change of the hydraulic gradient from downward to upward across the repository. Thus, radionuclides released from the repository under the conditions resulting from $T 8$ would move to the middle sandstone aquifer and be transported along this aquifer with discharge to the surface environment at River L. Preliminary analyses showed that ground-water travel times from the repository to River $L$ were not significantly different for the BC Scenario and T8. Thus, because the $B C$ scenario resulted in no discharge, it was felt that detailed transport calculations need not be performed for Scenario T8. A similar argument was used to eliminate the need for performing transport calculations on Scenario T1, T8, based on its similarity to Scenario T2.

The final set of scenarios on which radionuclide transport and health effects calculations were performed are 11sted in Table 4. The results of these transport and health effects calculations can be found in the projects's final report [Cranwell et al., 1987]. The scenarios 1isted in Table 4 are numbered according to the same scheme used in the final report.

It should be emphasized once more that the scenarios selected depended, in part, on the characteristics of a hypothetical reference site. Thus, different scenarios would probably be selected for a site-specific analysis. Undoubtedly there will be disagreement on the scenarios selected for retention and on those eliminated. The reader should keep in mind that the scenarios selected were the result of a demonstration of a scenario selection procedure applied to a hypothetical site. 
Table 4

Final Set of Scenarios

Scenario

1 (BC)

2 (T2)

3 (R2)

4. (R2, T2)

5 (R2, T8)

$6(\mathrm{R} 2, \mathrm{~T} 1, \mathrm{~T} 8)$

$7(R 2, T 10)$

8 (R1)

9 (R3)

$10(\mathrm{R} 3, \mathrm{~T} 1)$

11 (R4)

$12(\mathrm{R} 4, \mathrm{~T} 1)$

\section{Description}

Reference site with repository but without other disruptions

Withdrawal wells into lower sandstone aquifer downdip form repository

Borehole or shaft through repository to lower sandstone aquifer

Borehole or shaft through repository to lower sandstone aquifer with withdrawal wells into lower sandstone downdip from repository

Borehole or shaft through repository to lower sandstone aquifer with a low conductivity fault or dike in lower sandstone downdip from repository

Borehole or shaft through repository to lower sandstone aquifer with withdrawal wells into middle sandstone aquifer and a low conductivity fault or dike in lower sandstone downdip from repository

Borehole or shaft through repository to lower sandstone aquifer with a low conductivity fault or dike to land surface downdip from repository

Borehole or shaft to repository intersecting a canister or leached waste from a canister

U-tube connection through repository to middle sandstone aquifer

U-tube connection through repository to middle sandstone aquifer with withdrawal wells into middle sandstone downdip from repository

Massive dissolution cavity from middle sandstone aquifer to repository

Massive dissolution cavity from middle sandstone aquifer to repository with withdrawal wells into middle sandstone downdip from repository 


\subsection{SUMMARY AND CONCLUSIONS}

This report has presented a procedure for selecting and screening scenarios for use in the analysis of a radioactive waste disposal site. This procedure was demonstrated by applying it to a hypothetical reference site containing a bedded-salt formation as the host medium for the waste. All aspects of the scenario selection procedure were presented with the exception of those involving detailed radionuclide transport and health effects calculations. The results of these calculations can be found in the project's final report [Cranwell et al., 1987].

In the development and demonstration of the scenario selection procedure discussed in this report, several observations were made concerning the topic of selection and screening of scenarios for radioactive waste disposal in deep geologic formations. First, no matter what criteria are used to select and screen scenarios for a real site analysis, the selection and screening should be done by means of an objective and consistent methodology involving several levels of analysis and screening. The factors affecting the long-term isolation of radioactive waste in deep geologic formations are too complex to involve simple selection procedures applied with just one level of screening. The evaluation of any site will generally be a sequential process involving several levels of analysis and evaluation. As the study of a site progresses and knowledge is gained with respect to what is known and unknown about the site, it will be necessary to modify the analysis of scenarios appropriately.

Second, the quantification of scenarios in terms of probabilities is undoubtedly one of the most difficult tasks in the scenario selection and screening procedure. The development of generic probabilistic models and techniques for assigning probabilities to every possible scenario is unrealistic. Many scenario probabilities will be purely subjective due to sparsity of data, or will involve the analysis of extremely sitespecific data by experts in the area associated with a scenario.

Finally, one is always faced with the problem of "completeness." The procedure of classifying events and processes (demonstrated in this report) is felt to be a helpful aid in addressing the problem of completeness. The formation of scenarios by taking sequences of these phenomena decreases the possibility of overlooking potentially important scenarios. However, the importance of a scenario is, quite frequently, dependent upon the geologic and hydrologic properties assumed when analyzing that scenario. Thus, care also needs to be exercised when evaluating the importance of a scenario based on the physical properties assumed for the components comprising that scenario.

What has been presented in this report is just one procedure for selecting and identifying important scenarios that potentially could disrupt a radioactive waste disposal site or affect radionuclide transport. As was mentioned earlier, we do not claim that this procedure is the only one available for scenario selection. Furthermore, the 
scenarios selected in the demonstration analysis may not be those selected in a real-site analysis. Nevertheless, the procedure presented does provide a systematic means for selecting and screening scenarios and can be applied to any geologic site being considered. 


\section{METEORITE IMPACTS}

The total depth of large meteorite impact craters has been determined to be about one-third of the crater's diameter [Claiborne, 1974]. Depth here means the distance from the top of the surrounding plane to the bottom of the "crushing zone" (Figure A.1). The crushing zone is formed by shattered rock fragments dispersed into the air at the time of impact and falling back into the crater after impact. Below the crushing zone is what is commonly referred to as the "fracture zone". This is the zone where underlying material was highly fractured but left in situ. Generally, the depth to the bottom of the fracture zone is determined to be one-haif the crater's diameter.

The impact of meteorites will be considered as a random process. There is evidence that this may not be entirely true because a slight latitude effect seems to exist [Halliday, 1964]. To determine the probable number of craters of different diameter, a relationship between the number of craters and size observed for the moon will be used [Hartmann, 1965]; namely

$$
\mathrm{N}=\mathrm{KD}^{-2.4}
$$

where

$$
\begin{aligned}
& N \text { - the number of craters with diameter larger than } D \text {, } \\
& D \text { - the diameter of the crater }(\mathrm{km}) \text {, and } \\
& \text { K = empirical constant. }
\end{aligned}
$$

On the basis of Canadian impact craters, the frequency of impacts producing craters larger than $1 \mathrm{~km}$ in diameter falls between $0.8 \times 10^{-13}$ and $17 \times 10^{-13} \mathrm{~km}^{-2} \mathrm{yr}^{-1}$ [Hartmann, 1965]. The lower limit appears to be more consistent with geologic data and with Dietz's estimate of one every ten thousand years [Dietz, 1961]. Therefore,

$$
1 \times 10^{-13} \mathrm{~km}^{-2} \mathrm{yr}^{-1}
$$

will be taken as the best estimate of the frequency of impacts producing craters of $1 \mathrm{~km}$ or greater in diameter. Using Equation (A-1), we have

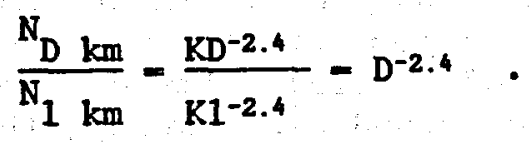




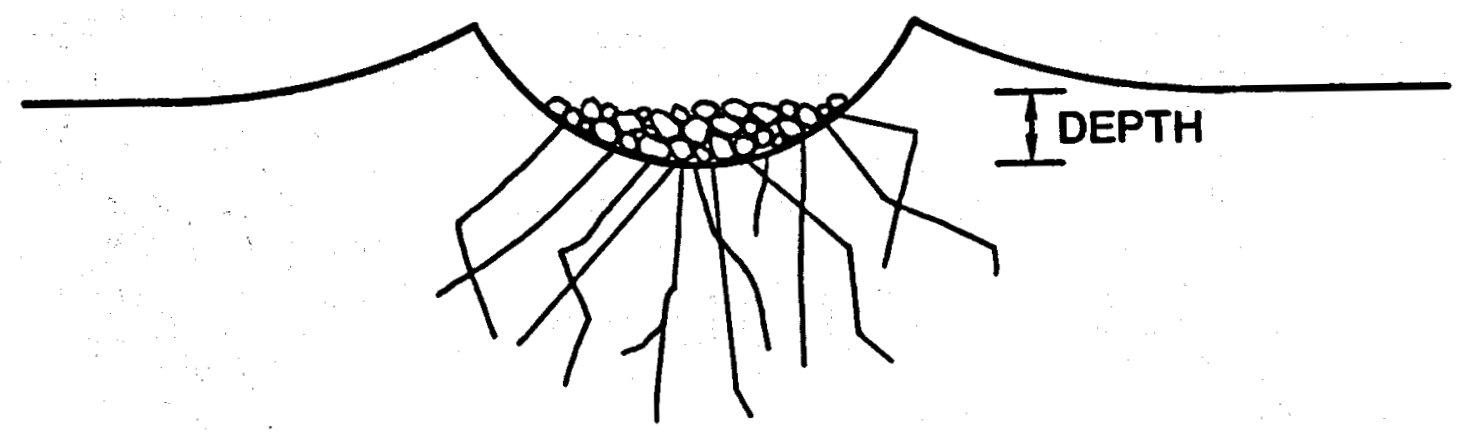

Figure A.1. Schematic Representation of Meteorite Crater

Thus, the probability of formation of a crater $D \mathrm{~km}$ in diameter or greater is $D^{-2.4}$ times the probability of formation of a crater $1 \mathrm{~km}$ or greater. Let $P_{D}$ be this probability. Then, using (A-2),

$$
\begin{gathered}
P_{D}=\left(1 \times 10^{-13}\right) D^{-2.4} / \mathrm{km}^{2}-y r \\
\text { Set } F_{D}=1-P_{D} .
\end{gathered}
$$

Then

$$
\frac{\mathrm{dF}_{\mathrm{p}}}{\mathrm{dD}}=\left(2.4 \times 10^{-13}\right) \mathrm{D}^{-3.4}
$$

Now consider a waste repository at $h$ (depth) below the land surface and with dimensions of $\ell$ (length) and $w$ (width). Assuming the total depth of a meteorite crater to be approximately one-third the diameter, it would take a direct impact by a meteorite of crater diameter $3 \mathrm{~h}$ to cause instantaneous release of radionuclides to the air or land surface. However, an impact by a meteorite of crater diameter larger than $3 \mathrm{~h}$ could cause immediate release even if it were not a direct impact. Therefore, the plane region to consider concerning meteorite impacts should extend beyond that of the region of the repository (Figure A.2). From this figure, the plane of interest should extend a distance of $(D / 2)-k$ beyond the repository boundary. That is, the plane of interest should be $(l+(D / 2)-k) \times(w+(D / 2)-k)$. To determine $k$, we use the general form of the equation of a parabola:

$$
(x-u)^{2}-4 p(y-v)
$$




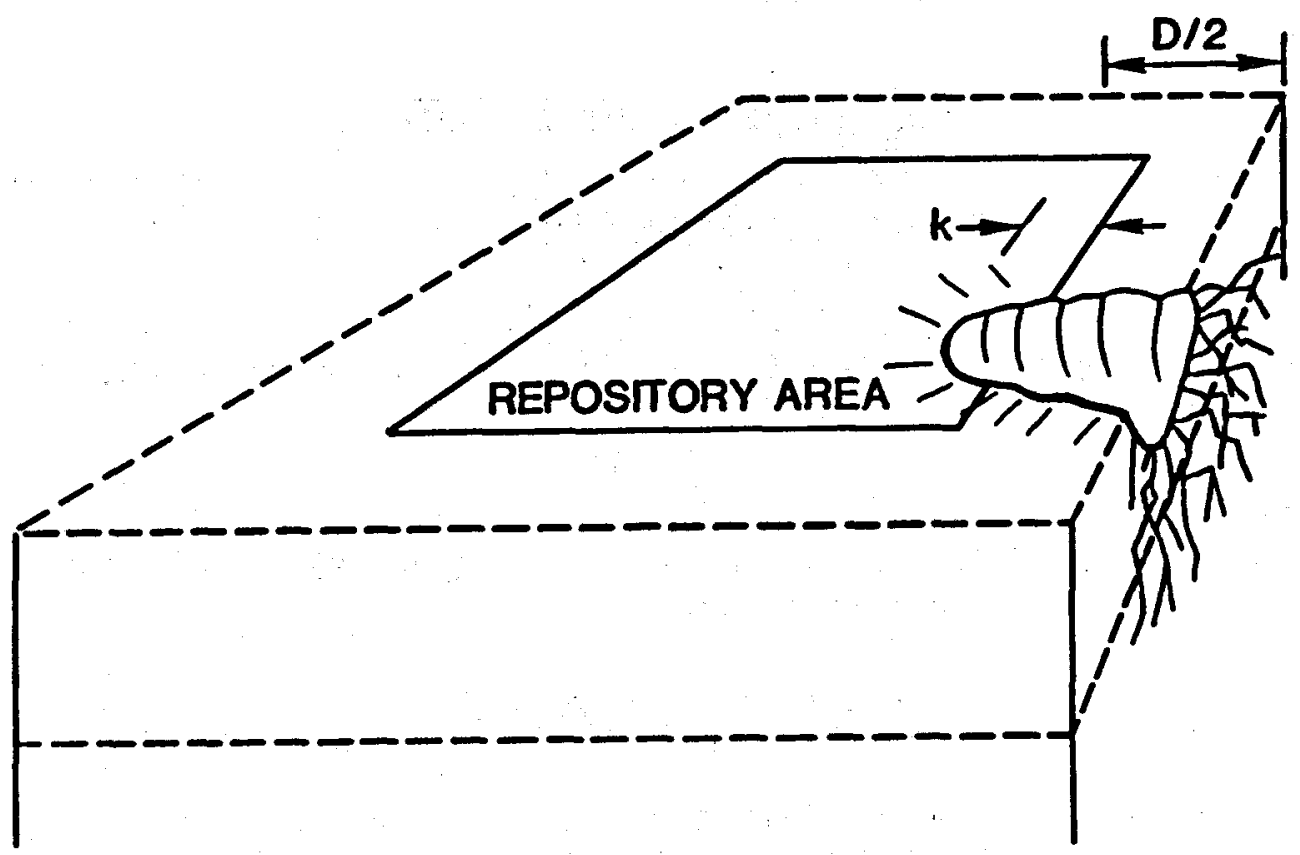

Figure A.2. Critical Region for Impact Craters

For our case, $y=-h$ when $x=0$, and $v=-h$ when $u=0$. Furthermore (because crater diameter is 3 times the depth), $y=0$ implies $x= \pm 3 h / 2$. Thus,

$$
k=3 / 2\left[\sqrt{(D / 3) h}-\sqrt{(D / 3) h-h^{2}} .\right.
$$

Using this and Equation (A-3), the probability, $P$, of a crater intersecting the plane of interest is given by

$$
P=\int_{3 h}^{\infty}[l+(D / 2)-k][w+(D / 2)-k] \times\left(2.4 \times 10^{-13}\right) D^{-3.4} d D
$$

For the Sandia reference repository we have $l \propto 4 \mathrm{~km}, \mathrm{w} \approx 2 \mathrm{~km}, \mathrm{~h} \approx 630$ $m$. Substituting these values into the integral in Equation $(A-6)$, we get

$$
P=7.82 \times 10^{-13} / y^{x}
$$

as the (yearly) probability of meteorite impact of sufficient force to cause instantaneous release. 
For the fracture zone, the diameter of the crater is twice the fracture zone. In this case, $k$ takes the form

$$
k=\sqrt{(D / 2) h}-\sqrt{(D / 2) h-h^{2}}
$$

and the integral in Equation $(A-6)$ becomes

$$
P=\int_{2 h}^{\infty}[\ell+(D / 2)-k][w+(D / 2)-k] \times\left(2.4 \times 10^{-13}\right) D^{-2.4} d D
$$

For the Sandia reference repository, the middle shale is about $400 \mathrm{~m}$ below the surface. From Equation (A-8), the (yearly) probability of this being fractured by meteorite impact is

$$
P=1.27 \times 10^{-12 / y r}
$$




\section{VOLCANIC ACTIVITY}

The probability that a volcano will disrupt the repository site is calculated using the probabilistic model described in Beckman and Johnson [1982]. This model yields the following equation.

$$
\begin{aligned}
& P_{r} \text { (disruptive event before time } t \text { ) } \\
& =1-\exp \left[-\left[\sum_{i=1}^{n} \lambda_{i} P_{i}\right] t\right],
\end{aligned}
$$

where

$\lambda_{1}$ - rate of occurrence of volcanos at site 1 ,

$p_{i}$ - probability that a volcano at site 1 will disrupt the repository, and

$n$ - the number of sites in the vicinity of the repository where volcanic activity occurs.

Because this study is not site-specific, only one region for volcanic activity is considered: the entire western United States (Washington, Oregon, California, Idaho, Nevada, Montana, Utah, Arizona, Wyoming, Colorado, and New Mexico). Furthermore, the repository is assumed to be located somewhere in this region. Thus, the model reduces to

$$
\left.P_{x} \text { (disruptive event before time } t\right)=1-e^{-\lambda p t} \text {, }
$$

where

$$
\begin{aligned}
& \lambda=\text { rate of occurrence of volcanos in the western United States } \\
& \text { (number of volcanos/number of years), and } \\
& p=\text { probability that a volcano will disrupt the repository. }
\end{aligned}
$$

Now, the number of volcano vents that have shown activity within the last 10 million years in the western United States is approximately 1300 [Arthur D. Little, 1980]. Thus,

$$
\lambda=1300 / 10^{7}=1.3 \times 10^{-4} \text {. }
$$

The dimensions of the waste repository are 1.8 by $2.4 \mathrm{~km}$. Crowe [1978] states that the maximum zone of a volcanic disruption is $66 \mathrm{~km}^{2}$ or a circle of radius $4.6 \mathrm{~km}$. Thus, for a volcano to disrupt the repository, 
it must be within $4.6 \mathrm{~km}$ of boundary of the repository or within an area of $128 \mathrm{~km}^{2}(11.0 \times 11.6 \mathrm{~km})$. This yields

$$
\begin{aligned}
p=\text { area of disturbance/total area of western United States } \\
-128 / 3 \times 10^{5}=4.3 \times 10^{-5}
\end{aligned}
$$

and so

$$
\begin{aligned}
& P_{r} \text { (disruptive event within } 1 \text { year) } \\
& \quad=1-\exp \left[-5.6 \times 10^{-8}\right] \\
& \quad \simeq 5.6 \times 10^{-9}
\end{aligned}
$$

This probability estimate is conservative in a number of ways. In the calculation, an equal distribution of volcanos is assumed. Actually, volcanos occur together in specific regions. The actual repository site would presumably be outside such regions. Some of the 1300 volcanos used in the calculation of $\lambda$ occurred more than 10 million years ago. The actual value of $\lambda$ should be somewhat smaller. The value of $66 \mathrm{~km}^{2}$ is a maximum zone of disruption. Most zones will be much smaller, making the estimate of $p$ much smaller. 
In determining the probability of radionuclide release resulting from drilling activity, both the probability of drilling into the 1100-acre parcel containing the repository and the probability of hitting a canister of waste material must be considered. Both of these determinations assume that drilling activity will continue in bedded-salt regions into the future and that the waste material remains in the canisters.

Although one of the selection criterla for the proposed repository sites is low resource potential, the possibility of future driling cannot be eliminated. Because of the unpredictability of the economic factors that control oil and gas exploration, exploratory drilling rates cannot be projected with any certainty into the future. To determine the probability of a random drill hole in a bedded-salt region being in the 1100 acres containing the repository, an average drilling rate for bedded salt regions for approximately the years 1970 through 1979 was calculated. This range in years includes the recent national low in drilling activity in 1972 and a recent near-record high in 1979. The areas from which drilling data were used are the New York portion of the Appalachian Basin, the Michigan Basin, the Permian Basin, the Northern Denver Basin, the Powder River Basin, and the Williston Basin (Figure C.1.) Only those counties that are at least half underlain by bedded salt were included, and only exploratory drill holes were tabulated. The drilling data are compiled by state in Table C.1. Based on these drilling rates and the assumption that the repository area will be 1100 acres, the mean drilling rate at the hypothetical reference site is taken as $1.18 \times 10^{-2} / \mathrm{yr}$. This would amount to 1180 exploratory holes drilled into the 1100-acre site over the $10^{5}$-year period of our analysis.

Given that drilling has occurred at the site, the probability that a canister is intersected is determined by examining extraction ratios for rooms and the use of geometric probabilities. For the hypothetical reference site, the extraction ratio is approximately 25 percent. Rooms are $560 \times 18 \times 18 \mathrm{ft}$ [Campbell et al., 1978].

Each room is designed to contain 32 canisters of nuclear waste with each canister $10 \mathrm{ft}$ long and $1 \mathrm{ft}$ in diameter. The diameter of the drill bit is assumed to be $1 \mathrm{ft}$. A drill bit would only have to nick the edge of the canister to release some of the waste. Because the center of the drill bit must be within 1 ft of the center of the canister in order to hit the canister (Figure C.2), the effective target area of each canister is a circle with a radius of $1 \mathrm{ft}$. 


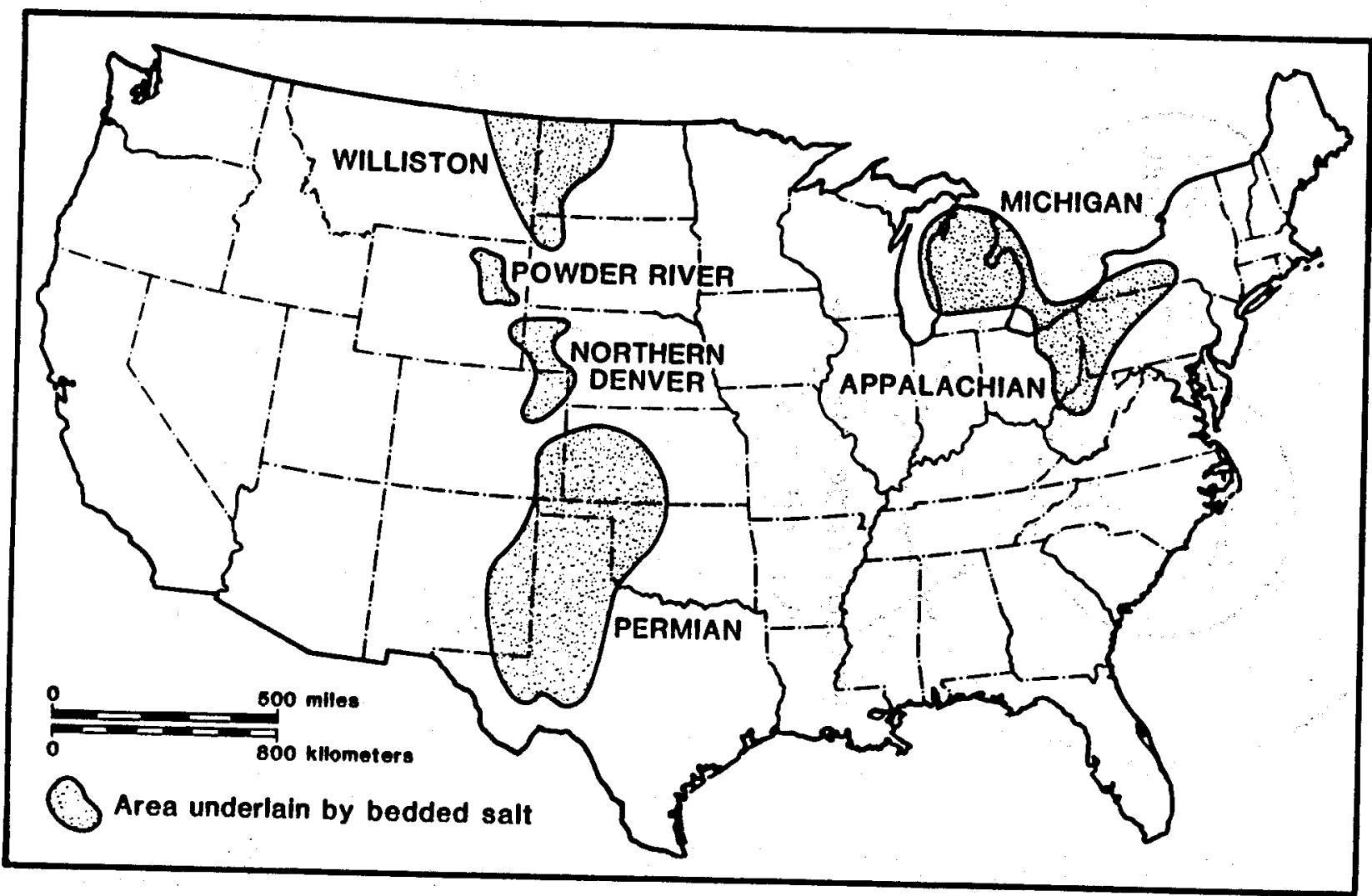

Figure C.1. Areas for Drilling Data 


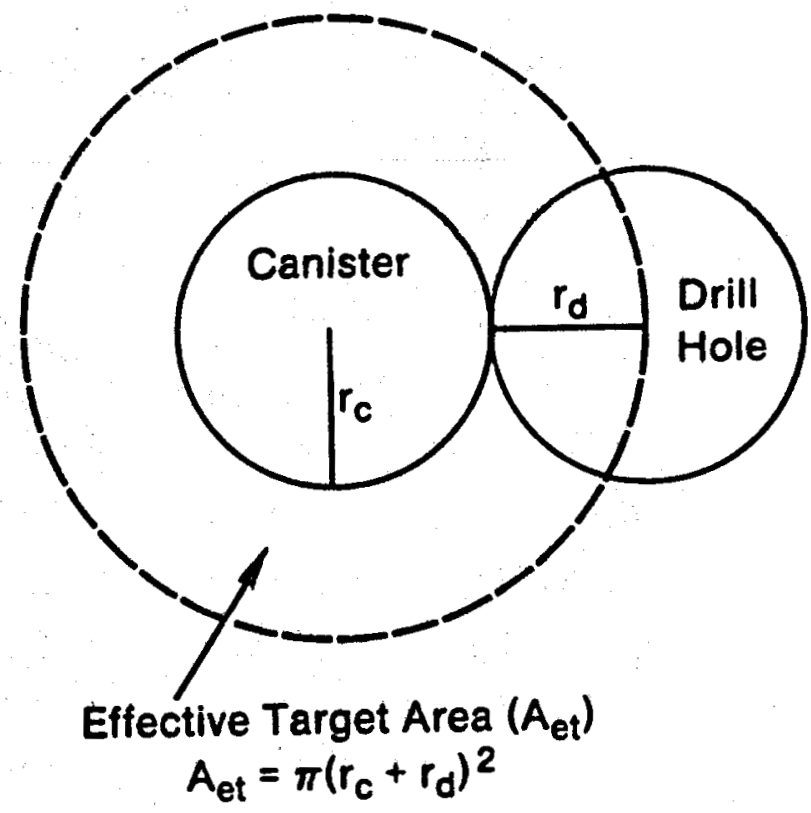

Figure C.2. Effective Target Area of a Canister

The probability that a random drill hole through the repository will hit a canister is determined as follows:

where

$$
P_{h c}=P_{h r} \bullet P_{c r},
$$

$$
\begin{aligned}
& P_{b c} \text { - probability of a random drill hole hitting a canister, } \\
& P_{h x} \text { - probability of hitting a room, } \\
& P_{c x}=\text { probability of hitting a canister within a room, } \\
& P_{h r} \approx \text { extraction ratio }\left(E_{r}\right) \\
& P_{c x}=A_{c t} / A_{x},
\end{aligned}
$$

where

$$
\begin{aligned}
& A_{\text {ot }}=\text { effective target area within a room, } \\
& A_{x}=\text { area of each room, } \\
& A_{\text {ot }}=n_{c} \pi\left(r_{c}+r_{d}\right)^{2}
\end{aligned}
$$

where

$$
\begin{aligned}
& n_{c}=\text { number of canisters per room, } \\
& r_{c} \text {-radius of canister, and } \\
& r_{d}=\text { radius drill bit. }
\end{aligned}
$$


Table C.1

Drilling Rates for Areas Underlain by Bedded Salt

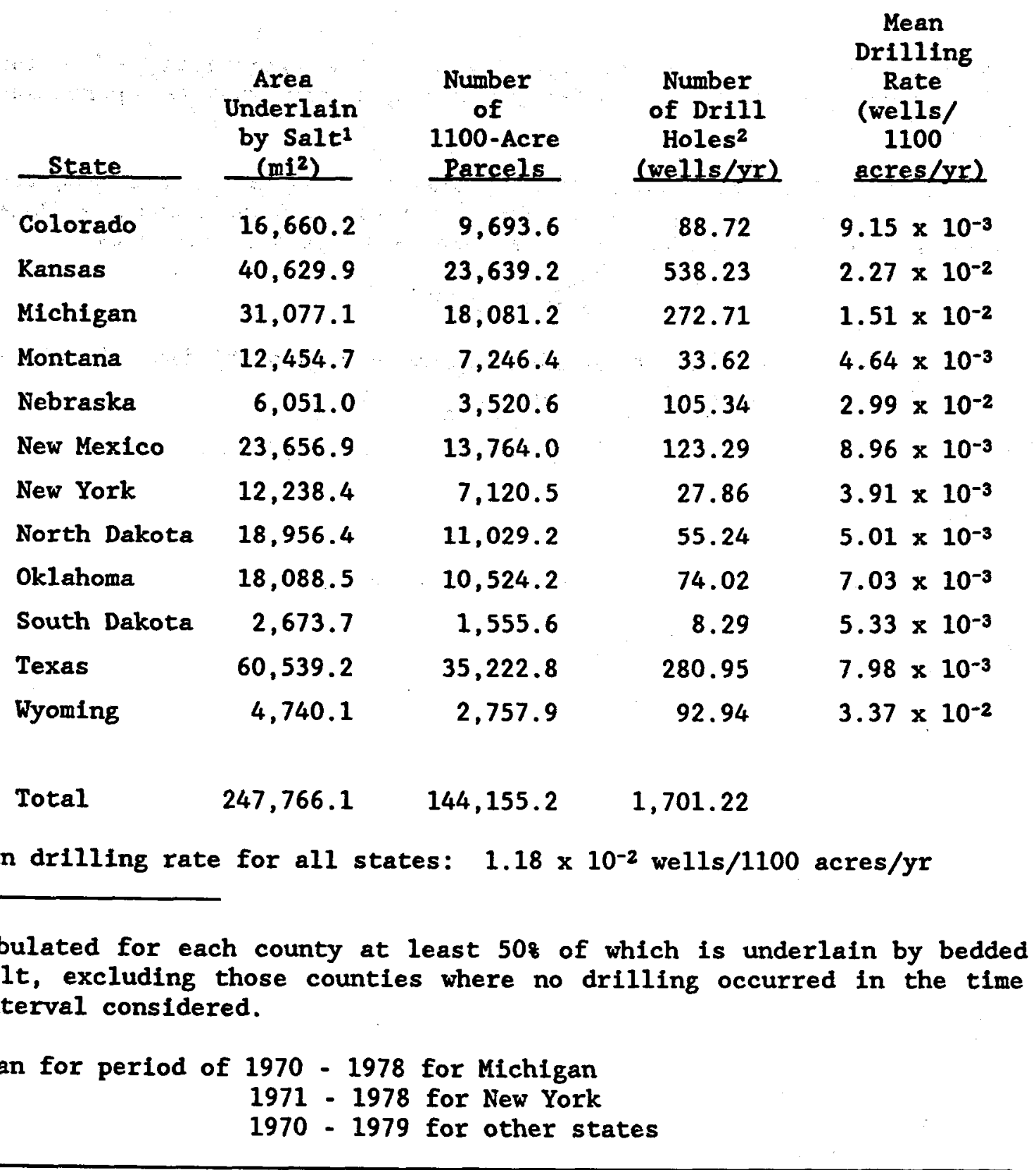


Therefore,

$$
P_{h c}=\frac{E_{r} n_{c} \pi\left(r_{c}+r_{d}\right)^{2}}{A_{r}}
$$

For the model repository described above, the probability of a random drill hole within the repository hitting a canister is approximately $2.5 \times 10^{-3}$.

If we assume that the number of such disturbances (1.e., drilling into a canister) occurring during a time interval $t$ constitutes a Poisson process, then the probability of release in $t$ years is given by

$$
p=1 \cdot e^{-\lambda t}
$$

where $\lambda$ is the fallure rate (1.e., per year probabllity of release). According to the above discussion,

$$
\lambda=0.0118 \times .0025-2.95 \times 10^{-5} .
$$

Thus,

$$
p=1-\exp \left[-2.95 \times 10^{-5} t\right] \ldots
$$

For a $10^{5}$-year perlod of analysis,

$$
p=1 \cdot e^{-2.95}=.95 \text {. }
$$




\section{APPENDIX D}

\section{FAULTING}

We shall assume that at the time of repository closure the mean density of faults existing in a region $R$ surrounding the repository site is $\lambda_{0}$ per unit area. We shall assume further that new faults appear in this region according to a nonstationary Poisson process with mean rate $\lambda_{1}(t)$ per unit area per year, where $t$ indicates the time-dependent rate of formation of new faults. Then, the mean density of faults existing in the region $R$ at some time $t$ following closure of the repository site can be represented by

$$
\lambda(t)=\lambda_{0}+\int_{0}^{t} \lambda_{1}(t) d t
$$

From Equation (D-1) the probability of exactly $N$ faults existing in the region $R$ by the time $t$ is given by

$$
P(N, t)=\frac{[\lambda(t) A]^{N}}{N !} e^{-\lambda(t) A}
$$

where $A$ is the area of region $R$.

We will let $p$ denote the conditional probability that if a fault exists in the region $R$ it will intersect the repository site. Then, the probability that at least one fault intersects the repository site in the time interval $(0, t)$ is given by

$$
P=1-e^{-\lambda(t) p A}
$$

From Equation (D-3) we see that to determine a value of $P$, we need to know values of $\lambda(t)$ and $p$. The value of $\lambda(t)$ can be evaluated once a specific site for the waste repository has been selected. Geologic and historic records of tectonic and seismic activity, determination of ages of existing faults, and in situ measurements of local stresses can all be used to arrive at a representation of $\lambda(t)$.

The parameter $p$ is calculated in terms of the spatial density of faults In the region $R$ and the average length of these faults. The repository is considered to be a subregion, $R_{0}$, of $R$, Both $R$ and $R_{0}$ are taken as rectangular regions and thus are convex (1.e., any line connecting two points on the perimeter of the region lies entirely within the region). Faults in $R$ are taken as line segments of length $l$, where $l$ is the mean length of the faults in $R$. 
According to Santalo [1976], the probabllity that a line segment of length $\ell$ in $R$ intersects $R_{0}$ is given by

$$
p=\frac{2 \pi A_{0}+2 l P_{0}}{\pi a b-2(a+b) l+l^{2}}
$$

where $A_{0}$ and $P_{0}$ are the area and perimeter, respectively, of $R_{0}$ and $a$ and $b$ are the lengths of the sides of region $R$.

To determine the probability that an existing but undetected fault in region $R$ intersects the plane of the repository, we take $\lambda(t)$ in Equation $(D-1)$ to be $\lambda_{0}$. For the hypothetical reference site, the repository has the dimensions of $1.42 \mathrm{mi} \times 1.52 \mathrm{mi}$. The valley containing the repository is assumed to have the dimensions of $57 \mathrm{mi} \times 152 \mathrm{mi}$ (Campbell et al., 1978). Mean fault lengths in this region will be taken as 2 mi. Thus, using Equation (D-4)

$$
P=\frac{2 \pi(1.73)+2(2)(5.32)}{\pi(57)(152)-2(57+152)(2)+2^{2}}=1.22 \times 10^{-3}
$$

Thus,

$$
P=1-\exp \left(-\left[\lambda\left(1.22 \times 10^{-3}\right)\right]\right)
$$

where $\lambda=\lambda_{0} A$.

Below are several values of $P$ for different values of $\lambda$ :

$$
\begin{aligned}
& \lambda_{0}=1 ; \mathrm{P}=1.22 \times 10^{-3} \\
& \lambda_{0}=2 ; \mathrm{P}=2.44 \times 10^{-3} \\
& \lambda_{0}=3 ; \mathrm{P}=3.65 \times 10^{-3} \\
& \lambda_{0}=4 ; \mathrm{P}=4.87 \times 10^{-3} \\
& \lambda_{0}=5 ; \mathrm{P}=1 \times 10^{-2} \\
& \lambda_{0}=6 ; \mathrm{P}=1 \times 10^{-2}
\end{aligned}
$$

For new faults, the probability that at least one intersects the plane of the repository is found by using the rate of formation of new faults, $\lambda_{1}(t)$, in Equation (D-3). Data from the Delaware and Palo Duro Basins indicate that the rates of formation of faults in these regions is on the 
order of 10-8 faults/year. Th1s rate is used for the hypothetical reference site. Thus, the probability that at least one of these intersects the plane of the repository is given by

$$
P=1-\exp \left(-\left[\left(10^{-8}\right)\left(1.22 \times 10^{-3}\right)\right]\right)-1.22 \times 10^{-11}
$$


Andersson, J. and T. Eng, The Jolnt SKI/SKB Scenario Development Profect, Proceedings of the International Symposium on the Safety Assessment of Radioactive Waste Repositories, OECD/NEA, Paris, France, October 1989.

Arnet, R. C., R. G. Baca, J. A. Caggiano, D. J. Carrell, and S. E. Logan, Radionuclide Release scenarlo Selection Process for a Possible Repository in Basalt, Rockwell International, Richmond, WA, RHO-BWISA-83, 1980.

Beckman, R. J. and M. E. Johnson, Probabilistic Model for Estimating the Effects of Volcanism on Nuclear Waste Repositories, Los Alamos Scientific Laboratory, Los Alamos, NM, LA-UR-80-2166, 1982.

Billington, D. E., D. A. Lever, and S. J. Wisbey, Radiological Assessment of Deep Geologic Disposal: Work for UK Nirex Ltd, Proceedings of the International Symposium on the Safety Assessment of Radioactive Waste Repositories, OECD/NEA, Paris, France, October 1989.

Bingham, F. W. and G. E. Barr, Scenarios for Long-Term Release of Radionuclides from a Nuclear-Waste Repository in the Los Medanos Region of New Mexico, SAND78-1730, Sandia National Laboratories, Albuquerque, NM, 1979.

Bloom, A. L., The Surface of the Earth, Englewood Cliffs, NJ: PrenticeHall, Inc., 1969.

Bonano, E. J., S. C. Hora, R. L. Keeney, and D. von Winterfeldt, Elicitation and Use of Expert Judgment in Performance Assessment for HighLevel Radioactive Waste Repositories, NUREG/CR-5411, SAND89-1812, Sandia National Laboratories, Albuquerque, NM, 1990.

Bonano, E. J., P. A. Davis, L. R. Shipers, K. F. Brinster, W. E. Beyeler, C. D. Updegraff, E. R. Shepherd, L. M. Tilton, and K. K. Wahi, Demonstration of a Performance Assessment Methodology for High-Level Radioactive Waste Disposal in Basalt Formations, NUREG/CR-4759, SAND86-2325, Sandia National Laboratories, Albuquerque, NM, 1989.

Bonilla, M. G., Historic Surface Faulting - Map Patterns, Relation to Subsurface Faulting and Relation to Pre-Existing Faults, Open-File Report USGS-79-1239, U.S. Geological Survey, 1979.

Burkholder, H. C., Comments on the NRC Approach to Radioactive Waste Disposal standards and the Technical Approach to Performance Assessment in the NWTS Program, NUREG/CP-0022, CONF-81-0372, Oak Ridge National Laboratory, Gatlinburg, TN, 1981. 
Campbell, J. E., R. I. Dillon, M. S. Tierney, H. I. Davis, P. E. McGrath, F. J. Pearson, H. R. Shaw, J. C. Helton, and F. A. Donath; RIsk Methodology for Geologic pisposal of Radioactive Waste: Interim Report, NUREG/CR-0458, SAND78-0029, Sandia National Laboratories, Albuquerque, NM, 1978.

Claiborne, H. C. and F. Gera, Potential Containment Failure Mechanisms and Their Consequences at a Radioactive Waste Repository in Bedded Salt in New Mexico, ORNL-TM-4639, Oak Ridge National Laboratory, Oak Ridge, TN, 1974 .

Cranwe11, R. M., J. E. Campbel1, and S. E. Stuckwisch, Risk Methodology for Geologic Disposal of Radioactive Waste: The DNET Computer Code User's Manual, SAND81-1663, NUREG/CR-2343, Sandia National Laboratories, Albuquerque, NM 1982.

Cranwel1, R. M., J. E. Campbell, J. C. Helton, R. I. Iman, D. E. Longsine, N. R. Ortiz, G. E. Runkle, and M. J. Shortencarier, Risk Methodology for Geologic Disposal of Radioactive Waste: Final Report, SAND81-2573, NUREG/CR-2452, Sandia National Laboratories, Albuquerque, NM, 1987.

Crowe, B. M., Disruptive Event Analysis: Volcanism and Igneous Intrusion, LA-UR-78-2643, Los Alamos Scientific Laboratory, Los Alamos, NM, 1978 .

Dietz, R. S., "Astroblems," Scientific American, 205 (1961).

Donath, F. A. and R. M. Cranwell, "Probabilistic Treatment of Faulting in Geologic Media," American Geophysical Union Monograph, 1980.

F1int, R. F., Glacial and Quaternary Geology, Toronto: John Wiley \& Sons, 1971.

Franke, O. L. and P. Cohen, "Regional Rates of Groundwater Movement on Long Island, New York," Professional Paper 800-C, U.S. Geological Survey, 1972 .

Gilluly, J. A., C. Waters, and A. O. Woodford, Principles of Geology, third edition, San Francisco: W. H. Freeman \& Company, 1968.

Glasstone, S., Effects of Nuclear Weapons, revised edition, U.S.: Atomic Energy Commission, April, 1962.

Griesmeyer, J. M. and D. Okrent, on the Development of Quantitative Risk Acceptance Criteria, AL0-130, UCLA-ENG-7969, UCLA School of Engineering and Applied Science, Los Angeles, CA, 1981. 
Guzowski, R. V. Potential Scenarios for Use in Performance Assessment of High-Level Waste Repositories in Unsaturated Tuff, SAND86-7170, NUREG/CR-4770, Sandia National Laboratories, Albuquerque, NM. (Draft available in NRC Public Document Room.)

Halbouty, M. F., Salt Dome: Gulf Region, United States and Mexico, second edition, Houston: Gulf Publishing Company, 1979.

Halliday, I., "The Variation in the Frequency of Meteorite Impact with Geographic Latitude," Meteorites, 2, No. 3, 1964.

Hartmann, W. K., Long-Term Meteorite Hazards to Burled Nuclear Waste, Pacif1c Northwest Laboratories, Richland, WA, PNL-2851, 1979.

Hartmann, w. K. , Terrestrial and Lunar Flux of Large Meteorites in the Last Two. B111ion Years, ICARUS 4, 1965.

Helton, J. C. and P. C. Kaestner, Risk Methodology for Geologic Disposal of Radioactive Waste: Model Description and User Manual for Pathways Mode1, SAND78-1711, Sandia National Laboratories, Albuquerque, NM, 1981.

Hodgkinson, D. P. and T. J. Summerling, A Review of Approaches to Scenario Analysis for Repository Safety Assessment, Proceedings of the International Symposium on the Safety Assessment of Radioactive Waste Repositories, OECD/NEA, Paris, France, October 1989.

Hodgkinson, D. P., Systematic Approaches to Scenario Development, PAAG/DOC(88)2 ESG-006, Rev. 1, Nuclear Energy Agency, Paris, France, 1988.

IAEA (International Atomic Energy Agency), Concepts and Examples of Safety Analyses for Radioactive Waste Repositories in Continental Geological Formations, Safety Series No. 50, 1983.

Johnson, K. S., Evaluation of the Permian Salt Beds in the Texas Panhandle and Western Oklahoma for Underground Storage of Radioactive Wastes, Y/OWI/SUB-4494/1, Office of Waste Isolation, 1976.

Johnson, K. S. and S. Gonzales, Salt Deposits of the United States and Regional Geologic Characteristics Important for storage of Radloactive Waste, Y/OWI/SUB-7414/1, Office of Waste Isolation, 1978.

Jones, C. L., Salt Deposits of the Clovis-Portales Area, East-Central New Mexico, Open-File Report USGS-4339-9, U.S. Geological Survey, 1974.

Judson, S. and D. F. Ritter, "Rates of Regional Denudation In the United States," Journal of Geophysical Research, 69, 1964. 
Karnbranslesakerhet (KBS), Handling of Spent Nuclear Fuel and Final Storage of Vitrified High-Level Reprocessing Waste, Stockholm, Sweden, 1978.

Koplik, C. M., M. F. Kaplan, and B. Ross, "The Safety of Repositories for Highly Radioactive Wastes," Reviews of Modern Physics, 54, No. 1, January, 1982.

Little, Arthur D., Inc., Technical Support of Standards for High-Level Radioactive Waste Management, EPA 520/4-79-007D, 1980.

Logan, S. E. and M. C. Berbano, Development and Application of a Rlsk Assessment Method for Radioactive Waste Management, 520/6-78-005, EPA, 1978.

Press, F, and R. Siever, Earth, San Francisco: W. H. Freeman Company, 1974 .

Reeves, M. and R. M. Cranwell, User's Manual for the Sandia WasteIsolation Flow and Transport Model (SWIFT), Release 4.81, SAND81-2516, Sandia National Laboratories, Albuquerque, NM, 1981.

Ried, H. F., "Studies of Muir Glacier, Alaska," National Geographic Magazine, 4, 1982.

Santalo, L. A. , Integral Geometry and Geometric Probabilities, Reading, MA: Addison-Wesley, 1976.

Scenario Identification Panel; The Scenario Identification Panel Members and their affiliations are William S. Twenhofel, USGS, Denver, Co; William W. Dudley, USGS, Denver, CO; Randolph Stone, LLL, Livermore, CA; Frederick J. Pearson, USGS, Reston, VA; Herbert R. Shaw, USGS, Menlo Park, CA; Donald Caldwe1l, USNRC, Washington, D.C.; Ben Ross, The Analytical Sciences Corp., Reading, MA; Edward Hawkins, USNRC, Washington, DC; and Martin Tierney, Sandia National Laboratories, Albuquerque; NM. Working sesstons of this panel were held on December 7-8, 1976, at Grand Canyon, AZ, and again on April 13, 1977, in Carlsbad, NM.

Schneider, K. J. and A. M. Plath, High-Level Radioactive Waste Management Alternatives, BNWL-1900, Battelle Pacific Northwest Laboratories, Richland, WA, 1974.

Stephens, M. E. and B. Goodwin, Systematic Scenario Analysis for the Post-Closure Assessment of the Canadian Concept for Nuclear Waste Disposal, Proceedings of the International Symposium Safety Assessment of Radioactive Waste, OECD/NEA, Paris, France, 1989.

Stone \& Webster, Subregional Characterization Report. Palo Duro and Dalhart Basins. Texas, ONWI Draft Report, Stone \& Webster Engineering Corporation, Boston, MA, February 1981. 
Thurston, W., National Academy of Sclences, National Research Council, Division of Earth Sclences, Committee on Geologic Aspects of Radioactive Waste Advisory to the U.S. Atomic Energy Commission, 1961.

U.S. Environmental Protection Agency, "Environmental Standards for the Management and Disposal of Spent Nuclear Fuel, High-Level and Transuranic Radioactive Wastes; Final Rule," Federal Register, 50, 38066-38089 (40 CFR 191), 1985.

U.S. Nuclear Regulatory Commission, "Disposal of High-Level Radioactive Wastes In Geologic Repositories," Code of Federal Regulations, Title 10, Part 60, 1988.

U.S. Nuclear Regulatory Commission, Reactor Safety Study. An Assessment of Accident Risks in U.S. Commercial Nuclear Power Plants, WASH1400, NUREG-75/014, 1975 .

WIPR (Waste Isolation Pllot Plant), DOE/EIS-0026-D, U.S. Dept. of Energy Report, 1979. 


\section{TITLE ANO SUBTITLE}

Risk Methodology for Geologic Disposal of Radioactive Waste:

Scenario Selection Procedure

3. DATE REPORT PUBLISHED

\begin{tabular}{l|l} 
MONTH & 1990
\end{tabular}

4. FIN OR GRANT NUMBER

Al165

5. AUTHOR(S)

6. TYPE OF REPORT

Technical

R.M. Cranwe11, R.V. Guzowski, J.E. Campbe11, N.R. Ortiz

7. PERIOO COVERED IInclusive OAResi

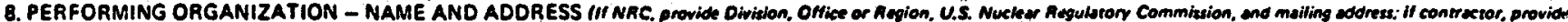
mame end mailing adoress

Sandia National Laboratories

Albuquerque, NM $87185-5800$

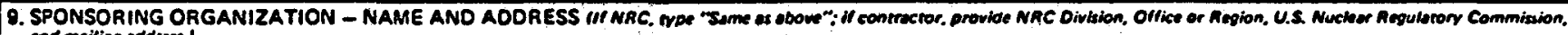
and maiting addresel

Division of High Level Waste Management

Office of Nuclear Materlal Safety and Safeguards

U.S. Nuclear Regulatory Commission

Washington, DC 20555

10. SUPPLEMENTARY NOTES

11. ABSTRACT 1200 monds or hess

This report contains the description of a procedure for selecting scenarios that are potentially important to the lsolation of high level radioactive wastes in deep geologic formations. In this report, the term scenario is used to represent a set of naturally occurring and/or human-induced conditions that represent realistic future states of the repository, geologic systems, and ground-water flow systems that might affect the release and transport of radionuclides from the repository to humans. The scenario selection procedure discussed in this report is demonstrated by applying it to the analysis of a hypothetical waste disposal site containing a bedded-salt formation as the host medium for the repository. A final set of 12 scenarios is selected for this site.

12. KEY WOROSIDESCR!PTORS (Lizt words or phroses that will essist reseancher in loceting ine wport.)

scenario

performance assessment

risk methodology

geologic disposal

radioactive waste

13. AVAILABILITY STATEMENT

Unlimited

14. SECURITY CLASSIFICATION

TThls Pogel

Unclassified

(This Rapori)

Unclassified

15. NUMBER OF PAGES

16. PRICE 
U.S. Nuclear Regulatory Commission (3) Office of Nuclear Regulatory Research

Attn: M. Silberberg, NLS260

T. J. Nicholson, NLS260

W. R. Ott, NLS260

Washington, DC 20555

U.S. Nuclear Regulatory Commission (3) Office of Nuclear Regulatory Research

Attn: J. D, Randal1, NLS260

T. J. MeCartin, NLS260

R. L. Shephard, NL-007

Washington, DC 20555

U.S. Nuclear Regulatory Commission (5) Office of Nuclear Material Safety and Safeguards

Attn: R. E. Browning, $4 \mathrm{H} 3$

E. J. Youngblood, $4 \mathrm{H3}$

R. Ballard, $4 \mathrm{H} 3$

P. Brooks, $4 \mathrm{H} 3$

Document Control Center, DWM

Washington, DC 20555

U.S. Nuclear Regulatory Commission (5) Office of Nuclear Material Safety and Safeguards

Attn: K. C. Chang, $4 \mathrm{H3}$

R. B. Code11, 4H3

N. M. Coleman, $4 \mathrm{H3}$

S. M. Coplan, $4 \mathrm{H} 3$

N. A. Eisenberg, $4 \mathrm{H3}$

Washington, DC 20555

U.S. Nuclear Regulatory Commission (2) Office of Nuclear Material Safety and

Safeguards

Attn: D. J. Fehringer, $4 \mathrm{H} 3$

P. S. Justus, $4 \mathrm{H} 3$

Washington, DC 20555

U.S. Nuclear Regulatory Commission (4) Office of Nuclear Material Safety and Safeguards

Attn: M. S. Nataraja, $4 \mathrm{H3}$

J. J. Peshel, 4H3

P. Altomare, $4 \mathrm{H} 3$

J. S. Trapp, $4 \mathrm{H} 3$

Washington, DC 20555

DIST-1
U.S. Department of Energy (2)

Regulatory Compliance Branch

Office of Civilian Radioactive

Waste Management

1000 Independence Avenue

Attn: D. Alexander

S. Gomberg

Washington, DC 20585

P. Dickman

U.S. Department of Energy

Nevada Operations Office

P. 0. Box 98518

Las Vegas, NV 89193-8518

U.S. Department of Energy (2)

Yucca Mountain Project Office

Attn: J. R. Dyer

J. Boak

P. O. Box 98518

Las Vegas, NV 89193-8518

Center for Nuclear Waste (2)

Regulatory Analysis

Attn: B. Sagar

W. Patrick

6220 Culebra Road

P. O. Drawer 28510

San Antonio, TX 78284

A. L. Gutjahr

Department of Mathematics

New Mexico Institute of Mining and Technology

Socorro, NM 87801

G. Apostolakis

University of California

5532 Boelter Hall

Los Angeles, CA 90024

GRAM Incorporated (6)

Attn: K. K. Wahi

D. A. Zimmerman

R. Knowlton

M. T. Goodrich

C. D. Updegraff

A. R. Gribble

1709 Moon, N.E.

Albuquerque, NM 87112 
G. de Marsily

Ecole des mines de Paris

35, Rue Saint-Honore

77305 Fontainbleau

FRANCE

INTERA Environmental Consultants,

Inc. (2)

Attn: D. E. Longsine

M. Reeves

6850 Austin Center Blvd.

Suite 300

Austin, TX 78731

W. J. Conover

College of Business Administration

Texas Tech University

Box 4319

Lubbock, TX 79409-4319

SAIC

Attn: R. V. Guzowski

2109 Air Park Road, S.E.

Albuquerque, NM 87106

Sandia National Laboratories

3141 S. A. Landenberger (5)

3151 W. I. Klein

3200 N. R. Ortiz

6310 T. O. Hunter

6312 F. W. Bingham

6340 W. D. Weart

6342 D. R. Anderson

6342 M. G. Marietta

6344 E. D. Gorham

6400 D. J. McCloskey

6410 D. A. Dahlgren

6413 J. C. Helton

6415 R. M. Cranwe11 (7)

6415 J. E. Campbel1 (7)

6415 R. L. Iman

6415 M. S. Tierney

6416 E. J. Bonano

6416 M.S.Y. Chu

6416 P. A. Davis

6416 C. P. Harlan

6416 L. L. Price (6)

6416 D. P. Gallegos

6416 N. E. Olague

6416 E. A. Bernard

6416 S. H. Conrad

6416 M. W. Kozak

6416 J J TeCord :

6416 f $\mathrm{R}$. Lindyteh

$8524^{*}$ J. A. Wackerly
Applied Physics, Inc.

Attn: J. D. Johnson

5353 Wyoming Blvd., N.E.

Sulte 3

Albuquerque, NM 87109

Battelle Pacific Northwest

Laboratories (4)

Attn: P. G. Doctor

P. Eslinger

C. Cole

A. E. Van Luik

3100 Port of Benton

Sigma V Building

Richland, WA 99352

Remote Sensing Systems, Inc.

Attn: K. N. Gaither

4300 San Mateo Blvd., N.E.

Sulte A-220

Albuquerque, NM 87110

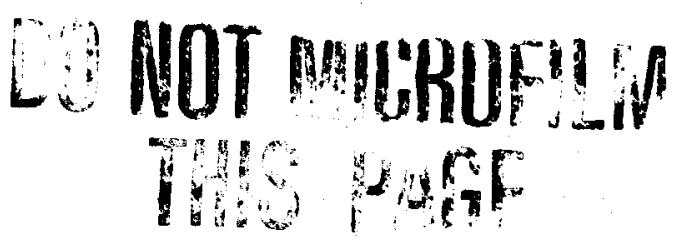

